\title{
I. \\ Herbst 1918 - Herbst 1938: Europas Weg bis an die Schwelle zum Krieg
}

In der Sylvesternacht des Jahres 1938 schrieb Harold Nicolson, einflußreicher englischer Historiker und Journalist, der seit 1935 außerdem als Abgeordneter im Unterhaus saß, voll Bitterkeit in sein Tagebuch: „Es war ein böses Jahr. Chamberlain hat das Gleichgewicht der Kräfte zerstört." ${ }^{1}$ Nicolsons Vater, Lord Carnock, hatte bei Beginn des Weltkriegs im Sommer 1914, er hieß damals noch Sir Arthur Nicolson, unter dem Minister Edward Grey als beamteter Staatssekretär das Foreign Office geleitet, das britische Außenministerium, und der Sohn hatte bis zu seinem Ausscheiden im Jahr 1932 - zuletzt Botschaftsrat im krisengeschüttelten Berlin - ebenfalls als einer der Besten im Diplomatischen Dienst Großbritanniens gegolten; im Unterhaus äußerte er sich mit Sachkenntnis und Eloquenz vor allem zu Fragen der Außenpolitik. So war es Harold Nicolson ganz natürlich, seinen zornigen Rückblick, in dem auch eine überaus pessimistische Prognose steckte, in jene Formel der internationalen Beziehungen zu fassen, die ihm vertraut wie das Einmaleins - am knappsten ausdrückte, was ihn im Blick auf das künftige Geschick Europas bewegte: Einmal die Erkenntnis, daß der britische Premierminister Neville Chamberlain, als er im Herbst 1938 den entscheidenden Beitrag leistete, die Tschechoslowakische Republik zur Abtretung der Sudetengebiete an das Deutsche Reich zu zwingen, dem nationalsozialistischen Deutschland zu einem Machtzuwachs verholfen hatte, der es zum absolut stärksten und zum bereits dominierenden Staat auf dem europäischen Kontinent machen mußte; ferner die Annahme, daß ein nationalsozialistisches Deutschland von der hegemonialen Position, die ihm das Münchner Abkommen vom 29. September 1938 beschert hatte, keinen zurückhaltenden oder gar wohltätigen Gebrauch machen, vielmehr sogleich der Verlockung zu weiteren Aktionen einer expansionistischen Politik erliegen und jetzt erst recht die Herrschaft über Europa anstreben werde; schließlich die Überzeugung, daß mithin die um des Friedens willen geschehene Opferung der CSR in Wahrheit nicht den Frieden gesichert, sondern lediglich den Krieg sicherer gemacht habe - den Krieg zur Verteidigung der Unabhängigkeit der Staaten Europas gegen offenbar uferlose Herrschaftsgelüste des Deutschen Reiches und zugleich, 
von West- und Nordeuropa aus gesehen, einen Krieg zur Rettung der europäischen Nationen und der liberaldemokratisch geprägten politischen Kultur vor dem totalitären Nationalsozialismus.

Chamberlain selbst war ganz anderer Meinung. Die Politik der Beschwichtigung und der Konzessionen, des „Appeasement", die er, manchmal alternierend, manchmal gleichzeitig, gegenüber dem nationalsozialistischen Deutschland und dem faschistischen Italien verfolgte, sollte keineswegs der Vertagung eines großen europäischen Krieges dienen, etwa um in der gewonnenen Frist aufzurüsten, sondern der definitiven Verhinderung eines solchen Krieges. Und im Herbst 1938 glaubte der Premier tatsächlich, daß er mit dem Münchner Abkommen sein Ziel bereits erreicht habe, daß es ihm gelungen sei, das nationalsozialistische Deutschland mit dem Geschenk der Sudetengebiete zu saturieren und damit diesem Staat seine unbegreifliche Kriegsbereitschaft wieder zu nehmen. Vorerst hielt er Maßnahmen zur Erweiterung und Beschleunigung der militärischen Rüstung Großbritanniens für gänzlich überflüssig. Als ihm zwei Kabinettskollegen, Oliver Stanley und Lord De La Warr, wenige Tage nach München mitteilten, sie seien nur dann bereit, mit ihm die Münchner Regelung zu vertreten, wenn nun für künftige Fälle deutscher Aggressionslust intensiv gerüstet werde, antwortete Chamberlain kühl, er sei nicht gewillt, sich zu ,irgendeinem besonderen Rüstungsprogramm zu verpflichten“, ehe die Lage nicht „im Lichte der jüngsten Ereignisse“ geprüft worden sei, und zu Lord Swinton, seinem Luftfahrtminister, der gleichfalls für eine größere Rüstungsanstrengung plädierte, sagte er: „But don't you see, I have brought back peace!" 2

Adolf Hitler, der „Führer“ des nationalsozialistischen Deutschland, der die Außenpolitik des Deutschen Reiches diktatorisch bestimmte, hatte für Neville Chamberlain und dessen Illusionen nichts als bösartige Verachtung. Seine Einschätzung der im Herbst 1938 entstandenen Situation deckte sich durchaus mit dem Urteil Harold Nicolsons, nur mit dem Unterschied, daß Hitler die zu seinen Gunsten geschehene Zerstörung des europäischen Kräftegleichgewichts mit höhnischer Befriedigung konstatierte und den künftigen Akten einer nun möglich gewordenen weit ausgreifenden Kriegs- und Expansionspolitik mit freudiger Erwartung entgegensah. Zwar hatte ihn das Münchner Abkommen tief verstimmt. Es war ja seine Absicht gewesen, das tschechoslowakische Stück in einem Akt zu spielen, d.h. am Ende und als Ergebnis der von ihm inszenierten Sudetenkrise die ganze Tschechoslowakei, die ihm aus geographischen, strategischen und wirtschaftlichen Gründen für seine Eroberungspolitik unentbehrlich schien, in einem schnellen, lokalisierten Feldzug in Besitz zu nehmen. Daß ihn Großbritannien und Frankreich zum Verzicht auf die militärische Kampagne und zur lästigen Vorbereitung eines zweiten Aktes zwangen, indem sie die

2 Zit. nach T. Taylor, Munich. The Price of Peace, London 1979, S. 926. 
Prager Regierung nötigten, Deutschland die deutsch besiedelten Gebiete Böhmens und Mährens anzubieten, verdroß ihn sehr. Schon einige Tage vor der Münchner Konferenz hatte er sich in einer Unterhaltung mit dem Botschafter des gegen die Tschechoslowakei praktisch mit Deutschland verbündeten Polen darüber beklagt und förmlich dafür entschuldigt, daß ihm das Entgegenkommen der Westmächte eine militärische und vollständige Lösung des tschechoslowakischen Problems vermutlich unmöglich machen werde; offeriere man ihm die Sudetendeutschen, könne er dem deutschen Volk keinen Krieg mehr zumuten ${ }^{3}$. Doch war Hitler selbstverständlich klar, daß ihm auch der „Kompromiß“ von München einen gewaltigen Machtgewinn eingebracht hatte, der über die territoriale Vergrößerung des Deutschen Reiches hinausreichte; was wirtschaftlichen und politischen Einfluß angeht, hatte das nationalsozialistische Deutschland bereits jetzt, nachdem im März 1938 Österreich annektiert worden war und die restliche Tschechoslowakei sich nun im Status eines völlig abhängigen Vasallen des Reiches befand, das Erbe Österreich-Ungarns in Ostmitteleuropa und Südosteuropa angetreten, und zwar, weil viel stärker als die 1918 untergegangene Donaumonarchie, mit der Möglichkeit, die Erbschaft alsbald kräftig zu mehren. In den Monaten bis zum Frühjahr 1939 nahm in den ost- und südosteuropäischen Staaten die Anerkennung der deutschen Führungsrolle allmählich sogar die Form der Unterwürfigkeit an; z.B. ist eine bislang von der Presse jener Länder gern geübte Praxis, nämlich der Nachdruck von Zeitungsartikeln britischer Politiker - die ja oft ebenso leidenschaftliche wie glänzende Journalisten waren -, jäh abgebrochen worden, sofern es sich um Politiker wie Winston Churchill, Anthony Eden, Clement Attlee oder Duff Cooper handelte, die sich durch Kritik am nationalsozialistischen Regime und durch Warnungen vor nationalsozialistischer Eroberungspolitik in Berlin mißliebig gemacht hatten ${ }^{4}$.

So faßte Hitler in der Tat sofort nach München zuversichtlich nächste Schritte ins Auge. Am 10. November 1938 suchte er rund vierhundert namhaften deutschen Journalisten und Verlegern einzuhämmern, daß ihre Aufgabe in den kommenden Monaten darin bestehe, die deutsche Nation, die in den Wochen vor München nicht genügend Kriegslust an den Tag gelegt hatte, psychisch in Kriegsform zu bringen. In seiner Rede rief er seinen Hörern, nachdem er ihnen erklärt hatte, allein der Zwang der Umstände sei die Ursache dafür gewesen, daß er jahrelang nur vom Frieden geredet habe, ebenso zynisch zu: „Irgendwie glaube ich, hat sich diese Platte, die pazifistische Platte, bei uns abgespielt."s Und am 16. Dezember 1938 setzte Ernst v. Weizsäcker, unter Reichsaußenminister Joachim v. Ribben-

${ }^{3}$ Akten des Polnischen Außenministeriums (künftig APA), Poln. Botschaft Berlin, Mappe 18 (Archivum Akt Nowych, Warschau), Hitler-Lipski, 20.9.1938.

${ }^{4}$ M. Gilbert, Winston S. Churchill, Bd. 5, 1922-1939: The Prophet of Truth, Boston 1977, S. 1068.

5 Vierteljahrshefte für Zeitgeschichte (VfZ) 6 (1958), S. 183. 
trop als Staatssekretär Leiter des Berliner Auswärtigen Amts, seinem Besucher Ulrich v. Hassell, bis 1938 deutscher Botschafter in Rom, in tiefer Sorge auseinander, sein Chef und Hitler seien offensichtlich auf Krieg aus: „Man schwanke nur, ob gleich gegen England, indem man sich dafür noch Polens Neutralităt erhalte, oder zuerst im Osten zur Liquidation der deutsch-polnischen und der ukrainischen Frage, sowie natürlich der Memelsache, die aber nach Hitlers Ansicht keiner Waffengewalt, sondern nur eines eingeschriebenen Briefes an Kaunas bedürfe."6

Allenthalben in Europa sprach man also im Herbst 1938, ob in Resignation und Verzweiflung oder in Hoffnung und Begierde, mit großer Selbstverständlichkeit vom kommenden Krieg, und zwar nicht allein in den Zirkeln der Politiker, Diplomaten und Soldaten. Nur zwanzig Jahre zuvor, im November 1918, war aber doch ein Weltkrieg zu Ende gegangen, der in fast viereinhalb Jahren ungeheure Opfer an Blut und Gut gefordert hatte und den die siegreichen Westmächte zuletzt als einen Krieg geführt hatten, dessen wichtigstes Ergebnis darin bestehen müsse, Kriege ein für allemal unmöglich zu machen: „Safe for democracy“ sollte die Welt werden, und mit einer globalen Organisation der Staatengesellschaft, einem Völkerbund, wollten die Sieger ein internationales System schaffen, in dem an die Stelle des kriegerischen Austrags von Konflikten Verhandlung, Diskussion, Schiedsgerichtsbarkeit traten, in dem jeder etwaige Aggressor sofort auf die Sanktionen aller Mitglieder des Bunds traf; „kollektive Sicherheit“ hieß der Begriff für die erhofften Mechanismen der Abschreckung und, wenn nötig, der Zähmung von Friedensstörern. Wie war es nur möglich, daß all die Visionen, Ziele und Pläne, die am Ende des Weltkriegs die siegreichen und auch Teile der besiegten Nationen in ihren Bann geschlagen hatten, lediglich zwanzig Jahre später offenbar verweht oder bedeutungslos geworden waren?

\section{Ergebnisse des Weltkriegs}

Dabei hatte das Kriegsende, so sah es 1918/19 aus, eigentlich ganz brauchbare Voraussetzungen für die Errichtung einer friedlichen Ordnung der Staatengesellschaft gebracht. Der Krieg war 1914 vom wilhelminischen Deutschland, von der habsburgischen Donaumonarchie und vom zaristischen Rußland begonnen worden, teils um vermeintlicher und tatsächlicher macht- und sicherheitspolitischer Interessen willen, teils um durch militärische Triumphe und durch die Gewinne einer imperialistischen Politik scharfe innere Spannungen und Konflikte zu überwinden oder doch zu betäuben, d.h. um so die reformerische oder revolutionäre Modernisierung

6 U. v. Hassell, Die Hassell-Tagebücher 1938-1944, hrsg. v. F. Freiherr Hiller von Gaertringen, Berlin 1988, S. $68 \mathrm{f}$. 
ihrer illiberalen und antidemokratischen politischen Strukturen zu verhindern oder wenigstens hinauszuschieben? ${ }^{7}$ Im Herbst 1918 waren alle drei Staaten nicht nur militärisch geschlagen: In Rußland hatte erst die Erhebung liberaler und sozialistischer Gruppen, dann die kommunistische Oktoberrevolution von 1917 den Zarismus beseitigt und das Land in die Wirren eines blutigen Bürgerkriegs gestürzt; Österreich-Ungarn war in der Niederlage und nach dem Willen der Siegermächte auseinandergebrochen, in den Nachfolgestaaten brachen zum Teil ebenfalls heftige Kämpfe um die innere Ordnung aus; auch Deutschland glitt mit der Niederlage in eine Periode bürgerkriegsähnlicher Zustände. Zeitweise schien es sogar, als drohe die Revolution der Bolschewiki, die in Rußland die „Diktatur des Proletariats" proklamiert hatten, auch auf Deutschland und einige Nachfolgestaaten der Donaumonarchie überzugreifen. Indes sind die mit und ohne die Unterstützung durch die russischen Bolschewiki unternommenen sozialistischen Revolutionsversuche außerhalb Rußlands sämtlich gescheitert. Sowohl in Deutschland wie in den Nachfolgestaaten des habsburgischen Reichs setzte sich zunächst der Parlamentarismus durch, und in Ungarn ist nicht allein die kommunistische Räterepublik Bela Khuns blutig liquidiert, sondern überdies die Monarchie restauriert worden, wenn auch ohne Monarch und nur mit einem sogenannten Reichsverweser. In entscheidenden Punkten entsprach also das Ergebnis des großen Krieges offenbar ganz den Vorstellungen, die in den Westmächten dominierten. Der europäische Führungs- und Herrschaftsanspruch des Deutschen Reiches war abgewiesen, im Reich anscheinend der liberalen Demokratie zum Sieg verholfen worden, und nach seiner Niederlage sah sich Deutschland vorerst ohnehin zu militärischer Ohnmacht und politischer Friedfertigkeit verurteilt. Die beiden anderen gleichgewichtsfeindlichen Imperien des Kontinents hatten die Fähigkeit zur Bedrohung des Friedens ebenfalls verloren: Österreich lag in Trümmern, und Rußland steckte als Folge der bolschewistischen Revolution in einer offensichtlich lange lähmenden inneren Krise. Die in Paris tagende Friedenskonferenz der alliierten Mächte und der ihnen ,assoziierten " Macht USA konnten mithin den besiegten Staaten Friedensverträge oktroyieren, von denen tatsächlich die Schaffung und die Sicherung einer gleichgewichtsfreundlichen und die Erhaltung des Friedens garantierenden Ordnung Europas erhofft werden durfte. Am 28. Juni 1919 mußte Deutschland den Vertrag von Versailles unterzeichnen, am 10. September 1919 Österreich den Vertrag von St. Germain-en-Laye, am 27. November 1919 Bulgarien den Vertrag von Neuilly und am 4. Juni 1920 Ungarn den Vertrag von Trianon 8 .

Die Pariser Vorortsverträge gaben um so mehr Anlaß zu Hoffnung, als in ihnen zum ersten Mal in der Geschichte der Versuch Gestalt gewann, libe-

7 J. Joll, The Origins of the First World War, London-New York 1985.

8 G. Schulz, Revolutionen und Friedensschlüsse 1917-1920, München 1967. 
raldemokratische Grundsätze und das Prinzip der Gerechtigkeit auf die Ordnung der Staatengesellschaft zu übertragen. So haben die Pariser Friedensmacher namentlich den Prozeß der Befreiung und Verselbständigung kleiner Nationen bewußt fortgesetzt, den einst das Absterben des türkischen Reiches eingeleitet hatte und den man auch als die Entkolonialisierung Mittel-, Ost- und Südosteuropas bezeichnen kann. Mit dem „Selbstbestimmungsrecht der Völker" war für diese historische Bewegung das Schlüsselwort gefunden, dem die Friedenskonferenz ernsthaft gerecht werden wollte. Ein solcher Versuch mußte freilich alte Staatskörper zerstören oder durch Einschnitte verwunden, die eben nicht nach derartigen Prinzipien geschaffen, sondern auf Grund bestimmter Machtlagen und dynastischer Interessenpolitik historisch gewachsen waren. Aus der Erbmasse des zerfallenen habsburgischen Imperiums, aus bislang von Ungarn beherrschten Territorien, aus Teilen des alten Zarenreichs und aus preußischen Gebieten des geschlagenen Deutschland sind nach dem politischen Willen der dort lebenden Völker Staaten gebildet oder arrondiert worden, die noch während der Friedenskonferenz Aufnahme in die Staatengesellschaft fanden und eine möglichst solide Basis für eine selbständige politische Existenz erhielten: Estland, Lettland, Litauen, Polen, die Tschechoslowakei, Rumänien.

Selbst in die Behandlung außereuropäischer Kolonialfragen mischte sich erstmals eine anti-imperialistische und antikolonialistische Tendenz ein?. Zwar wurde Deutschland gezwungen, seine Kolonien an andere Mächte abzutreten, an Japan, Frankreich, England und britische Dominions wie Südafrika und Australien. Aber der Vorgang durfte nicht mehr als ordinäre Annexion erscheinen, er mußte vielmehr mit der mangelnden Fähigkeit Deutschlands und mit der gegebenen Fähigkeit der neuen Besitzer zur Entwicklung jener Kolonien begründet werden. Die ehemals deutschen Kolonien galten nicht länger als Kolonien, sondern bekamen den Status von „Mandaten“, und daneben wurde nun jede Form kolonialer Herrschaft mit der Erklärung gerechtfertigt, die Bewohner der betreffenden Territorien seien zur Selbstregierung ,noch nicht“ fähig. Gewiß ist das Mandatsund Entwicklungsprinzip oft - und auch von manchem seiner Verkünder lediglich als Bemäntelung der Aneignung des deutschen Kolonialbesitzes und der Ausdehnung des britischen und französischen Einflusses auf den Mittleren Osten verstanden worden. Trotzdem: die Mandats- und Kolonialmächte hatten grundsätzlich das Ende aller Kolonialherrschaft proklamiert und damit der Entkolonialisierung Afrikas und Asiens den Weg geöffnet. Nach Jahrzehnten hemmungsloser Eroberung bekannte sich Europa jetzt zu dem Gesetz, daß technische, wirtschaftliche und militärische Überlegenheit nicht einfach in politische Herrschaft umgesetzt werden dürfe.

9 Vgl. F. P. Walters, A History of the League of Nations, London-New York-Toronto 1960. 
Diese Selbstbeschränkung wirkte um so glaubwürdiger und zukunftsträchtiger, als die Mandatsmächte über moralische Verpflichtungen hinaus bereits eine rechtliche Bindung an das Entwicklungsprinzip eingingen. Mit Unterschrift sagten sie nämlich zu, über die Verwaltung ihrer Mandate einer Gemeinschaft zivilisierter Staaten Rechenschaft abzulegen, die sich in einem „Völkerbund“ eine politische Organisation gegeben hatte.

Es ist damals weithin als das wichtigste Ergebnis des Krieges angesehen worden, daß es 1919 tatsächlich gelang, die während der Kriegsjahre in England, den USA und Frankreich gereifte Idee zu realisieren und einen Völkerbund zu schaffen, dem zunächst 45 europäische und außereuropäische Staaten angehörten und der am 16. Januar 1920 mit der ersten Sitzung seines Rats offiziell seine Tätigkeit aufnahm ${ }^{10}$. In der Tat war die Gründung des in Genf beheimateten Bundes ein Akt, der sich an universalhistorischer Bedeutung durchaus mit den großen Revolutionen in England, Amerika und Frankreich messen kann, der selbst eine Revolution von einschneidender Radikalität darstellte. Wiederum zum ersten Mal in der Geschichte unternahm eine bislang nahezu anarchische Staatenwelt den Versuch, sich eine internationale Verfassung, ein internationales Parlament und eine internationale Regierung zu geben: Satzung, Vollversammlung und Rat. An die Stelle einer Gesellschaft absolut souveräner Staaten, die außer ihren eigenen Wachstumsgesetzen nichts und niemand verantwortlich sein wollten und konnten, die daher jederzeit zum gewaltsamen Austrag zwischenstaatlicher Divergenzen fähig und bereit sein mußten, sollte die pluralistische Staatengesellschaft treten, die bei gebändigter Souveränität ihrer Glieder in der Lage ist, ihre Meinungs- und Interessenkonflikte in einem rationalen Geist und mit rationalen Methoden zu regeln. Mit diesem Triumph westlicher Gesellschaftsphilosophie schien der Krieg als Mittel der Politik überwunden und eine friedliche Entwicklung Europas wie der Welt gesichert zu sein. „Deprimierend“, schrieb Joseph Goebbels, der Propagandachef des nationalsozialistischen Deutschland, am 25. September 1933 in sein Tagebuch, als er in Genf persönlich eine Sitzung des Völkerbunds beobachtete: „Eine Totenversammlung. Parlamentarismus der Nationen."11

Auf der anderen Seite waren schon bei Kriegsende Resultate der großen Auseinandersetzung zu sehen, die auf eine problemreiche Zukunft deuteten. Das weltweite Handelssystem, als dessen Mittelpunkt Europa fungiert hatte, bot sich in einer Unordnung dar, die an Zerstörung grenzte. Die europäische Finanzkraft war erschöpft, und den einzelnen europäischen Währungen drohte der Kollaps oder doch eine Periode ernster Erkrankung. Die Vereinigten Staaten hatten Europa in finanzielle Abhängigkeit gebracht, zum militärischen Sieg der Westmächte beigetragen, die Ideologie und die

$10 \mathrm{Vgl}$. H. Graml, Europa zwischen den Kriegen, München $1976^{3}$, S. 9 ff.

11 Die Tagebücher von Joseph Goebbels. Sämtliche Fragmente, hrsg. v. E. Fröhlich, Teil I. Bd. 2, München 1987, S. 465. 
Kriegsziele ihrer Verbündeten maßgeblich beeinflußt und schließlich bei der Gründung des Völkerbunds eine führende Rolle gespielt, aber offenbar ohne bereit zu sein, ihre bis zum Krieg dominierende Neigung zur politischen Selbstgenügsamkeit auf Dauer preiszugeben. Am Ende eines Krieges, der ohnehin eine große Müdigkeit hinterließ, schien also die weltpolitische Schlüsselfunktion Europas verloren zu sein, ohne daß ein Ersatz sichtbar geworden wäre.

\section{Scheitern der Versuche zur Stabilisierung Europas}

Bald stellte sich jedoch heraus, daß schon die Hoffnung auf eine friedliche Entwicklung der zwischenstaatlichen Beziehungen keine solide Grundlage besaß und vermutlich nicht in Erfüllung gehen würde. Von einer Bewegung, die vornehmlich aus innenpolitischer Gegnerschaft weitere internationale Triumphe des Präsidenten Woodrow Wilson verhindern wollte, sind die Vereinigten Staaten in der Tat noch 1919/20 zum Verzicht auf die vorübergehend übernommene internationale Führungsrolle und zur Rückkehr zum gewohnten politischen Isolationismus gezwungen worden ${ }^{12}$. Selbst dem Völkerbund, an dessen Entstehung sie so großen Anteil gehabt hatten, sind die USA schließlich nicht beigetreten. Auf der anderen Seite trennte sich ja auch Rußland vom übrigen Europa und blieb dem Völkerbund fern. Die Radikalität der leninistischen Revolution hatte zwischen Rußland und der Außenwelt eine tiefe Kluft aufgerissen, und der Völkerbund ist von den Bolschewiki ohnehin nur als eine raffinierte Maskerade der imperialistischen Kapitalisten Westeuropas verstanden worden, die aus den feinen Fäden moralischer Phrasen feste Fesseln für die im Weltkrieg unterlegenen Imperialisten knüpfen und den Bund außerdem zur Organisierung einer kapitalistischen Einheitsfront gegen Moskau, die Zentrale der kommunistischen Weltrevolution, benützen wollten ${ }^{13}$. Zwischen einem gleichgültigen Amerika und einem feindseligen Rußland blieb Europa sich selbst überlassen, und wenn auch diese Lage die Illusion einer Wiederkehr der Vorkriegszeit erzeugte und so eine gewisse Restaurierung des angeschlagenen europäischen Selbstbewußtseins erlaubte, hat sie andererseits die im Völkerbund konstituierte kollektive Friedensordnung mit einer untragbaren Hypothek belastet.

Ohne die Mitgliedschaft der potentiell stärksten Mächte vermochte der Völkerbund weder einen funktionsfähigen Sanktionsmechanismus gegen eventuelle Friedensstörer aufzubauen noch überhaupt Vertrauen in seine Zukunft zu schaffen. Die an den europäischen Differenzen nicht unmittel-

12 Th. A. Bailey, A Diplomatic History of the American People, New York 1958; vgl. auch A. Walworth, Woodrow Wilson, Baltimore 1965, S. $333 \mathrm{ff}$.

13 K.H. Ruffmann, Sowjetrußland. Struktur und Entfaltung einer Weltmacht, München 1967 
bar interessierten USA wären nicht zuletzt als ausgleichendes Element zwischen Siegern und Besiegten benötigt worden. Allein sie hätten den Völkerbund zu einer behutsamen Revision allzu harter Teile der Pariser Friedensregelung veranlassen oder aber die Besiegten zur endgültigen Annahme der zwischen 1918 und 1920 entstandenen territorialen Ordnung nötigen können. War der Völkerbund, in seiner tatsächlichen Zusammensetzung, sowohl zur Änderung wie zur Verteidigung des Status quo zu schwach, so hingen Arbeit, Prestige und politische Zukunft der Genfer Institution letzten Endes davon ab, ob der Status quo allgemeine Anerkennung oder - irgendwann angriffsfähige - Opposition fand. Wenn europäische Staaten auf revisionistischen Kurs gingen, mußten sie nämlich von der Immobilităt Genfs ebenso sehr gereizt wie von der Ohnmacht des Bundes verlockt werden, Politik ohne Rücksicht auf die Organisation der kollektiven Sicherheit zu machen und auf die bis 1914 unbestritten gültigen außenpolitischen Mittel und Methoden zurückzufallen, am Ende eben doch wieder auf den Krieg.

Wohl durfte der Bund in den ersten Jahren seiner Existenz beachtliche Erfolge verzeichnen ${ }^{14}$ : So ist der finnisch-schwedische Streit um die Aalands-Inseln zugunsten Finnlands geschlichtet und der deutsch-polnische Konflikt um Oberschlesien mit der Teilung des Industriegebiets geregelt worden; im zeitweise von Deutschland gelösten Saargebiet fungierte der Bund fünzzehn Jahre lang - bis zu einer auf 1935 angesetzten Volksabstimmung - als oberste politische Instanz, die ausgezeichnete Arbeit leistete; am 1922/23 zunächst gelungenen Versuch, Währung und Wirtschaft des aus der habsburgischen Erbmasse gebildeten Staates Deutsch-Österreich vor dem Zusammenbruch zu retten, hatte Genf hervorragenden Anteil, und Albanien konnte durch rasche Aufnahme in den Bund vor dem $\mathrm{Zu}$ griff Italiens, Jugoslawiens und Griechenlands geschützt werden. Aber abgesehen davon, daß der Völkerbund bereits in der für sein Prestige entscheidenden Anfangsphase immer dann versagte, wenn er es mit wichtigen Interessen der europäischen Großmächte zu tun bekam, beseitigten all die Erfolge nicht die Befürchtung, daß Genf an der Spannung zwischen den Verteidigern und den Gegnern des Status quo scheitern werde. Als erste Folge blieben, neben den Institutionen und Formen einer neuen Außenpolitik der kollektiven Sicherheit, Geist und Rezepte der Außenpolitik alten Stils unverändert lebendig, blieb auch die vorerst wichtigste Aufgabe des Bundes, eine allgemeine Abrüstung, ungelöst. Allerdings begann sich eine Partei der revisionistischen Staaten schon frühzeitig zu formieren ${ }^{15}$.

So entwickelte Rußland neben seinem ideologisch begründeten weltrevolutionären Imperialismus auch einen altmodischen Revisionismus, der auf die Rückgewinnung der baltischen Länder und der an Polen verlorenen

14 Graml, Europa, S. $165 \mathrm{ff}$.

15 P. Krüger, Die Außenpolitik der Republik von Weimar, Darmstadt 1985. 
Territorien zielte. Ungarn wiederum wollte vor allem den Verlust der Slowakei und Siebenbürgens rückgängig machen und erhob die entsprechenden Ansprüche an die CSR und an Rumänien zu bestimmenden Leitlinien seiner Außenpolitik. In beiden Staaten verfügte der Revisionismus auch deshalb über eine zähe Konstitution, weil in ihnen politische Eliten herrschten, die nicht allein den Status quo ablehnten, sondern überdies nicht das geringste Verständnis für den Geist und die Prinzipien der mit dem Völkerbund versuchten Rationalisierung der Außenpolitik aufbrachten. Hatten in Rußland Revolutionäre die Macht übernommen, die schon für eine radikal veränderte Welt lebten, so war in Ungarn nach dem Zwischenspiel der Räterepublik eine nationalistische und konservative Gentry an der Macht geblieben, die auch unabhängig von der revisionistischen Problematik in den Kategorien von 1914 dachte und den Völkerbund nicht zur Kenntnis nehmen wollte.

Indes gab es auch im Lager der Sieger und der neuen Länder Staaten, die den Status quo in Frage stellten und zu einer völkerbundsfremden Politik neigten. Polens territoriale Wünsche waren weder im Osten noch im Westen ganz befriedigt worden, und die Warschauer Außenpolitik wurde von Konservativen und Nationalisten gemacht, die ihr außenpolitisches Denken an Petersburger, Berliner und Wiener Traditionen geschult hatten und gelegentlich gefährlichen Träumen von einem mächtigen Großpolen nachhingen. In Rom glaubte man sogar Anlaß zu bitterer Enttäuschung über die Ergebnisse des Krieges zu haben. Zwar hatte Italien eine reiche Beute eingeheimst und z.B. die Brennergrenze erreicht. Aber ausschweifende imperialistische Forderungen in Dalmatien, Albanien, Kleinasien und Afrika waren von der Friedenskonferenz nicht berücksichtigt worden, obschon die Westmächte 1915 den italienischen Kriegseintritt an ihrer Seite mit der Anerkennung eines beträchtlichen Teils auch dieser nun übergangenen Forderungen erkauft hatten. Wohl waren alle nicht erfüllten - und manche erfüllten - italienischen Ansprüche völlig ungerechtfertigt und lediglich Zeugnisse eines adriatischen und meditteranen Imperialismus, für den weder der Zeitgeist noch die Kraft des Landes eine Basis boten, doch setzte sich in Italien das Gefühl durch, auf der Friedenskonferenz wie eine geschlagene Nation behandelt worden zu sein; bald gehörte das Wort vom „verstümmelten Frieden“ - eine groteske Verfehlung der Realität - zum gängigen politischen Vokabular der Italiener. Der Zorn über die entgangenen Gewinne richtete sich aber weniger gegen die eigentlichen Hindernisse der italienischen Expansion, Jugoslawien und die Türkei, sondern in erster Linie gegen Wilson und die bisherigen Verbündeten, von denen man sich betrogen wāhnte. Der Völkerbund blieb von diesem Zorn nicht verschont, zumal er ja die italienischen Ambitionen einzufrieren schien, und so bestand in Italien von Anfang an die Bereitschaft, zur Korrektur des Status quo Außenpolitik auch außerhalb der neuen internationalen Legalität zu treiben. In der leidenschaftlichen Auseinandersetzung um das Kriegsergeb- 
nis und in der gesellschaftspolitischen Krise, die der Krieg hinterlassen hatte, agierten zudem bereits die Stoßtrupps einer antiliberalen und nationalistischen Bewegung, die sich faschistisch nannte und den permanenten Kampf als Grundgesetz der internationalen Beziehungen proklamierte; ihre Anhänger machten kein Hehl daraus, daß die Zukunft Italiens nur das rücksichtslos anzustrebende mediterrane Imperium sein könne.

Allerdings: der Völkerbund mochte von den USA im Stich gelassen worden sein und vom Sowjetstaat boykottiert werden, die Partei der revisionistischen und unzufriedenen Staaten mochte auf die Chance lauern, sich den hemmenden neuen Regeln wieder zu entziehen - die Frage, ob das Genfer Experiment völlig scheitern und das Feld der internationalen Beziehungen wieder ganz der traditionellen Machtpolitik gehören werde, hatte letztlich Deutschland zu beantworten. Ein tödlicher Schlag gegen den Status quo und das System der kollektiven Sicherheit war nur dann denkbar, wenn die potentiell stärkste der potentiell revisionistischen Mächte, Deutschland, gleichsam die Führung der Revisionisten-Partei übernahm. Rußland und Ungarn waren zu schwach, ebenso Italien und Polen, die zudem mit vielen Fäden an die Garanten des Status quo, Frankreich und Großbritannien, gebunden blieben. Allein Deutschland war so kräftig und geographisch so zentral gelegen, daß es sich bei der Verfolgung der eigenen territorialen revisionistischen Ziele zum aufmunternden, koordinierenden und lenkenden Bundesgenossen der übrigen Revisionismen machen konnte. Und wenn die anderen revisionistischen Staaten zu Passivität verurteilt waren, sofern Deutschland ruhig blieb, so brach andererseits unweigerlich der ganze Katarakt territorialer revisionistischer Forderungen auf die politische Landschaft Europas nieder, wenn Deutschland tatsächlich auf revisionistischen Kurs ging und sich dabei der Hilfe fremder Revisionismen bediente. Eine solche Bewegung mußte nicht nur den Status quo auslöschen, sondern zugleich die Prinzipien des Völkerbunds und die Institution selbst liquidieren, weil sie, das lag in der Natur der Sache, zum Rückgriff auf militärische Mittel gezwungen war und zwangsläufig die Macht wieder zum einzigen Faktor der Außenpolitik erhob, während Schiedsgerichtsbarkeit und friedliche Verständigung von der internationalen Bühne gefegt wurden.

Am Ende der Revision stand überdies ohne Frage die mit Genf ebenfalls unvereinbare deutsche Hegemonie in Europa. Da Deutschland in jeder denkbaren revisionistischen Kombination seine Partner an Macht weit übertraf, konnte es nicht ausbleiben, daß sich Verbündete Deutschlands schon während der einzelnen Aktionen einer territorialen Revisionspolitik in Klientelstaaten verwandelten. Da die Erfüllung aller deutschen Wünsche dem Reich außerdem ein erdrückendes Übergewicht auf dem Kontinent verschaffen mußte, stand dann den Klientelstaaten unweigerlich das weitere Absinken zu bloßen Satelliten bevor, und wer sich der Revision erfolglos widersetzte, hatte dieses Schicksal naturgemäß zu teilen. Eine Wendung 
Deutschlands zu aktiver territorialer Revisionspolitik hieß mithin Rückkehr zum internationalen Faustrecht, und erfolgreiche Revision hieß zudem Zerstörung des europäischen Gleichgewichts. Berlin hatte also zu wählen zwischen einer an den Prinzipien der kollektiven Sicherheit orientierten Außenpolitik, die den Verzicht auf die Korrektur des Kriegsergebnisses einschloß, und einer abermaligen Herausforderung Europas, die alle erreichten Fortschritte der internationalen Politik wieder aufheben und das Rad der Geschichte zurückdrehen mußte.

Daß Deutschland eines Tages in der Lage sein würde, revisionistische Politik zu treiben, war nicht zu bezweifeln ${ }^{16}$. Zwar hatte das Reich seinen territorialen Bestand nicht ganz behaupten können. Durch den Vertrag von Versailles waren die 1870/71 eroberten Elsaß und Lothringen an Frankreich zurückgefallen, das außerdem die Kohlengruben des vom Völkerbund verwalteten Saarlands kontrollierte; Eupen und Malmedy waren an Belgien verlorengegangen, Posen und Teile Westpreußens an Polen, das Memelgebiet an Litauen, ein Teil Schleswigs an Dänemark und das Hultschiner Ländchen an die Tschechoslowakei. Die Kolonien hatten abgetreten werden müssen, ebenso Danzig, das allerdings nicht an Polen fiel, sondern zur Freien Stadt unter der Aufsicht des Völkerbunds erklärt wurde; 1921 folgte schließlich noch die Teilung des oberschlesischen Industriegebiets. Aber diese Abtretungen entsprachen nahezu überall dem Willen einer Mehrheit der in den betreffenden Territorien lebenden Bevölkerung. Ansonsten hatte auch Deutschland durchaus den Schutz des in „14 Punkte“ gefaßten Wilsonschen Friedensprogramms genossen, dessen Kernstück das Selbstbestimmungsrecht der Völker war, und der amerikanische Präsident hatte die von ihm formulierten Prinzipien sogar mit der Drohung eines Separatfriedens als Grundlage des deutschen Friedensvertrags durchgesetzt; wilde Zerstückelungspläne, wie sie in den Kriegsjahren geschmiedet worden waren, hatten auf der Friedenskonferenz keine Chance mehr gehabt. Gewiß war auch die Vorstellung wirksam gewesen, Deutschland müsse für seinen entscheidenden Anteil am Ausbruch des großen Krieges bestraft werden. Doch hatte diese Vorstellung ihren Ausdruck nicht in der territorialen Verkleinerung des Reiches gefunden, sondern in der Aufbürdung wirtschaftlicher Lasten und in ebenso harten wie unsinnigen und unrealisierbaren Reparationsforderungen. Das Sicherheitsbedürfnis der Nachbarn, nach dem langen und opferreichen Krieg hoch entwickelt, hatte Deutschland ebenfalls keine territorialen Einbußen gekostet. Es war vielmehr mit der befristeten Besetzung des linksrheinischen Territoriums, mit der Entmilitarisierung eines 50 Kilometer breiten rechtsrheinischen Streifens, mit der Reduzierung der Armee auf 100000 Mann und vor allem mit der Verweigerung territorialer Gewinne für Deutschland

16 P. Krüger, Versailles. Deutsche Außenpolitik zwischen Revisionismus und Friedenssicherung, München 1986. 
aus dem Erbe Österreich-Ungarns abgefunden worden: den Deutschen Österreichs und der böhmisch-mährischen Länder war der von ihnen gewünschte Anschluß an das Reich verwehrt worden.

Die Masse seines Staatsgebiets hatte Deutschland jedoch behaupten können und stellte, wenn auch im Augenblick geschlagen, teilweise besetzt und fast entwaffnet, nach wie vor die wirtschaftlich und potentiell auch politisch und militärisch stärkste Macht des Kontinents dar. Daß diese Macht versuchen würde, die Einschränkung ihrer Souveränität wieder abzuschütteln, war selbstverständlich; die Einschränkung galt ohnehin nur für eine bestimmte Frist. Die einseitige Abrüstung des Reiches war auf die Dauer ebenfalls unhaltbar. Ebenso selbstverständlich war es endlich, daß sich Deutschland um eine Revision des absurden alliierten Reparationsprogramms bemühen würde. Solche revisionistischen Tendenzen der deutschen Außenpolitik konnten im übrigen, für sich allein betrachtet, kaum zu einer Gefährdung der europäischen Sicherheit führen, und so lag in ihrer Unausweichlichkeit an sich noch nichts Bedrohliches. Wie aber würde Deutschland auf seine territorialen Verluste und auf den entgangenen Gewinn Österreichs oder der Sudetengebiete reagieren? Noch wichtiger: Waren die hegemonialen Ambitionen der Vorkriegszeit und die imperialen Träume der Kriegsjahre tatsächlich tot? Durfte erwartet werden, daß Deutschland die Abweisung seines Führungs- und Herrschaftsanspruchs hinnahm? Oder würden die Berliner Kabinette eine Konzeption wählen, in der die Wiedergewinnung der Souveränität, der militärischen Gleichberechtigung und der finanziellen Freiheit lediglich als Stufe zu einer gleichgewichts- und völkerbundsfeindlichen Politik der territorialen Revision und der großdeutsch-imperialen Expansion diente?

Als am 15. November 1920 die erste Vollversammlung des Völkerbunds begann, war die Entscheidung über den künftigen Weg der deutschen Politik im Grunde bereits gefallen. Die Revolutionsversuche der radikalen Linken waren zusammengebrochen, und die demokratische Linke hatte, erschreckt von der Möglichkeit einer Revolution nach russischem Muster, ein Bündnis mit den alten Gewalten in Wirtschaft, Bürokratie und namentlich Armee geschlossen, das es ihr verwehrte, die vorübergehend übernommene politische Führung zu einer Politik in ihrem Sinne auszunutzen ${ }^{17}$. Wenig später hatte sie auch diese Führung wieder verloren, als in den ersten Wahlen nach dem Kapp-Putsch - dem frühesten Ansatz der extremen Rechten zur Machteroberung - der für lange Jahre letzte sozialdemokratische Reichskanzler, Hermann Müller, stürzte. Nach dem Zwischenspiel sozialdemokratischer Regierungsverantwortung stellte sich sofort heraus, daß die Niederlage, die Republikanisierung und die folgende innere Erschütte-

17 H. Möller, Weimar. Die unvollendete Demokratie, München 1985; vgl. auch P. Krüger, Deutschland und die Reparationen 1918/19, Stuttgart 1973; H. Schulze, Weimar. Deutschland 1917-1933, Berlin 1982; E. Kolb, Die Weimarer Republik, MünchenWien 1984. 
rung an der Grundstruktur der deutschen Gesellschaft und an den innenpolitischen Machtverhältnissen kaum etwas geändert hatten. Zwar blieb Deutschland eine Republik, in der das Parlament eine gewisse Rolle spielte. Doch dominierten schon im Parlament die von großbürgerlichen, agrarischen und mittelständischen Interessenverbänden gelenkten Parteien des in Wahrheit immer noch parlamentsfeindlichen nationalen Bürgertums, und hinter diesen bewegten Szenen im Vordergrund regierten in Wirklichkeit nach wie vor Bürokratie und Armee, in denen gleichfalls, wie in den Parteien der Mitte und der Rechten, die Konservatoren bürgerlichnationalistischer und aristokratisch-konservativer Traditionen die Richtung angaben. Die Republik von Weimar, wie der neue Staat nach dem Ort der ersten und verfassunggebenden Nationalversammlung genannt wurde, stellte faktisch - etwas übertreibend gesagt - nur eine Fortsetzung des wilhelminischen Deutschland mit anderen Mitteln dar.

Gerade auch in der Außenpolitik war von sozialdemokratischen oder linksbürgerlichen Einflüssen keine Rede. Und die außenpolitische Grundstimmung der noch immer oder jetzt wieder herrschenden Schichten hatte sich trotz Krieg und Niederlage offensichtlich nicht gewandelt. Eine übergroße Mehrheit identifizierte sich nach wie vor mit der imperialen Tendenz des Kaiserreiches und unterließ sogar jede Kritik an den ausschweifenden Expansions- und Herrschaftsprogrammen der Kriegsjahre. Der Völkerbund wurde - wie schon während des Krieges die in Westeuropa und den USA entworfenen Planskizzen meist nur Spott und Hohn geerntet hatten - entweder als überflüssiger internationaler Debattierklub verachtet oder als britisch-französisches Instrument zur Niederhaltung Deutschlands bzw. zur Erstickung jeglicher freien Entfaltung des souveränen Machtstaats - angefeindet und abgelehnt. Allen, die so dachten, mußte die Anpassung an die neue europäische Ordnung unmöglich scheinen und die große deutsche Mitverantwortung für das Gelingen des Genfer Experiments gleichgültig bleiben. Daß Deutschland bei erster Gelegenheit auch territoriale revisionistische Außenpolitik machen werde, verstand sich für den Chef der Heeresleitung, General v. Seeckt, ebenso von selbst wie für die meisten Beamten des Auswärtigen Amts, für die Leiter bürgerlicher Parteien ebenso wie für die Repräsentanten der meinungsbildenden Wissenschaften ${ }^{18}$.

Indes ging es nicht allein um die Korrektur dieser oder jener Grenze, um die Wiedergutmachung der vermeintlichen oder tatsächlichen Ungerechtigkeiten des Versailler Vertrags. Mehr noch ging es um die Wiederherstellung der imperialen Position und der imperialen Möglichkeiten Deutschlands. Was als Revisionspolitik bezeichnet wurde, hatte seine Wurzeln keineswegs in den einzelnen Bestimmungen des Vertrags von Versailles, sondern im eigentlichen Kriegsergebnis, der Abweisung des deutschen Führungsanspruchs auf dem europäischen Kontinent, und so erfaßt die Bezeichnung „Revisionspolitik“ lediglich die konkrete Anfangsphase einer $18 \mathrm{Vgl}$. Graml, Europa, S. $55 \mathrm{ff}$. 
Politik, die jene an sich unvermeidliche Konsequenz des territorialen deutschen Revisionismus, die Erneuerung und den Ausbau der deutschen Hegemonie, aus älteren Wurzeln als ihr wahres Ziel anstrebte. Im Grunde handelte es sich von Anfang an nicht um Revisionspolitik, sondern um Restaurationspolitik. Auch von einem milderen Frieden wären diese völkerbunds- und gleichgewichtsfeindlichen Tendenzen der deutschen Außenpolitik mithin nicht beruhigt worden. Ohne gänzlich instrumentalisiert zu werden, fungierten die einzelnen revisionistischen Forderungen doch zugleich als territoriale Mittel zum machtpolitischen und imperialen Zweck. Der Wille zur Führung Europas und zur imperialen Expansion auf dem europäischen Kontinent war ungebrochen.

Daher ist stets weniger die Rangfolge der einzelnen territorialen Revisionsziele diskutiert worden als vielmehr die Frage, welche Position des kaiserlichen Deutschland restauriert werden solle. Drei große Gruppen lassen sich, schematisch vereinfacht, unterscheiden: Auf dem gemäßigten linken Flügel standen Konservative wie General v. Seeckt, die einfach zum Sommer 1914 zurückkehren wollten und darüber zunächst nicht hinausdachten. Die Mitte bildeten innenpolitisch oft mehr liberal orientierte Anhänger eines unter der Leitung Großdeutschlands wirtschaftlich und politisch zusammengeschlossenen Mitteleuropas, das sich während des Krieges bereits abgezeichnet hatte. Und auf dem rechten Flügel sammelten sich die Verfechter einer überhaupt nicht mehr begrenzten deutschen Expansion; hier wurde nach wie vor ein Imperialismus gepredigt, der unter Parolen wie „Herrenvolk“ und „Lebensraum“, die von den Alldeutschen der Vorkriegszeit geprägt worden waren, nicht nur auf Führung und Hegemonie zielte, sondern auf die Unterwerfung und Germanisierung - durch Ausrottung und Ansiedlung - weitester und unterschiedlichster nichtdeutscher Territorien, namentlich in Osteuropa. $\mathrm{Zu}$ den Wortführern dieses prononciert antiliberalen und häufig auch antikonservativen rechten Flügels, der Verwandtschaft mit den italienischen Faschisten empfand und besaß, gehörte Oswald Spengler, der unmittelbar nach dem Kriege mit seinem Buch „Untergang des Abendlandes" Ansehen erwarb, zu Beginn der zwanziger Jahre ideologischen Einfluß auf nationalistische Organisationen gewann und enge Beziehungen zu nationalistischen Industriellen knüpfte. Im Rückblick auf das Frühjahr 1918 und auf die Möglichkeiten, die der Frieden von Brest-Litowsk - vom Deutschen Reich damals dem besiegten Rußland diktiert - ja erst angedeutet hatte, setzte Spengler schon im Dezember 1918 auf eine Diktatur, die mit dem ,politischen Dilettantismus von Mehrheiten“ Schluß machen werde: „Und dann hoffe ich, ... daß der Aufbau von Mitteleuropa aus uns die Stellung verschafft, die unsere Bestimmung ist und an die ich unerschütterlich glaube. Der Friede von heute ist nur ein Provisorium ... Tatsăchlich tritt der Weltkrieg erst jetzt in sein zweites Stadium."19

19 Spengler, Briefe 1913-1936, München 1963, S. 113. 
Angesichts der Realitäten der ersten Nachkriegsjahre wirkten die Träume aller drei Gruppen recht ungereimt. Indes fühlten sich die Verfechter der Restaurationspolitik keineswegs schwach. Deutschland habe lediglich, so glaubten sie, einen Rückschlag erlebt wie Preußen 1806/7 nach Jena und Tilsit. Bereits 1919 sah Spengler den „Weg Tilsit-Leipzig“ vor sich liegen. Anders als damals, war dem Zusammenbruch von 1918 überdies eine in der Tat imponierende wirtschaftliche, organisatorische und vor allem militärische Leistung vorhergegangen, die gerade im nachhinein zu einer Überschätzung der eigenen Kraft verführte. Das während des Krieges und danach gewonnene Kraftbewußtsein wurde sogar zu einer selbständigen Ursache - und mentalen Rechtfertigung - des imperialen Willens, zumal die ausschlaggebenden Ursachen der militärischen Erfolge Deutschlands - im Westen die zeitweilige Überlegenheit der defensiven Kampfform, im Osten die in jeder Hinsicht bestehende qualitative Überlegenheit über die zaristische Armee - unbegriffen blieben. Die Tatsache der am Ende eben doch erlittenen militärischen Niederlage schrieb man der inneren Zersetzung durch die Linke, dem "Dolchstoß“ in den Rücken der ansonsten zum Sieg noch fähigen Kampftruppe, zu oder stempelte sie zum Zufallsergebnis einzelner Fehler und Versäumnisse. Nicht die Niederlage wurde erklärt, sondern die Verfehlung des immer wieder zum Greifen nahen Sieges 20.

Gewiß war Deutschland vorerst durch den Vertrag von Versailles gefesselt. Doch verriet gerade der häufige Gebrauch der Formel „Fesseln“ oder „Ketten“ von Versailles, daß eine Mehrheit der Deutschen glaubte, ihre Nation leide nicht unter einem Mangel an Kraft, sondern bloß unter einem Mangel an Bewegungsfreiheit, und die Wiedergewinnung der Handlungsfreiheit wurde als lösbare Aufgabe angesehen. Zumindest für die revisionistische Phase der Restaurationspolitik waren taktische Mittel und Wege durchaus zu entdecken, ob man nun sogleich gegen den Klub der Sieger die Partei der Revisionisten und Unzufriedenen sammelte, wie es Walther Rathenau, Chef der AEG und 1922 Außenminister, schon 1919 vorschwebte, oder ob man sich „rebus sic stantibus ... auf die demokratisch-pazifistische Seite" legte, wie im Herbst 1918 Paul v. Hintze, der Staatssekretär im Auswärtigen Amt, geraten hatte, um über den Eintritt in den Völkerbund die alte Machtposition zurückzugewinnen.

In dieser Atmosphäre begann die politische Karriere eines Mannes, der bald zu der Überzeugung kam, daß es seine Mission sei, das Eroberungsund Herrschaftsprogramm des rechten Flügels der deutschen Restaurationsbewegung zu popularisieren, zu komplettieren und vielleicht auch zu realisieren. Als Adolf Hitler wenige Jahre später - in einem Buch, das er

${ }^{20}$ F. Freiherr Hiller von Gaertringen, „Dolchstoß“-Diskussion und „Dolchstoß-Legende“ im Wandel von vier Jahrzehnten, in: Geschichte und Gegenwartsbewußtsein. Festschrift f. H. Rothfels, hrsg. v. W. Besson und F. Freiherr Hiller von Gaertringen, Göttingen 1963, S. 122-160. 
„Mein Kampf“ nannte - ein leidenschaftliches Plädoyer für jenes Programm der Öffentlichkeit präsentierte, hat er eine souveräne Verachtung der „Ketten von Versailles“ an den Tag gelegt, wie sie aus dem Bewußtsein der ungeheuren Kräfte Deutschlands folgte, und die Erschließung ausreichender materieller wie psychischer Reserven für den kommenden Eroberungskrieg als pure Willensfrage behandelt.

Für viele Anwälte der Restauration, namentlich für preußische Konservative, lag es dabei nahe, als erstes Ziel der revisionistischen Phase Polen zu wählen und zu diesem Zweck die angesichts völlig veränderter Umstände wieder möglich gewordene Allianz zu restaurieren, die zwischen Preußen und Rußland vom Ende des 18. bis zu den achtziger Jahren des 19. Jahrhunderts bestanden hatte; daß in Rußland jetzt kommunistische Revolutionäre an der Macht waren, störte sie wenig, solange auch die Bolschewiki im Hinblick auf Polen revisionistische Neigungen zeigten. Bereits im polnisch-russischen Krieg von 1920 beobachtete Deutschland eine prorussische Neutralität, und 1921 wurde zwischen Moskau und Berlin eine - zunächst geheime - militärisch-industrielle Zusammenarbeit aufgenommen. Als schrillstes Signal des deutschen Willens zur Revisions- und Restaurationspolitik folgte dann, am 16. April 1922 mit der Sowjetunion abgeschlossen, der Vertrag von Rapallo, der auf der einen Seite eine zur Anerkennung des Status quo führende Verständigung mit den Westmächten verhindern, auf der anderen Seite das besondere deutsch-russische Verhältnis gegen Polen befestigen und die schon bestehende deutsch-sowjetische Militärallianz politisch stützen sollte21.

In den Nachbarstaaten Deutschlands ist der Vertrag von Rapallo mit Recht als Beweis dafür genommen worden, daß von Deutschland statt der Eingliederung in die Nachkriegsordnung eine Fortsetzung expansiver Politik zu erwarten sei. Die französischen Politiker waren nach zwei deutschen Invasionen ohnehin geneigt, die aggressive Unruhe Deutschlands als chronische Erscheinung zu betrachten. Den Genfer Prinzipien weniger nahe als ihre angelsächsischen Kollegen und daher von Beginn an ohne rechtes Vertrauen in die Funktionsfähigkeit des Völkerbunds, machten sie sich bei Kriegsende sogleich daran, das System der kollektiven Sicherheit durch ein Allianzsystem alten Stils zu ergänzen. Als Frankreich eine zugesagte amerikanisch-britische Sicherheitsgarantie gegen Deutschland, für die Paris mit dem Verzicht auf eigene Annexionen und mit dem Verzicht auf die Schaffung einer politisch autonomen rheinischen „Pufferzone“ bezahlt hatte, schließlich doch verlor, weil sich die USA politisch wieder aus Europa zurückzogen, glaubten sich die französischen Kabinette außerdem berechtigt, Deutschland möglichst lange im Zustand politischer und militärischer

${ }^{21}$ H. G. Linke, Deutsch-sowjetische Beziehungen bis Rapallo, Köln 1972; G. Wagner, Deutschland und der polnisch-sowjetische Krieg, Wiesbaden 1979; H. Graml, Die Rapallo-Politik im Urteil der westdeutschen Forschung, in: VfZ 18 (1970), S. 366-392; C. Fink, The Genoa Conference. European diplomacy 1921-1922, Chapel Hill 1984. 
Ohnmacht zu halten und gleichzeitig ein defensives französisches Hegemonialsystem aufzubauen. Im Gefühl langfristiger Unterlegenheit nutzte daher Frankreich seine momentane Überlegenheit zunächst zur Organisierung antirevisionistischer Bündnisse. Mitte August 1920 schlossen sich die Tschechoslowakei, Jugoslawien und Rumänien unter französischem Patronat gegen Ungarn zur sogenannten „Kleinen Entente“ zusammen, die Anfang März 1921 durch eine rumänisch-polnische Allianz und Anfang November 1921 durch ein polnisch-tschechoslowakisches Neutralitätsabkommen erweitert wurde. Als Frankreich im Februar 1921 ein Bündnis mit Polen einging und im Januar 1924 auch noch das längst bestehende freundschaftliche Verhältnis zur Tschechoslowakei vertraglich abstützte, erhielt das ganze System seine Verklammerung und seine Spitze22.

Zugleich wurde Deutschland auf französische Initiative mit unerfüllbaren alliierten Reparationsansprüchen konfrontiert (132 Milliarden Goldmark), die eine Wiedergewinnung der finanziellen und damit auch der militärischen und politischen Bewegungsfreiheit Deutschlands verhindern sollten ${ }^{23}$. Daß überhaupt - wie das auch Deutschland für den Fall des Sieges vorgehabt hatte - hohe Reparationen verlangt wurden, lag natürlich auch am Finanzbedarf der Siegermächte, die ihre Kriegsschäden zu ersetzen und vor allem ihre von Washington unerbittlich eingeforderten amerikanischen Kredite zurückzuzahlen hatten. Daß aber die Reparationen auf eine Höhe geschraubt wurden, die offensichtlich in keiner Beziehung mehr zur deutschen Zahlungsfähigkeit stand, lag doch in erster Linie an der politischen Instrumentalisierung der Reparationen durch Frankreich. Nachdem Deutschland mit dem Vertrag von Rapallo so frühzeitig und so offen eine Kriegserklärung an den Status quo formuliert hatte, vermochten sich in $\mathrm{Pa}$ ris sogar Kräfte durchzusetzen, die den Versailler Vertrag für zu milde und in einem französischen Sinne für revisionsbedürftig hielten. Seit der Friedenskonferenz hatten sie auf die Okkupation des Ruhrgebiets hingearbeitet, mit der sie Deutschland weiter zu schwächen hofften und in deren Schatten sie zumindest die Schaffung der 1919 vẹrpaßten rheinischen Pufferzone nachzuholen gedachten. Nach Rapallo fanden die französischen Anwälte totaler Sicherheit kaum noch Widerspruch und schließlich bekamen sie vorübergehend auch außenpolitische Handlungsfreiheit, als die deutsche Regierung einige Monate nach Rapallo ihrer Kriegserklärung an den Status quo auch noch die Einstellung barer Reparationszahlungen und die Verweigerung des Eintritts in den Völkerbund hinzufügte. Beides zusammen lief auf den Abbruch der am 31. August 1921 mit der ersten tatsächlich gezahlten Milliarde Goldmark eingeleiteten „Erfüllungspolitik“ hinaus. Auf eine gleichwohl fadenscheinige juristische Begründung gestützt, rückten am 11. Januar 1923 französische und belgische Truppen ins

22 P. Wandycz, France and her Eastern Allies, Minneapolis 1962.

23 Vgl. P. Krüger, Versailles, S. $93 \mathrm{ff}$. 
Ruhrgebiet ein, wo sie ein Besatzungsregime etablierten, das sich alsbald zu einer üblen Militärdiktatur mit zahllosen Ausweisungen, barbarischen Haftstrafen und sogar Erschießungen entwickelte; gleichzeitig begann die verstärkte Ermunterung und Unterstützung rheinischer Separatistengruppen. Die Reichsregierung, unfähig, sich mit Waffengewalt zur Wehr zu setzen, antwortete mit einem zunächst im gesamten besetzten Gebiet befolgten Aufruf zum passiven Widerstand. Zwischen Frankreich und Deutschland herrschte wieder eine Art Kriegszustand.

Frankreich fühlte sich von Deutschland herausgefordert und meinte daher bei seinem Vorgehen im Recht zu sein. Doch stellte die französische Aktion einen schweren Rückfall in die internationale Anarchie der Vorkriegsjahre und damit eine erste Sünde wider den Geist des Völkerbunds dar. Anfänglich schien der Bund auch scharf regieren zu wollen, doch beugte er sich am Ende dem Druck Frankreichs - immerhin eines der wichtigsten Mitglieder -, das selbst vor der Drohung mit dem Austritt nicht zurückschreckte; Frankreichs Rückkehr zum internationalen Faustrecht blieb ungeahndet und sogar ungerügt. Lasteten schon die hegemoniale Politik und Position Frankreichs steinschwer auf dem Versuch, die Idee der kollektiven Sicherheit zu einer politischen Realität zu machen, so hatte sich nun das französische Sicherheitsbedürfnis zu einem Akt hinreißen lassen, der die Restauration des Machtprinzips fast ebenso förderte und das Prinzip des Rechts fast ebenso schwächte wie die grundsätzliche Völkerbundsfeindschaft Deutschlands. Erstmals zeichnete sich die Möglichkeit ab, daß die internationale Friedensordnung und mit ihr die gesamte Neuordnung des europäischen Kontinents zwischen den Mühlsteinen der deutschen Restaurationspolitik und der französischen Sekuritätspolitik zerrieben werden könnten. Bereits das Auftauchen dieser Möglichkeit bescherte dem Völkerbund eine Stagnation, gegen die niemand ein probates Mittel einfallen wollte. Insofern reichte die Bedeutung des französischen Abenteuers an der Ruhr weit über das deutsch-französische Verhältnis hinaus, dem natürlich ebenfalls eine schwere Hypothek aufgebürdet wurde.

Daß es schließlich doch zu einem Zwischenspiel der Verständigung und zu einer vorübergehenden Stabilisierung kam, war denn auch keine Leistung des Völkerbunds. Vielmehr lag es einfach daran, daß die Situation unerträglich wurde. Die Unerträglichkeit zwang Großbritannien zu einer nachdrücklich vermittelnden Intervention in die kontinentalen Angelegenheiten und zwang sowohl Frankreich wie Deutschland zu partiellem und zeitweiligem Einlenken. Die britischen Politiker standen - auf Grund der größeren Stärke ihres in Jahrhunderten gereiften liberal-parlamentarischen Verfassungsdenkens - dem Völkerbundsgedanken näher als die französischen Kollegen. Sie hatten außerdem mit der Vernichtung der deutschen Kriegsflotte ihr wichtigstes konkretes Kriegsziel erreicht. Jetzt waren sie, von der deutschen Gefahr ohnehin weiter abgesetzt und nun vornehmlich von den wirtschaftlichen Sorgen ihres hochindustrialisierten Landes be- 
drängt, in erster Linie an der Erholung des Welthandels und folglich an der wirtschaftlichen Gesundung des europäischen Kontinents - einschließlich des bedeutendsten Handelspartners Deutschland - interessiert. Seit dem Ende des Krieges hatten sie den Repräsentanten Frankreichs begreiflich zu machen versucht, daß sowohl die Zukunft des Völkerbunds wie die Regeneration der europäischen Wirtschaft von der politischen Stabilisierung des Kontinents abhingen und daß die politische Stabilisierung wiederum nicht ohne die Aussöhnung Deutschlands mit der europäischen Nachkriegsordnung zu erreichen sei. Lloyd George, der damalige britische Premier, hatte sich schon auf der Friedenskonferenz bemüht, die Praktizierung dieses Grundgedankens wenigstens vorzubereiten, indem er sich in Grenzfragen nicht ohne Erfolg zum Anwalt deutscher Interessen gemacht hatte ${ }^{24}$. Auch in der seit Versailles erheblich veränderten Situation setzte die britische Regierung auf eine Beruhigung der Stimmung in Deutschland, die sie dann für möglich hielt - und hier geriet sie in einen schroffen Gegensatz zur französischen Konzeption -, wenn die Sieger bereit waren, die Fesseln von Versailles bald zu lösen und Deutschland seine wirtschaftliche wie seine politische Bewegungsfreiheit zurückzugeben. Selbst spätere Korrekturen der deutschen Ostgrenze schloß man in London nicht aus, wie die mehrmalige Weigerung bewies, sich für die territoriale Integrität Polens zu engagieren - bei gleichzeitiger Bereitschaft zum Engagement für die französische Ostgrenze. Konzessionen und die im Hintergrund stehende Warntafel „Entente“, auf die man keinesfalls zu verzichten gedachte, sollten Deutschland während seines Wiederaufstiegs in die internationale Ordnung einzugliedern, hielten die britischen Politiker jene Herausforderung für sehr wahrscheinlich. Daß der deutsche Wiederaufstieg selbst unvermeidlich und liedern, hielten die britischen Politiker jene Herausforderung für sehr wahrscheinlich. Daß der deutsche Wiederaufstieg selbst unvermeidlich und die französische Repressionskonzeption nicht auf die Dauer durchzuhalten war, lag für die Briten auf der Hand.

Im Rahmen dieser Appeasement-Politik, wie man im Londoner Foreign Office das eigene Konzept bald zu nennen pflegte, hat die britische Regierung beharrlich versucht, Frankreichs Reparationsforderung auf ein wirtschaftlich vertretbares $\mathrm{Maß}$ zurückzuschrauben. Zunächst freilich erfolglos. Immerhin brachte es Lloyd George fertig, einige Jahre lang den französischen Einmarsch ins Ruhrgebiet zu verhindern, obwohl die reparationspolitische Störrigkeit der deutschen Kabinette, die bis Mitte 1921 jede Barzahlung verweigert hatten, eher der französischen Politik in die Hände arbeitete. Indes ist in London auch die diplomatische Aktivität Frankreichs mit wachsendem Unbehagen verfolgt worden. Die britischen Anhänger des Völkerbunds nahmen übel, daß die französischen Allianzen die Diplomatie der Vorkriegszeit ungehemmt fortsetzten und der Völkerbundsidee psychologisch wie faktisch schweren Schaden zufügten. Politiker wie Lloyd 24 Vgl. Graml, Europa, S. 87 ff. 
George konstatierten mit zunehmender Verbitterung, daß Frankreichs Sammlung der Status-quo-Partei lediglich dazu beitrug, die Spaltung Europas bis zum fast unvermeidlichen Gegenschlag der Revisionspartei gleichsam zu institutionalisieren. Bereits Ende 1921 konzipierte Lloyd George ein großes Projekt zur wirtschaftlichen und politischen Sanierung Europas, das - in Form einer gesamteuropäischen, auch von Deutschland mitgetragenen, wirtschaftlichen Hilfs- und Entwicklungsaktion für Sowjetrußland sowohl Deutschland wie Rußland in den Kreis der europäischen Mächte zurückholen, eine vernünftige Regelung der Reparationsfrage ermöglichen und die Übersteigerungen der französischen Sicherheitspolitik überflüssig machen sollte 25 . Zwar mußten solche Gedanken vorerst wieder begraben werden, als im April 1922 die Konferenz von Genua statt einer produktiven Diskussion über das Projekt Lloyd Georges die deutsch-sowjetische Separatverständigung von Rapallo brachte. Angesichts der revisionspolitischen Provokation, die sich Deutschland geleistet hatte, sah sich die britische Regierung sogar zu Konzessionen an die französische Sicherheitspolitik veranlaßt: Als die französischen Truppen das Ruhrgebiet besetzten, nahm Großbritannien anfänglich eine Haltung der „surly neutrality“ ein ${ }^{26}$.

Nachdem jedoch ganz klar geworden war, in welches politische und wirtschaftliche Chaos die französische Aktion Europa stürzte, kehrte London sogleich zur Appeasement-Politik zurück. Mit der Drohung, notfalls den Versailler Vertrag zu kündigen, wurde Frankreich zunächst gezwungen, die rheinischen Separatisten fallenzulassen, die ohne französische Unterstützung eine handlungsunfähige kleine Minderheit darstellten. Sodann zeigte sich die britische Regierung entschlossen, Paris nun außerdem eine praktikable Lösung des Reparationsproblems und darüber hinaus eine generelle Annäherung an Deutschland zu oktroyieren. Poincaré, der damalige französische Regierungschef, der schon eine Torpedierung des Sanierungsprojekts Lloyd Georges vorbereitet hatte, ehe ihn Rapallo aller eigenen Mühen enthob, fand an dem britischen Vorhaben wenig Geschmack. Aber die außenpolitische Isolierung, in die er sein Land mit der Ruhraktion geführt hatte, konnte nicht lange ertragen werden, und als ihn das britische Kabinett zum Verzicht auf die rheinische Pufferzone nötigte, war der eigentliche politische Zweck der Aktion ohnehin verfehlt. Widerwillig fand sich Frankreich bereit, dem britischen Druck nachzugeben - zumal Deutschland inzwischen nachgegeben hatte 27.

Deutschland war mit seiner Politik in eine Lage geraten, in der die - zumindest scheinbare - Kapitulation nur eine Frage der Zeit sein konnte. Da

${ }^{25}$ Vgl. C. Fink, The Genoa Conference.

26 Viscount d,Abernon, Memoiren, Bd. 2, S. 114.

27 G. Bertram-Libal, Aspekte der britischen Deutschlandpolitik 1919-1922, Göppingen 1972; B. Dohrmann, Die englische Europapolitik in der Wirtschafskrise 1921-1929, München-Wien 1980; M. Trachtenberg, Reparation in world politics. France and European economic diplomacy 1916-1923, New York 1980. 
das Reich nicht mehr über die Produktions- und Finanzkraft seines wichtigsten Industriegebiets verfügte und überdies den passiven Widerstand nicht etwa durch eine entsprechende steuerliche Belastung der Bevölkerung des unbesetzten Gebiets finanzierte, sondern im wesentlichen durch eine enorme Produktionssteigerung der Druckerpresse, war das Ende des Widerstands sogar mit fast mathematischer Sicherheit zu bestimmen. Die durch die Kriegsfinanzierung schwer angeschlagene und dann durch die ebenfalls mit einer laufenden Erhöhung der schwebenden Schuld arbeitende Finanzpolitik der ersten Nachkriegskabinette endgültig ruinierte Währung trieb in eine Inflation von phantastischen Ausmaßen, die wiederum innenpolitische Konflikte aller Art in unerträglicher Weise verschärfte. Bereits im Frühsommer 1923 blieb der Reichsregierung nichts anderes übrig, als den Alliierten mitzuteilen, daß Deutschland hinsichtlich der Reparationen zur Erfüllungspolitik zurückkehren wolle.

Nun ist es durchaus möglich, daß sich lediglich die Entwicklung von 1921/22 wiederholt hätte. Jedoch nahm die Zügel der Berliner Außenpolitik jetzt ein Mann in die Hand, der zwar während des Krieges zu den Wortführern imperialistischer Politik und zu den parlamentarischen Vertrauensleuten der Obersten Heeresleitung gehört, seither aber eine Wandlung erfahren hatte, die ihn befähigte, die realitätsvernebelnde nationalistische Egozentrik abzuschütteln, die in der politischen Führungsschicht Deutschlands Tradition geworden und sogar zur staatsbürgerlichen Tugend stilisiert worden war ${ }^{28}$. Gustav Stresemann, der an der Spitze der nationalliberalen Deutschen Volkspartei (DVP) stand, hatte sich zu einem Patriotismus bekehrt, dem nicht die Realisierung möglichst weit gespannter Herrschaftsansprüche seiner Nation, sondern die nüchterne und vor allem erfolgreiche Wahrung ihrer konkreten Interessen und ihrer Wohlfahrt als die wahrhaft nationale Pflicht galt. Er verlor weder die Revision der deutsch-polnischen Grenze aus den Augen noch dachte er im späteren Sinne des Wortes „europäisch“. Doch hatte er Deutschland im europäischen Zusammenhang zu sehen begonnen, und so begriff er, daß der Wiederaufstieg und eine dauerhafte Sicherung der politischen Existenz Deutschlands niemals gegen die Entente erreicht werden konnten, vielmehr eine Verständigung mit den Alliierten und gerade auch mit Frankreich voraussetzten. Der in Versailles und seit Versailles versäumte wahrhafte Friedensschluß mußte nachgeholt werden. Hatte er im Vorjahr noch die Rapallo-Politik begrüßt und unterstützt, so war er durch die französische Ruhraktion zu der Einsicht gekommen, daß Deutschland das Ergebnis des Krieges nicht länger ignorieren dürfe, daß der besonders im deutschen Interesse liegende Friedensschluß nicht ohne eine deutlich bekundete Anerkennung zumindes der neuen Westgrenzen Deutschlands zu haben sei. Und Stresemann besaß zugleich die Entschlossenheit und das taktische Geschick, einen an realistischen

${ }^{28}$ K. Koszyk, Gustav Stresemann. Der kaisertreue Demokrat, Köln 1989. 
Einsichten orientierten Kurs auch durchzusetzen. So begann ein erstaunliches Schauspiel: Ausgerechnet der Führer einer prononciert nationalistischen Rechtspartei, der die emotionsgeladene Sprache des deutschen $\mathrm{Na}$ tionalismus meisterhaft beherrschte und intern jeden seiner Schritte weiterhin in dieser Sprache erklärte, steuerte Deutschland auf den Kurs einer konsequenten rationalen Verständigungspolitik. Nachdem er im August 1923 Reichskanzler geworden war, hielt Stresemann das noch von seinem Vorgänger gemachte Angebot einer reparationspolitischen Kapitulation aufrecht, und am 26. September brach er außerdem den passiven Widerstand ab. In den letzten Monaten des Jahres 1923 beseitigte das Kabinett Stresemann ein weiteres Hindernis, das einer brauchbaren Regelung des Reparationsproblems nach wie vor im Wege stand. Mit der Schaffung der Rentenmark und dem Ausgleich des Haushalts wurden die Grundlagen für eine stabile Währung gelegt, und mit dem Ende der Inflation zerriß jener sinnverwirrende Zahlenschleier, den Berlin bislang benutzt hatte, um eine realistische Einschätzung der deutschen Zahlungskraft und damit eine realistische Reparationskalkulation zu verhindern.

Die erfolgreiche Finanzreform schuf außerdem die Vertrauensbasis für internationale Anleihen zur Stärkung der deutschen Kapitalkraft und die Voraussetzung für die Konstruktion der finanztechnischen Mechanismen, die einen Transfer deutscher Reparationsgelder ohne Gefährdung des Kurswerts der Mark erlaubten. Gewiß hatte die Finanzierung des passiven Widerstands die Mark in so bodenlose Tiefen gestürzt, daß die lange verzögerte Sanierung der Währung schon aus wirtschaftlichen und innenpolitischen Gründen unumgänglich geworden war. Aber Stresemann betrachtete die Liquidierung der Inflation mit Recht auch als Teil jener kalkulierten außenpolitischen Kapitulation, die er als deutschen Beitrag zur Überwindung der chaotischen Zustände in Europa und damit zugleich als ersten Schritt Deutschlands zur Rückkehr in die europäische Staatengesellschaft verstand.

Nachdem die Reichsregierung im April 1924 die Vorschläge einer inzwischen unter der Leitung des Amerikaners Charles G. Dawes gebildeten Expertenkommission grundsätzlich angenommen hatte, mußte auch Poincaré in den sauren Apfel beißen und eine Regelung der Reparationsfrage akzeptieren, die seinen Versuchen, das Problem für politische Zwecke zu instrumentalisieren, den Boden entzog und außerdem der französischen Anstrengung ein Ende setzte, Deutschland im Zustand von Versailles zu halten. Der Dawes-Plan legte Deutschland fraglos eine schwere Last auf: Im ersten Zahlungsjahr hatte das Reich eine Milliarde Mark aufzubringen, und in den folgenden drei Jahren sollten die Raten von 1,22 auf 1,75 Milliarden steigen; für das fünfte Jahr war die Zahlung von 2,5 Milliarden in Aussicht genommen, wenn auch schon 1924 feststand, daß nach vier gezahlten Raten neu verhandelt werden müsse. Aber die Belastung war erträglich, zumal die erste Rate zu 80 Prozent mit einer im Ausland aufzunehmenden Anleihe 
gedeckt werden konnte und auch in den folgenden Jahren genügend ausländisches Kapital - namentlich aus den USA - nach Deutschland floß. Und die politische Entlastung war enorm. So formulierte der Dawes-Plan den Grundsatz, daß die wirtschaftliche und steuerliche Einheit des Reiches wiederherzustellen sei und nicht mehr angetastet werden dürfe, was auf eine Garantie der Reichseinheit hinauslief. Auf der Londoner Konferenz (16.7. - 16.8.1924), die den Dawes-Plan endgültig billigte, ist ferner vereinbart worden, daß Sanktionen - erst recht Sanktionen wie die Ruhrbesetzung - lediglich bei schweren deutschen Versäumnissen zulässig seien, und auch dann nur nach einem einstimmigen Beschluß aller Gläubiger Deutschlands.

Mit der Entgiftung des Reparationsproblems schien die politische Verständigung zwischen Deutschland und den Alliierten tatsächlich in erreichbare Nähe zu rücken. Schon auf der Londoner Konferenz hatte im Gegensatz zu früheren deutsch-alliierten Begegnungen eine Atmosphäre der Gleichberechtigung geherrscht, und in den folgenden Monaten trug das britische Bemühen, Deutschland und Frankreich einander anzunähern, erste Früchte. Vom britischen Botschafter in Berlin ermuntert, bot Stresemann - jetzt Außenminister - im Januar 1925 der Londoner Regierung die freiwillige Anerkennung der deutschen Westgrenze und einen diese Anerkennung dokumentierenden wie garantierenden Sicherheitspakt zwischen den interessierten Mächten an. Als Stresemann am 9. Februar 1925, nach einem Wink des britischen Kabinetts, das gleiche Angebot der französischen Regierung übermittelte, hatte er die Auseinandersetzung um einen deutsch-französischen Friedensschluß offiziell eröffnet ${ }^{29}$.

Obwohl aber die beiden Länder nach ihrer gemeinsamen Niederlage im Ruhrkonflikt eigentlich keine Alternative mehr hatten, war die Auseinandersetzung nicht leicht. Als die anfänglich geheimgehaltene Offerte Stresemanns bekannt wurde, zeigte sich, daß in Deutschland die Rechte schon eine partielle Anerkennung der Kriegsergebnisse nach wie vor als unerträglich empfand und ohne Rücksicht auf die gegebene Lage Miene machte, die Politik Stresemanns zu torpedieren. In Frankreich wiederum erhielt das geringer gewordene Mißtrauen in die Absichten Deutschlands sogar neue Nahrung, als sich die deutsche Regierung beharrlich weigerte, auch die Anerkennung der deutschen Ostgrenze in Betracht zu ziehen, vielmehr erklärte, daß Deutschland am antipolnischen Bündnis mit Moskau festhalten und selbst bei einem Eintritt in den Völkerbund keine Verpflichtung im Hinblick auf Osteuropa übernehmen werde; schließlich fürchtete man in Frankreich schon seit Kriegsende, daß Deutschland eines Tages über ein "polnisches Sadowa“ zu einem „neuen Sedan“ strebe. Jedoch gelang es dem taktischen Geschick Stresemanns, die innenpolitischen Gegner seines Kurses auszumanövrieren oder zeitweilig zu überzeugen - freilich nur mit dem

29 J. Jacobson, Locarno diplomacy. Germany and the West, Princeton 1972. 
Argument, daß allein sein Weg die Rückgewinnung der außenpolitischen Bewegungsfreiheit und baldige revisionspolitische Erfolge im Osten bringen werde. Zögernd und ohne Vertrauen in die deutsche Aufrichtigkeit folgte am Ende Frankreich ebenfalls dem britischen Drängen, da Paris auf solche Weise wenigstens ein festes britisches Engagement für die französische Ostgrenze erhielt und zumindest darauf hoffen durfte, im Zuge einer allgemeinen Entspannung Deutschlands Gewöhnung auch an die territoriale Neuordnung Osteuropas zu erreichen.

So kam es im Oktober 1925 in Locarno zu einer Konferenz, die tatsächlich eine vertragliche Fixierung der Vorschläge Stresemanns brachte: Zwischen Deutschland, Großbritannien, Frankreich, Belgien und Italien wurde ein Garantiepakt ausgehandelt, mit dem sich Deutschland nun freiwillig zur Anerkennung der in Versailles gezogenen deutsch-französischen bzw. deutsch-belgischen Grenze wie zu der im Versailler Vertrag festgelegten Entmilitarisierung des Rheinlands verpflichtete. Deutschland und Belgien bzw. Deutschland und Frankreich sagten sich ferner zu, ,in keinem Falle zu einem Angriff oder zu einem Einfall oder zum Kriege gegeneinander zu schreiten“. Die Funktion von Garantiemächten übernahmen Großbritannien und Italien. Deutschland war gleichsam in die europäische Staatengesellschaft zurückgekehrt, und als es zur Besiegelung dieser Rückkehr im September 1926 in den Völkerbund eintrat, durfte es mit einem ständigen Sitz im Völkerbundsrat auch gleich die Wiederaufnahme in den Klub der führenden europäischen Mächte demonstrieren.

Die Konferenz von Locarno und Deutschlands Eintritt in den Völkerbund sind zunächst in der Tat vielfach als Beginn jener deutschen Gewöhnung an den Status quo verstanden worden, die von den Westmächten erhofft wurde, mithin tatsächlich als Beginn einer Ära der Stabilisierung Europas. Der damalige britische Außenminister, Sir Austen Chamberlain, bezeichnete Locarno als „Trennungslinie zwischen den Jahren des Krieges und den Jahren des Friedens" 30 . Dementsprechend sind sofort etliche Projekte zu einer kräftigenden Reform des Völkerbunds und zur Lösung des Abrüstungsproblems ernsthaft in Angriff genommen worden. In Wirklichkeit aber schied Locarno lediglich die noch unmittelbar am letzten Krieg leidende Periode von einer Zeit der oberflächlichen Entspannung, die der Zukunft mehr kriegerische als friedliche Möglichkeiten vererbte.

Daß Frankreich mit Locarno auf die Ausübung seiner temporären hegemonialen Funktion praktisch verzichtete, hätte für sich allein noch nicht viel zu bedeuten brauchen, hätte sogar einen beruhigenden Effekt haben können. Daß aber die Westmächte zugleich Deutschlands Weigerung, die osteuropäischen Grenzen anzuerkennen, stillschweigend hinnahmen, hat von Anfang an jede tiefere Wirkung von Locarno verhindert. Damit war gewissermaßen eine „Rangordnung der Grenzen“ geschaffen worden, die

${ }^{30}$ Graml, Europa, S. 223. 
den „weniger vornehmen“ östlichen Grenzen schon jetzt die Dauer absprach. Deutschland hatte eine moralisch-politische Ausgangsbasis für die aktive Revisionspolitik der Zukunft besetzen dürfen, und da nicht allein Großbritannien, sondern offenbar auch Frankreich diese Basis respektierte, lief nach Locarno ein noch schwaches, doch deutlich spürbares Zittern durch Ost- und Südosteuropa. Namentlich die polnischen Besorgnisse wurden geweckt, und sie nahmen noch zu, als Deutschland am 24. April 1926 mit der Sowjetunion demonstrativ einen Freundschaftsvertrag schloß, der das in Rapallo begründete Verhältnis noch festigte. Ohne daß die Westmächte erkennbar opponierten, hatte Berlin wiederum seine gegen Polen gerichteten revisionspolitischen Ambitionen dokumentieren und auch praktisch fördern können. Kein Wunder, daß in Warschau ängstliche Gemüter und weitblickende Geister bereits die Zeichen einer neuen Teilung Polens an der Wand erscheinen sahen.

Gewiß waren das erst atmosphärische Veränderungen und vage Möglichkeiten. Aber die Entwicklung der Stimmung in Deutschland, wie sie sich an der Presse und an den Reden der Politiker ablesen ließ, beseitigte bald jeden Zweifel daran, daß die deutsche Führungsschicht, ohne sich durch den Eintritt in den Völkerbund irgendwie gebunden zu fühlen, entschlossen war, nach der Wiedergewinnung auch der finanzpolitischen und der militärischen Bewegungsfreiheit in der Tat von allen revisionspolitischen Möglichkeiten energisch Gebrauch zu machen. Von der zahlenmäßig keineswegs schwachen und einen beträchtlichen Teil der konservativen Deutschnationalen Volkspartei (DNVP) einschließenden äußersten Rechten abgesehen, die Locarno als Landesverrat betrachtete und weithin die Ermordung Stresemanns propagierte, verstanden die klügeren Offiziere der Heeresleitung, die Beamten des Auswärtigen Amts und die Führer der bürgerlich-nationalen Parteien das Vertragssystem von Locarno einfach als Instrumentarium zu einer revisionspolitisch nutzbaren Machtverschiebung in Europa und als Vorbereitung zur Isolierung Polens. Verständigungspolitische Gesichtspunkte tauchten im internen Schriftverkehr allenfalls in taktischen Zusammenhängen auf. Gerade der Eintritt in den Völkerbund und die künftige Rolle in Genf sind lediglich als machtpolitischer Vorgang und als machtpolitische Aufgabe interpretiert worden. Die Welt stelle die Frage, „ob wir in den letzten ... Jahren etwas hinzugelernt bzw. umgelernt haben“, und daher müßen die deutschen Vertreter in Genf die eigentlichen Bestrebungen des Reiches durch Reden verschleiern, denen sie einen „salbungsvollen Ton“ zu geben hätten, schrieb im Dezember 1925 der Leiter des Völkerbundsreferats im Auswärtigen Amt ${ }^{31}$. In der Heeresleitung entstanden zu dieser Zeit bereits Denkschriften, die als „nächste Ziele“ der deutschen Politik die Beseitigung der entmilitarisierten Zone im Westen, die Liquidierung des sog. „Polnischen Korridors“, d.h. die Wiederangliederung

31 Akten zur Deutschen Auswärtigen Politik (ADAP), Serie B, Bd. I, 1, S. 70 
des 1918/19 an Polen abgetretenen westpreußischen und Posenschen Territoriums, die Rückgewinnung „Polnisch-Oberschlesiens“ und den Anschluß Österreichs nannten; sei auf diese Weise die europäische Stellung Deutschlands restauriert und dann nach einer „erneuten Lösung der deutsch-französischen Frage" befestigt, werde das Reich wieder um seine „Weltgeltung“ kämpfen müssen, gegen den „amerikanisch-englischen Machtkreis".

So blieb die Sonne von Locarno blaß und wärmte niemanden, wie der britische Politiker Winston Churchill, damals gerade Schatzkanzler, klagte und wie die ungarischen Revisionisten oder die italienischen Imperialisten sogleich mit Genugtuung konstatierten ${ }^{32}$. Die Spaltung Europas in Verteidiger und Feinde des Status quo war kaum schmäler geworden, geschweige denn überwunden. Als Folge mußten auch die von solcher Überwindung abhängigen Aufgaben ungelöst bleiben: die Reform des Völkerbunds und die Abrüstung. Die neben und nach Locarno unternommenen Anstrengungen, aus dem Prinzip der kollektiven Sicherheit im Rahmen des Völkerbunds eine politische Realität zu machen, sind in der Tat sämtlich wieder erlahmt, und die Bemühungen um eine allgemeine Abrüstung kamen keinen Schritt weiter. Niemand vermag zu sagen, ob eine derartige Abrüstung zustande gekommen wäre, wenn Revisionismus und Imperialismus nicht ihre Schatten auf die politische Landschaft Europas geworfen hätten. Die tatsächliche Entwicklung ist jedoch zweifellos von dieser am Horizont sichtbaren Bedrohung bestimmt worden. In den Ländern, die an der Erhaltung des Status quo interessiert waren, namentlich in Frankreich, erstickte nun die Angst vor den Gefahren der Zukunft alle zuvor immerhin wahrnehmbaren Ansätze zur Abrüstungsbereitschaft, und so zerfaserten die eingeleiteten Gespräche in endlose Debatten über grundsätzliche und technische Schwierigkeiten, die man im Grunde nicht mehr lösen, hinter denen man sich vielmehr verschanzen wollte.

Als Briand, Stesemanns französischer Partner von Locarno, den Vereinigten Staaten im Sommer 1927 einen Vertrag vorschlug, in dem sich Frankreich und die USA zusichern sollten, nie Krieg gegeneinander zu führen, leitete ihn keineswegs ein Optimismus, der seine Rechtfertigung aus den Erfolgen einer Ära internationaler Verstāndigung geschöpft hätte, sondern die Erkenntnis, daß die Periode der Beruhigung, die mit dem Dawes-Plan, mit Locarno und mit Ansätzen zur Abrüstung verheißungsvoll begonnen hatte, ein bloßes Zwischenspiel zu bleiben drohte. Von Zweifeln am Völkerbund tief beunruhigt, wollte Briand mit einem neuen Anlauf die Dinge wieder in Bewegung bringen. Es entsprach der generellen Einsicht in die Notwendigkeit und Richtigkeit solcher Schritte, daß der amerikanische Außenminister Kellogg im Dezember 1927 antwortete, der Vertrag müsse in ein multilaterales Unternehmen verwandelt werden, und daß am

32. Graml, Europa, S. 228. 
27. August 1928 die Repräsentanten von fünfzehn Staaten in Paris tatsächlich ihre Unterschrift unter ein Abkommen setzten, das zum Verzicht auf den Krieg als Instrument nationaler Politik verpflichtete 33 ; bis 1933 traten dem Briand-Kellogg-Pakt nicht weniger als fünfundsechzig Länder bei. Der ebenso generellen Überzeugung, derartige Verträge seien im Grunde doch kein Schutz vor Konflikten und vor Angriffen, entsprach es freilich auch, daß sich die Signatarstaaten weder auf die Festlegung von friedenssichernden $Z$ wangsmitteln noch auf neue Abrüstungsversprechen eingelassen hatten, der Pakt mithin rein deklaratorischen Charakter besaß und so die immer noch bestehende Unfähigkeit, nationale Staatsräson in eine kollektive Friedensordnung einzuschmelzen, eher unterstrich. Um die Heilung der europäischen Spaltung, in der er die entscheidende Ursache der internationalen Unruhe sah, vielleicht doch etwas zu fördern, regte Briand im Herbst 1929 schließlich an, erste organisatorische Stützen eines europäischen Staatenbundes zu schaffen: eine regelmäßig tagende Konferenz, einen permanenten politischen Ausschuß als Exekutivorgan und ein kleines Sekretariat. Die Anregung fand eine höfliche Aufnahme, ohne die Stagnation der internationalen Verhältnisse beenden zu können. Allein Stresemann, dem seit Locarno zwar nicht die Ziele des deutschen Revisionismus, doch sicherlich ein Geist, der ausschließlich revisionistische Ziele verstand, fremd geworden war, griff Briands Gedanken mit lebhafter Zustimmung auf; allerdings konnte er in dieser Frage nicht für sein Land sprechen. Kurz darauf, am 3. Oktober 1929, starb er nach einem Schlaganfall. Briands Europaplan aber versackte in den Diskussionen der Völkerbundsversammlung vom Herbst 1930 und hinterließ lediglich eine Genfer Studienkommission für europäische Vereinigung.

\section{Verschärfung der internationalen Krisen im Niedergang der Wirtschaft}

Erlebnis und Ergebnis des Krieges hatten also die zwischenstaatlichen Spannungen in Europa nicht herabgesetzt, Bereitschaft und Fähigkeit zu internationaler Zusammenarbeit nicht über das Niveau der Zeit bis 1914 gehoben. Ein Abbau der nationalen Egoismen erschien - trotz Völkerbund - bald wieder als Utopie oder bestenfalls als eine vielleicht in ferner $\mathrm{Zu}$ kunft realisierbare Möglichkeit. Eine wesentliche Ursache dieses Mangels an Fortschritten zu einer dauerhaften Friedenssicherung lag nicht unmittelbar in den internationalen Beziehungen, sondern darin, daß die Wirtschaft des Kontinents und die Gesellschaft vieler europäischer Länder aus den

33 Vgl. P. Krüger, Friedenssicherung und deutsche Revisionspolitik. Die deutsche Außenpolitik und die Verhandlungen über den Kellogg-Pakt, in: VfZ 22 (1974), S. 227-257. 
vom Krieg geschaffenen oder verschärften Krisen nicht mehr herausfanden, daß deshalb die Handels- und die Außenpolitik der Staaten ständig unter einem Druck wirtschaftlicher Nöte und innenpolitischer Konflikte standen, der im nationalistischen Sinne radikalisierend wirkte. Wohl hatten nahezu rein außenpolitisch bedingte Antagonismen, vor allem der Gegensatz zwischen der französischen Sekuritätspolitik und dem zunächst die Revision von Versailles anvisierenden deutschen Imperialismus, in den ersten sechs Jahren nach Kriegsende ihrerseits einen kräftigen Beitrag zur Verhinderung der wirtschaftlichen Erholung geleistet. Doch hatten die wirtschafts- und gesellschaftspolitischen Probleme noch andere und wichtigere Wurzeln.

Schon die Einbuße der vor 1914 so profitablen zentralen Stellung im Welthandel konfrontierte die europäische Industrie mit ungewohnten und nicht sofort überwindbaren Hindernissen. Bald wurde auch deutlich, daß eine perfekte Restaurierung jener Stellung überhaupt nicht mehr zu erwarten war und daß selbst der Aufbau einer zwar nicht zentralen, so doch ähnlich stimulierenden Handelsposition auf ernste Widerstände stieß. Die internationale Struktur der Wirtschaft hatte sich in den Kriegsjahren grundlegend gewandelt. Die Produktionskraft Nordamerikas war voll mobilisiert worden, und die amerikanische Wirtschaft stand nun auch finanziell auf eigenen Füßen. In Ostasien hatte in fast vergleichbarer Weise Japan von den europäischen Streitereien profitiert. In Südamerika, in den britischen Dominions und sogar in vielen Kolonien hatten sich während des Krieges, als die europäische Produktionskapazität auf den - vornehmlich militärischen - Eigenbedarf konzentriert werden mußte, Industrien entwickelt, die zunächst als Ersatz fungierten und dann als Konkurrenz auftraten. Rußland schied als Wirtschaftspartner vorerst nahezu aus. Allenthalben waren Märkte, Anlagen und Anlagemöglichkeiten verloren worden, allenthalben traf sowohl der Export von Waren wie der Export von Kapital, der ja oft auch der eigenen Produktion Impulse gibt, auf inzwischen verschlossene Türen und auf neue - überdies nicht selten billigere - Konkurrenten.

Unter dieser Stagnation, der die europäischen Regierungen und die europäischen Unternehmer lange Zeit mit Ratlosigkeit begegneten, litt naturgemäß auch der innereuropäische Wirtschaftsverkehr, den zudem noch spezifische Beschwernisse drückten: So war der wirtschaftliche Großraum Österreich-Ungarn verschwunden, und die Nachfolgestaaten der Donaumonarchie trieben ebenso wie die neuen oder jetzt endlich politisch arrondierten Balkanländer eine Zollpolitik, die auf den internationalen Handel bremsend wirkte. Außerdem gaben sie einen erheblichen Teil ihrer relativ bescheidenen Nationaleinkommen oder von ausländischen Krediten für unverhältnismäßig große stehende Heere aus, was weder den Budgets noch den Währungen bekam und daher ebenfalls einen produktions- und handelsfeindlichen Effekt hatte. So war der Boom, den die Befriedigung des während des Krieges gestauten Bedarfs in einigen Staaten angeregt hatte, 
nur von kurzer Dauer, und in den meisten Ländern Europas herrschte Flaute, Rezession oder Krise.

Auch hatte der Krieg die internationalen Finanzbeziehungen an wichtigen Verbindungsstellen zerrissen und einzelne nationale Währungen schwer erschüttert oder sogar - wie im Falle der besiegten Staaten - ruiniert. Daß diese Schäden nicht rasch geheilt werden konnten, weil jetzt auch noch das Problem der interalliierten Schulden und der alliierten Reparationsforderung an Deutschland auf dem internationalen Finanzsystem lastete und die vom Krieg vererbte Finanzmisere noch verschlimmerte, hätte allein schon dem wirtschaftlichen Wiederaufstieg Europas ein beachtliches Hindernis in den Weg gestellt. Ihre volle Bedeutung erhielten derartige negative Faktoren, die im Grunde sekundärer Natur waren, aber erst durch die Finanzpolitik, mit der die europäischen Kabinette auf sie reagierten. Als sich die USA, die nach der Rückkehr zum politischen Isolationismus ihrer Mitverantwortung für die wirtschaftliche und politische Entwicklung in Europa nur noch sehr unvollkommen gerecht werden konnten, entschlossen zeigten, die während des Krieges den europäischen Alliierten, vor allem England, geliehenen Gelder als rein geschäftliche Angelegenheit - nicht etwa als abzuschreibenden Beitrag zur gemeinsamen Kriegsanstrengung - zu behandeln, zog sich das Londoner Kabinett, das die britischen Verpflichtungen im Interesse des wirtschaftlichen und politischen Ansehens Großbritanniens erfüllen wollte, auf eine deflatorische Politik der Sparsamkeit und des trotz der Zahlungen an Amerika ausgeglichenen Haushalts zurück. Das hielt zwar die Währung stabil, versagte aber dem inneren Markt die so dringend benötigten Impulse. Die deutsche Regierung wiederum suchte sich den alliierten Reparationsansprüchen auch dadurch zu entziehen, daß sie der von der Kriegsfinanzierung eingeleiteten Inflation freien Lauf ließ und damit die Kalkulation der deutschen Zahlungsfähigkeit unmöglich machte. Vorübergehend gab das der deutschen Industrie, die in der Inflation praktisch ohne Steuerbelastung und mit nahezu kostenlosen Krediten arbeiten konnte, einen Vorteil im internationalen Wettbewerb und so einen gewissen Auftrieb. Indes ruinierte es bald den eigenen Kapitalmarkt und schwächte mit der Vernichtung von Sparguthaben und vielen sonstigen Geldanlagen auf lange Zeit die innere Kaufkraft. Die anderen europäischen Kriegsteilnehmer, die sich gleichfalls den Forderungen der USA oder Großbritanniens - das eigene Gelder und einen Teil seiner amerikanischen Kredite verliehen hatte - gegenübersahen, antworteten mit einer jeweils milderen Nachahmung des britischen oder des deutschen Beispiels.

Im übrigen hat der während des Krieges mächtig angeheizte und in den Nachkriegsjahren nicht mehr abflauende wissenschaftliche und technische Fortschritt ebenfalls zu den wirtschaftlichen Schwierigkeiten beigetragen. Schon die Notwendigkeiten der Kriegsorganisation hatten die europäischen Industrien zur Beschleunigung ohnehin laufender Konzentrations- 
und Rationalisierungsprozesse gezwungen, und die wissenschaftlich-technischen Fortschritte trieben auch nach 1918 zur Fortsetzung jener Prozesse. Die Steigerung der Arbeitsproduktivität setzte aber Arbeitskräfte frei, die angesichts schrumpfender Märkte in Übersee und in Europa selbst keinen neuen Arbeitsplatz finden konnten und nur die bereits stattlichen Arbeitslosenheere vermehrten. In einer Phase allgemeiner Stagnation wirkten Konzentration und Rationalisierung bei der Reduzierung der Kaufkraft und der inneren Märkte kräftig mit. Immerhin bot das Rationalisierungsinstrumentarium wenigstens zahlreichen einzelnen Industriebetrieben - namentlich den großen Unternehmen - die Möglichkeit, auch bei sinkenden Umsätzen mit Gewinn zu arbeiten. Die europäische Landwirtschaft hingegen, die nach der Konjunktur des Krieges und der ersten Nachkriegsjahre ebenfalls unter Absatzproblemen und Preisverfall zu leiden begann, war zu Rationalisierung und Kostensenkung weitgehend unfähig, da sie - außer in den Inflationsjahren - den generellen Kapitalmangel besonders zu spüren bekam und da die stagnierende Industrie die bei Rationalisierung frei werdenden Arbeitskräfte nicht aufnehmen konnte. Personell überbesetzt und trotz rückläufiger Nachfrage zu teuer produzierend, glitt die Landwirtschaft in eine bald für alle Betriebsgrößen fühlbare Krise.

Angesicht einer so tief eingreifenden Störung, die von einer leichten Erholung zwischen 1924 und 1928 nicht behoben wurde, verschärften sich aber im ersten Nachkriegsjahrzehnt all jene sozialen und politischen Konflikte, die bereits vor Kriegsausbruch in den europäischen Ländern aufgebrochen waren ${ }^{34}$. So spitzte sich in der Arbeiterschaft die zu Beginn und während des Krieges von der patriotischen Aufwallung zurückgedrängte Kritik am Kapitalismus und an einem Parlamentarismus, der auf einem kapitalistischen Wirtschafts- und Gesellschaftssystem ruhte, abermals und jetzt noch schärfer zu. In vielen Ländern erhielten folglich die neben den sozialdemokratischen Parteien existierenden anarchistischen, syndikalistischen und kommunistischen Bewegungen erneut Zulauf und politische Bedeutung. Dazu fungierte die Sowjetunion gewissermaßen als ein Kraftwerk, das ständig revolutionäre Energie produzierte, und sowohl die offiziellen Vertreter des Sowjetstaates wie die Agenten der von Moskau dirigierten Kommunistischen Internationale (Komintern) waren eifrig bemüht, die Stimmung der Arbeiter und die Wirkung des russischen Beispiels zur weiteren Ausbreitung der kommunistischen Ideologie und zur organisatorischen Sammlung revolutionär gesinnter Arbeitermassen zu nutzen.

Ebenso gefährlich und in etlichen Ländern weit gefährlicher war die politische Radikalisierung kleinbürgerlicher Schichten. Von der Entwicklung zur wirtschaftlichen Konzentration und zur Massenproduktion in ihrer materiellen Existenz und in ihrer bisherigen Lebensform bedroht, wurden sie

${ }^{34}$ K. D. Bracher, Europa in der Krise. Innengeschichte und Weltpolitik seit 1917, Frankfurt-Berlin-Wien 1979. 
noch breiter und noch intensiver als vielfach schon vor 1914 - damals durch die ersten großen Wellen der Industrialisierung, Modernisierung und Urbanisierung - von einer tiefen Unzufriedenheit erfaßt, die sich als oft leidenschaftlicher Antimodernismus, vermischt mit einer starken Dosis Antikapitalismus, äußerte. Ähnliche Stimmungen regten sich, ob Bauern oder Großgrundbesitzer, auf dem Lande. Selbst im mittleren Besitz- und im Bildungsbürgertum, denen die wirtschaftlichen Kriegsfolgen ebenfalls schwer zu schaffen machten und die in den Inflationsländern überdies ihre finanziellen Reserven fast vollständig eingebüßt hatten, tauchten $Z$ weifel an der bestehenden Ordnung auf.

Bürgerlicher und agrarischer Unmut vermochte sich allerdings auch bei stärkster Abneigung gegen das Großkapital nicht zu grundsätzlicher Kritik am herrschenden Eigentumsbegriff und an einer hierarchischen Gesellschaftsstruktur zu verdichten. Die Annahme radikaldemokratischer und sozialistischer Vorstellungen hätte dem überkommenen und von der tatsächlichen materiellen Lage bislang auch gedeckten gesellschaftlichen Bewußtsein nicht entsprochen. Der herausgehobene Platz in der Gesellschaft und die mit ihm gegebene materielle, soziale und politische Distanz zu der jeweils auf tieferer Stufe existierenden Gruppe und zur Arbeiterklasse sollten ja gerade verteidigt oder restauriert werden, und zwar selbstverständlich in erster Linie gegen die von links anrollende Nivellierungswelle. Jedoch wurde das Großkapital zunehmend als ein zweiter Urheber nivellierender d.h. im subjektiven Verständnis zerstörerischer - Tendenzen verdächtigt und bekämpft. Und es schien nun innerhalb eines liberaldemokratischen Parlamentarismus vor dieser doppelten Gefährdung keine Zuflucht zu geben, sondern am Ende nur den Untergang. So führte die schon geschehene oder erst befürchtete wirtschaftliche und soziale Deklassierung jetzt auch größere Teile des Kleinbürgertums und des Mittelstands zu einer aggressiven Ablehnung von Liberalismus und Demokratie, andererseits zur Forderung nach einem ständisch oder korporativ verfaßten Staat, der jede Demokratisierungs- und Sozialisierungsbewegung unterdrücken und zugleich das Großkapital - ohne tiefere Eingriffe in die bestehende Besitz- und Gesellschaftsstruktur - bändigen sollte. Als Vehikel nahm sich der soziale Behauptungswille, der auf politischem Felde notwendigerweise zum Umsturzwillen wurde, den harten und imperialistisch zugeschliffenen Nationalismus, der als einziger unter den zeittypischen Emotionskomplexen so viel Bindekraft versprach, daß in seinem Zeichen der Staat erobert und dann das eigentliche Ziel, jene Unterwerfungs- und Bändigungsaufgabe, erreicht werden konnte. Da aber der imperialistische Nationalismus - von einzelnen konservativen Politikern abgesehen - nicht bewußt und zynisch gewählt, sondern instinktiv als tauglich ergriffen wurde, besaß er - wie vielfach bereits vor dem Kriege - nicht nur seine eigene Ernsthaftigkeit, sondern sogar eine geradezu religiöse Macht über Geist und Herzen der Menschen, eine Macht, die ihm vor, während und nach der Erfüllung irgend- 
welcher innenpolitischer Zwecke rasch eigenständige Dynamik und selbständige Gesetzmäßjigkeit verlieh. Konnte er seinen Gesetzen ungebremst folgen, mußte dieser Nationalismus letztlich wieder eine mit militärischen Mitteln arbeitende imperialistische Außenpolitik erzwingen.

Oft verband sich bürgerlicher und agrarischer Rechtsextremismus auch mit Antisemitismus ${ }^{35}$. Nicht in der Lage, den Prozeßcharakter der als bedrohlich empfundenen wirtschaftlichen und gesellschaftlichen Vorgänge zu erkennen oder gar deren wahre Ursachen und Entwicklungsgesetze zu durchschauen, neigten die verwirrten Verteidiger einer heilen vorindustriellen Welt dazu, alle unbegriffenen Einbrüche in die gewohnte Ordnung und alle unverstandenen Verfehlungen einer ersehnten Ordnung als das Werk sichtbarer Feinde identifizierbar und bekämpfbar zu machen. Da unter den Sozialistenführern und unter den Großkapitalisten - unter sämtlichen Personengruppen, die für moderne Erscheinungen und für Modernisierungsprozesse standen - zahlreiche Juden waren, kamen so aus dem bürgerlichen und agrarischen Antisozialismus, Antikapitalismus und Antimodernismus besonders kräftige Anstöße für die Umformung des tradierten religiösen Antijudaismus in eine säkularisierte Form, in einen modern-naturwissenschaftlich definierten rassistischen Antisemitismus. Bereits vor 1914, ja schon in den letzten Jahrzehnten vor der Jahrhundertwende überaus lebendig, breitete sich dieser Antisemitismus während der Erschütterung durch den Krieg und in den Krisen der Nachkriegszeit mit der Rapidität eines Steppenbrands aus. Namentlich der ohnehin schwächer ausgeprägte und vom bürgerlich-agrarischen Gesellschaftsbild naturgemäß behinderte Antikapitalismus geriet nun häufig in ein antisemitisches Fahrwasser; nicht selten trat er nur noch als Judenfeindschaft auf. Selbst die groteske Behauptung, Sozialisten und Großkapitalisten gehorchten in Wahrheit einer gemeinsamen jüdischen Zentrale und die bürgerliche Welt sei gleichsam einem vom "Weltjudentum" raffiniert geplanten Zangenangriff ausgesetzt, ist jetzt weithin geglaubt worden: Wall Street, die Londoner "City" und in Moskau die Bolschewiki mit ihrer Komintern galten nicht nur als gleich gefährlich, sondern als gleichgeschaltete Werkzeuge der jüdischen Weltverschwörung.

Der verselbständigte Nationalismus erwies sich aber als eine mindestens ebenso wichtige Wurzel des Antisemitismus. Weil die von Existenzangst ergriffenen klein- und mittelbürgerlichen Schichten keine unverfälschte politische Emanzipation mehr wollten und keine in der Spannung zwischen Pluralismus und Integration lebende demokratische Gesellschaft, sondern einen konfliktfreien und statischen Zustand, der in einem biologischen Sinne als die natürliche und gesunde Ordnung bezeichnet wurde, war auch ihr Nationalismus losgelöst von dem sowohl zum Emanzipations-

$35 \mathrm{Vgl}$. H. Graml, Reichskristallnacht. Antisemitismus und Judenverfolgung im Dritten Reich, München 1988. 
wie zum Integrationsinstrument tauglichen Nationalismus der Französischen Revolution. Als Ursprung und Garant der gesunden Ordnung konnte ihr Nationalismus vielmehr allein in biologischen Kategorien gedacht, definiert und erläutert werden, wurde er ausschließlich als das von einem gesunden Instinkt diktierte und von den ewig gültigen Erkenntnissen der Naturwissenschaft geforderte Bekenntnis zu dem vorgegebenen biologischen Organismus "Nation“ verstanden. Nach der vergröbernden Aneignung darwinistischer Denkmuster erschien dem - allmählich zu einem national fließend begrenzten Rassismus wachsenden - Nationalismus die Geschichte als ein ununterbrochener Wachstums- und Verfallsprozeß solcher biologischen Organismen, die außerdem miteinander in einem gnadenlosen Daseinskampf stünden. Wer aber die biologisch aufgefaßte Nation in diesem Sinne zur obersten Lebens- und Geschichtsmacht erklärte, suchte sich - neben den natürlichen Feinden in der Nachbarschaft, den anderen Nationen - eine als fremdrassig zu isolierende Minderheit, die er zur sichtbaren Erscheinungsform eines bösen Gegenprinzips stempeln konnte, die er dann als Bazillus - im Wortsinne - sah, als Keim aller inneren Krankheiten, zugleich als lenkende Kraft hinter allen äußeren Gefährdungen des Organismus. Wieder lag der religiöse Antijudaismus zur verwandelnden Aufnahme bequem zur Hand, zumal ganze Scharen von Wissenschaftlern und Publizisten, von Graf Arthur de Gobineau und Edouard Drumont über Heinrich v. Treitschke und Eugen Dühring bis zu Houston Stewart Chamberlain, für eine derartige Adaption schon in der zweiten Hälfte des 19. Jahrhunderts und in den ersten zwei Jahrzehnten nach der Jahrhundertwende das ideologisch-theoretische Rüstzeug geliefert hatten.

Die traditionellen Führungsschichten in den europäischen Ländern haben Entstehung und Ausbreitung des bürgerlich-agrarischen Rechtsradikalismus - nach der ersten erfolgreichen Spielart, der italienischen, bald $\mathrm{Fa}$ schismus genannt - sowohl mit Mißtrauen und Sorge wie mit Hoffnung beobachtet. Einerseits war unschwer zu erkennen, daß jene rechtsextremen Umstürzler, die den Großbesitz als Feind ansahen, die nach einem straff disziplinierten autoritären oder totalitären Staat verlangten und die in ihrem Nationalismus Reste des bürgerlichen Willens zur politischen Emanzipation transportierten, nivellierende Tendenzen mit großer Dynamik besaBen, die ihrer Natur nach nur antikonservativ sein konnten und oft sogar bewußt zum Angriff auf die älteren Eliten ansetzten; speziell den christlichen Kirchen mußte die biologische Vergötzung der Nation als Abfall in antichristliche Irrlehren und damit als Gefahr erscheinen. Wo freilich konservative Gruppen zur Behauptung oder Restaurierung ihrer Alleinherrschaft entschlossen waren und deshalb sowohl nach der Revision des bis 1919/20 allenthalben in Europa durchgesetzten liberaldemokratischen Parlamentarismus wie vor allem nach der Niederwerfung jeder sozialistischen Bewegung - ob anarchistisch, kommunistisch oder sozialdemokratisch trachteten, da entdeckten sie auch eine politische Verwendbarkeit des 
rechtsextremistischen Antisozialismus und der rechtsextremistischen Demokratiefeindschaft, zumal dann, wenn der Entschlossenheit zu reaktionärer Politik die Kraft zur Verwirklichung fehlte. In solcher Lage wirkte es als Verlockung zum Bündnis, wenn gesehen werden konnte, daß die rechtsradikalen Organisationen zur antisozialistischen und antidemokratischen Änderung von Verfassung und Verfassungswirklichkeit allein ebenfalls zu schwach waren, daß sie mithin der - doch wohl abhängig machenden - finanziellen und politischen Unterstützung bedurften. Schließlich stellte sich auch heraus, daß die rechtsradikalen Bewegungen angesichts ihrer sozialen Basis und ihrer ideologischen Schwerpunkte zwar niemals zum Verzicht auf den Kampf gegen die Linke und gegen die Demokratie, jedoch durchaus zur zeitweiligen Zurückstellung ihrer antikonservativen Tendenzen fähig waren, daß ihnen folglich als politische Möglichkeit nur die Anlehnung an konservative Gruppen blieb.

Viele Führer faschistischer und verwandter rechtsradikaler Bewegungen haben diese Situation durchaus verstanden und diese Anlehnung tatsächlich gesucht. Daher ist das politische Verhalten konservativer Aristokraten, Industrieller, Bankiers, Generäle oder Bürokraten häufig mehr von der - allerdings nie von Argwohn freien - Hoffnung auf die politische Nützlichkeit des Rechtsextremismus bestimmt worden, und zwischen Konservatismus und Rechtsradikalismus, zwischen konservativen Führungscliquen und den revolutionär auftretenden rechtsextremen Massenorganisationen kamen in der Tat Bündnisse zustande, denen der gemeinsame Nationalismus und Imperialismus als Katalysator und Bindemittel diente, die indes im Grunde den „Ideen von 1789“ und dem im Zeichen solcher Ideen agierenden inneren Feind galten. Auch den Kirchen erschien der Kampf gegen Rationalismus, Liberalismus, Demokratie und Sozialismus meist als dringlicher denn die Bekämpfung des biologistischen Nationalismus. Daß der Klerus deshalb gegenüber den rechtsradikalen Bewegungen - wenn auch nicht gegenüber rechtsextremistischen Theoremen - fast stets eine zumindest partiell wohlwollende Neutralität übte und sich gelegentlich sogar zu offenem $\mathrm{Zu}$ sammenwirken bereit fand, hat vielen kirchlich gebundenen Bürgern und Bauern den Weg in rechtsradikale Organisationen geöffnet und mancher kirchlich beeinflußten politischen Gruppierung den Weg in ein Bündnis mit einer rechtsradikalen Organisation erleichtert.

Erst die Allianzen zwischen konservativen Kräften und den rechtsrevolutionären Bewegungen haben aber bewirkt, daß die liberale Demokratie in Europa, unmittelbar nach ihrem triumphalen Sieg von 1918/20, in eine schleichende oder galoppierende Krise geriet. Dabei kam diesen Allianzen zugute, daß die stagnierende Wirtschaft einen Teil der nach 1918 aufgelösten Millionenarmeen nicht absorbieren konnte, daß vielen Soldaten die Rückkehr in eine friedliche und zivile Existenz auch psychologisch schwer fiel oder unmöglich war. Hier fanden die Rechtsradikalen und ihre konservativen Bundesgenossen ein volles Reservoir, aus dem sich starke Heerhau- 
fen zum militanten Austrag des großen Gesellschaftskonflikts und für eine militant nationalistische und imperialistische Außenpolitik rekrutieren ließen.

Die Krisensituation und der aus ihr stammende Rechtsextremismus waren gesamteuropäische Phänomene. Doch haben sich beide in den europäischen Lāndern höchst unterschiedlich entfaltet, so unterschiedlich, daß es eigentlich keinen rechten Sinn hat, für die Produkte der Krise, die diversen rechtsextremen Bewegungen, einen Sammelbegriff wie „Faschismus“ zu verwenden. Schon ein heftigerer Ausbruch der Krise und ein dementsprechend kräftiges Wachstum rechtsradikaler Organisationen waren keineswegs selbstverständlich. Daß dabei eine Grenze zwischen den Siegern und Besiegten des Weltkriegs zu verzeichnen sei, wie oft behauptet wird, daß also Niederlage und außenpolitische Bedrängnis zum Aufstieg und zum Triumph rechtsrevolutionärer Bewegungen entscheidend beigetragen hätten, wogegen die Teilhabe am militärischen Sieg Abwehrkräfte mobilisiert habe, ist freilich nicht richtig. Solchen außenpolitischen Dingen kam nur eine nebensächliche Bedeutung zu. Im Gegenteil läßt sich feststellen, daß schon stärkerer Zulauf zu einer rechtsextremen Bewegung und erst recht das für deren Erfolg unabdingbare Bündnis mit konservativen Gruppen nicht ohne eine ausreichende außenpolitische Manövrierfreiheit des jeweiligen Landes möglich waren. Wenn rechtsradikale Ziele und Parolen auf große Massen attraktiv wirken sollten, mußte der imperialistische Nationalismus plausibel und mußte die Verheißung außenpolitischer Erfolge glaubhaft sein, wenn bedächtigere und die außenpolitische Lage ihres Landes weniger sanguinisch beurteilende Konservative zu einer Allianz mit einer rechtsradikalen Organisation bereit sein sollten, mußten sie die Gewißheit außenpolitischer Gefahrlosigkeit ihres Handelns haben - schließlich war der nationalistische Imperialismus, den die Rechtsradikalen ungescheut offen predigten, eine ernste Gefahr für jeden Nachbarstaat - und dann ebenfalls Chancen für eine aggressive Außenpolitik sehen können. Dies wird vom Geschick der beiden stärksten und für Europa verhängnisvollsten rechtsextremen Bewegungen eindrucksvoll illustriert.

Der italienische Faschismus vermochte unter der Führung des ehemaligen Sozialisten Benito Mussolini schon früh das Bündnis mit konservativen Gruppen zu schließen und bereits im Oktober 1922 den Staat zu erobern, wobei die nationalistische Erregung in Italien ständig stieg und Konservative wie Faschisten das Wort vom „verstümmelten Frieden“, den man den Westmächten verdanke, sowohl als Einigungsmittel wie als wirkungsvollen Werbeslogan benutzten. Dabei gehörte doch Italien zu den Siegern des Krieges mit beträchtlichen - zum Teil problematischen und schwer verdaulichen - territorialen Gewinnen. Auch erfreute sich Italien, das zu den europäischen Großmächten rechnete, gerade in jenen Jahren totaler außenpolitischer Sicherheit. Dieser faschistische Chauvinismus hatte also offensichtlich nicht das mindeste mit der realen außenpolitischen Situation des 
Landes zu tun. Eben weil er aus ganz anderen Quellen gespeist wurde, durfte er auch mit völlig unsinnigen außenpolitischen Parolen erfolgreich arbeiten.

In Deutschland hingegen hat der Frieden von Versailles die Entwicklung des Rechtsextremismus nicht gefördert, sondern ernstlich behindert. Die deutschen Rechtsradikalen begannen mit zielstrebiger politischer Aktivität zur gleichen Zeit wie die italienischen Faschisten. Zwischen 1919 und 1924 herrschte in Deutschland kein Mangel an aktiven und potentiellen Rechtsradikalen, auch gab es genügend bündniswillige Konservative, und die Linke war relativ nicht stärker als in Italien. Trotzdem sind in jenen Jahren die beiden deutschen Versuche, den Staat zu erobern, kläglich gescheitert, nämlich im März 1920 der von Wolfgang Kapp inszenierte Putsch der Brigade Ehrhardt und im November 1923 der Münchner Putsch Adolf Hitlers. Erstens fehlte den Freikorps von der Art der Brigade Ehrhardt und damals auch noch der Nationalsozialistischen Deutschen Arbeiterpartei (NSDAP) Hitlers die Massenbasis, und zweitens konnten die rechtsradikalen Führer noch kein funktionierendes Bündnis mit handlungsfähigen konservativen Gruppen erreichen. Die hohe Wahrscheinlichkeit einer Intervention der Garantiemächte des Versailler Friedens bremste den Massenzulauf und hielt vor allem Konservative von einer offenkundig noch abenteuerlichen Politik ab. Es ist bezeichnend, daß in konservativen Zirkeln über eine parlamentsfeindliche Verfassungsänderung erstmals ernsthaft - wenn auch noch etwas vage - diskutiert wurde, als Stresemanns Locarno-Politik die Fesseln von Versailles zu lockern und dem Reich wieder eine gewisse außenpolitische Bewegungsfreiheit zu verschaffen begann. Kaum war dann 1930 die letzte besetzte Zone Deutschlands geräumt, da konnte Hitler den im Vergleich zu 1923 weder stärker noch schwächer gewordenen Nationalismus bei den Septemberwahlen jenes Jahres zum ersten Mal voll ausnutzen und seiner NSDAP - natürlich auch auf Grund der jäh verschärften Wirtschaftskrise - eine breite Gefolgschaft gewinnen; gleichzeitig eröffnete das Präsidialkabinett Brüning die erste Phase der Liquidierung des liberaldemokratischen Parlamentarismus. Als dieser Liquidierungsprozeß mit dem jetzt tatsächlich geschlossenen Bündnis zwischen konservativen Kräften und NSDAP um die Jahreswende 1932/33 in sein entscheidendes Stadium trat, als am 30. Januar 1933 die Ernennung Hitlers zum Reichskanzler die nationalsozialistische Bewegung an die Macht brachte, war das Reparationsproblem bereits erledigt und die militärische Gleichberechtigung Deutschlands von den europäischen Mächten grundsätzlich anerkannt. Von den territorialen Bestimmungen abgesehen, war Versailles tot.

Die große Krise der liberalen Demokratie ist von sozialen Gegensätzen und inneren Spannungen verursacht worden, und die Konflikte, die aus den Spannungen entstanden, drehten sich im Kern stets um verfassungsund gesellschaftspolitische Streitpunkte. Die Ausbrüche der Krise, die For- 
men ihres Verlaufs und ihre Resultate sind daher in erster Linie - auch wenn der Sieg einer rechtsradikalen Partei ein Resultat von größter außenpolitischen Bedeutung war - vom jeweiligen Stand der verfassungs- und gesellschaftspolitischen Entwicklung abhängig gewesen. Wo das Bürgertum seine politische Gleichberechtigung längst durchgesetzt, im Bunde mit Arbeiterorganisationen die politische Gleichberechtigung auch der Arbeiterschaft - statt sie zu fürchten - eingeleitet und mit dieser Allianz vor dem Kriege, während des Krieges und unmittelbar nach dem Kriege wesentliche verfassungs-, gesellschafts- und sozialpolitische Fortschritte erkämpft hatte, wo sich die traditionellen Eliten mit der Schmälerung ihrer Macht abfinden konnten, wo nun also die politische Verantwortung breit gestreut und das Parlament für die Repräsentanten aller Bevölkerungsschichten ein erreichbarer Zugang zur Regierungsverantwortung war, da sind die sozialen Konflikte weit weniger schroff aufgebrochen und die Radikalisierungstendenzen in allen Schichten der Bevölkerung in viel schwächerer Form aufgetreten; auch rechtsradikale Strömungen im Bürgertum blieben Randerscheinungen.

So behielt in Großbritannien und in den skandinavischen Staaten die politische Organisation der Gesellschaft ihre bis Kriegsende erreichte Stabilität. In den übrigen westeuropäischen Ländern, wo jene Allianz weniger fest und weniger erfolgreich gewesen war, kriselte es schon stärker, doch erwies sich auch hier der gesellschaftspolitische Fortschritt als so groß, daß ernsthafte Erschütterungen ausblieben und die entstandenen faschistischen Bewegungen nie in die Nähe der politischen Macht zu gelangen vermochten. Die industrielle und kommerzielle Krise hat West- und Nordeuropa, gerade auch Großbritannien, ebenfalls hart getroffen. Aber die an liberale Traditionen gebundene und nun weitgehend demokratisierte Gesellschaft reagierte auf diese Nöte zunächst nur mit Resignation, dann allmählich mit einer sozusagen tropfenweisen Sammlung neuen Reformeifers und mit Entwürfen neuer Reformpläne, die der weiteren Arbeit am Wohlfahrtsstaat galten. Da also der Demokratisierungsprozeß selbst jetzt nicht aus seiner normalen Bahn gedrängt wurde und sich in den west- und nordeuropäischen Nationen selbst jetzt keine nennenswerten Gruppen in den imperialistischen Nationalismus flüchteten, der dem Rechtsextremismus anhaftete, nahm auch die außenpolitische Aggressivität der Staaten West- und Nordeuropas nicht zu; vielmehr sank sie praktisch auf Null, zumal sich angesichts der inneren Situation die Erfahrung des Krieges, d.h. ein allgemeiner Abscheu vor dem Krieg, voll auswirken konnte.

Der offene Ausbruch der inneren Konflikte und als Konsequenz fast stets der Zusammenbruch des liberaldemokratischen Systems sind Phänome Mittel-, Süd- und Osteuropas gewesen. Hier gab es, etwas vereinfacht, drei Gesellschaftstypen, die in der krisenhaften wirtschaftlichen Nachkriegsentwicklung den inneren Machtkampf in ganzer Schärfe erlebten und am Ende totalitäre Rechtsdiktaturen hervorbrachten oder zu auto- 
ritären Herrschaftsformen älteren Stils zurückkehrten. Da war z.B. die Gesellschaft Italiens: Überwiegend agrarisch basiert, aber mit starken kommerziellen Zentren und auch schon mit beachtlichen industriellen Einsprengseln versehen. Auf solcher Grundlage hatten bürgerlich-liberale und sozialistische Kräfte bis 1918 zwar erhebliche verfassungs- und sozialpolitische Fortschritte erreicht, doch weder die gesellschaftspolitische Position und den Machtanspruch konservativer Herrschaftsgruppen erschüttert noch den Antisozialismus und die Demokratisierungsscheu einer Mehrheit des - überdies meist an eine ebenfalls demokratiefeindliche katholische Kirche gebundenen - Bürgertums überwunden. Eine Zuspitzung der wirtschaftlich-gesellschaftlichen Lage, die bei Passivität des rechten Lagers der Linken größere Möglichkeiten für nun auch gesellschaftspolitische Erfolge zu eröffnen schien, andererseits aber auch als Chance für die Rechte wirkte, mobilisierte daher in konservativen Zirkeln den Willen zu einem umfassenden Gegenangriff, während sich der Antisozialismus und die Demokratiefeindschaft von Teilen des Bürgertums zum gewalttātigen, d.h. innenpolitisch - der Tendenz nach - totalitären und außenpolitisch imperialistischen Faschismus verdichteten. Die Konservativen fanden sich mit den restaurativen Revolutionären in einem Bündnis, das die schwächeren linksbürgerlichen Kräfte und eine in die diversen Spielarten des Sozialismus gespaltene Arbeiterschaft niederzuwerfen vermochte. So entstand ein System, in dem die alten Gewalten - Kirche, Monarchie, Adel, Offizierkorps - und ein neuer faschistischer Machtapparat unter dem diktatorisch amtierenden Faschistenführer Mussolini in unsicherer Koexistenz lebten. Indes lösten sich hier auch die Faschisten nie völlig von den in Italien seit Jahrhunderten heimischen Traditionen des Humanismus und des Rationalismus: Sie beseitigten daher die geistige Freiheit nicht in gleichem Maße wie die politische Freiheit, ihr nationalistischer Imperialismus war - auch im Bewußtsein der relativ bescheidenen wirtschaftlichen und militärischen Ressourcen des Landes wie seiner Verwundbarkeit im Kampf gegen stärkere Seemächte - stets ebenso sehr theatralische Geste wie ernsthafter Anspruch, und Lehren wie der rassistische Antisemitismus fanden in Neapel, Rom, Florenz, Mailand oder Venedig überhaupt keinen Nährboden ${ }^{36}$.

In Deutschland lagen die Dinge anders ${ }^{37}$. In der verfassungspolitischen Entwicklung weit hinter Italien zurück, hatte das Reich vor 1914 nicht einmal jenes prekäre Gleichgewicht zwischen liberaldemokratischen und sozialistischen, konservativen und potentiell rechtsradikalen Kräften gekannt, das damals die italienische Situation charakterisiert hatte. In Deutschland

36 R. Pommerin, Rassenpolitische Differenzen im Verhältnis der Achse Berlin-Rom 1938-1943, in: VfZ 27 (1979), S. 646-660; E. Nolte, Der Faschismus in seiner Epoche. Die Action francaise - Der italienische Faschismus - Der Nationalsozialismus, München 1963.

37 Vgl. hierzu K. D. Bracher, Die Auflösung der Weimarer Republik. Eine Studie zum Problem des Machtverfalls in der Demokratie, Villingen 1964. 
hatte ein krasses Mißverhältnis zwischen einer bereits außerordentlich breiten industriellen Basis und einer Staatsstruktur geherrscht, die noch überwiegend von absolutistisch-bürokratischen und ständestaatlichen Elementen geprägt gewesen war; die Oberschicht, in der ein - etliche oberschlesische Familien ausgenommen - industrie- und handelsfremder Land- und Hochadel politisch dominierte, hatte noch weitgehend in der kriegerischen Wertwelt des Feudalismus gelebt und war zur Machtbehauptung fest entschlossen gewesen; ein quantitativ bedeutendes Bürgertum hatte seit 1848/49 und erst recht seit dem erfolgreichen Regiment Bismarcks mit gebrochenem politischen Rückgrat existiert, eine Demokratisierung als Weg in den Sozialismus gefürchtet und mit Vereinigungen wie dem Alldeutschen Verband oder dem Flottenverein bereits einflußreiche Massenorganisationen zur Stützung rechtsradikaler Innen- und Außenpolitik hervorgebracht; eine starke Arbeiterschaft war zwar in Gewerkschaften und in der Sozialdemokratischen Partei Deutschlands (SPD) schon hervorragend organisiert, hatte sich aber seit Aufhebung der Sozialistengesetze Bismarcks von denen durchaus zähmende Effekte ausgegangen waren - und seit der Bismarckschen Sozialgesetzgebung durch die ständige Bedrohung mit erneuter politischer Unterdrückung wie auch durch eine spürbare Besserung ihrer materiellen Situation auf einen reformerischen Kurs drängen lassen, der auf politischen Quietismus hinausgelaufen war. Bei solchen Voraussetzungen war Deutschland noch während des Krieges in die Militärdiktatur der dritten OHL unter dem Feldmarschall Paul v. Hindenburg und seinem Generalquartiermeister Erich Ludendorff geglitten, die wesentliche Eigenschaften einer rechtsradikalen Diktatur aufwies, eine dementsprechend ausgreifende Außenpolitik einzuleiten begann und außerdem die rechtsextremistischen Tendenzen im Bürgertum erheblich stärkte.

Als sich diese Nation in der Niederlage und von den Siegermächten zu einem liberaldemokratischen Parlamentarismus pressen ließ, besaß die neue Staatsstruktur lediglich in Teilen der Arbeiterschaft und in einer kleinen Minorität des Bürgertums Stützen. Versuche zur Abstreifung des als fremd empfundenen Verfassungsnetzes wären mithin auch ohne zusätzliche Faktoren unternommen worden. Aber durch die Zuspitzung der wirtschaftlich-gesellschaftlichen Lage, die hier ebenfalls als Gefahr wie als Chance gesehen wurde, erreichte in Deutschland die Gegenbewegung konservativer Gruppen und der rechtsradikalen agrarisch-bürgerlichen Kräfte den italienischen Faschismus weit übertreffend - eine ungewöhnliche Wucht und ein ungewöhnliches $\mathrm{Maß}$ an ideologischer Radikalisierung. Die Wendung gegen den politischen Wertekanon des Westens war bei den deutschen Rechtsrevolutionären, die ihr Sammelbecken seit der zweiten Hälfte der zwanziger Jahre mehr und mehr in der NSDAP Hitlers fanden, weitaus heftiger als bei den italienischen Faschisten und steigerte sich zur bewußten Lossagung von allen christlichen und humanistischen Traditionen des Abendlands. Sowohl die Tendenz zum innenpolitischen Totalita- 
rismus wie die Entschlossenheit zu einer expansionistischen Außenpolitik wurden hier, in einer historisch höchst seltenen Logik der Entfaltung, bis zur äußersten Radikalität geführt, wobei der nationalistische Imperialismus von Anfang an, in einer wiederum bewußten Konsequenz, aus einem antimodernistischen und biologistischen Gesellschaftsbild abgeleitet war: die Eroberung, Beherrschung und partielle Germanisierung neuen „Lebensraums" sollte einerseits der biologischen Ausdehnung des Volkskörpers dienen, den Deutschen eine die Weltvorherrschaft garantierende Machtbasis verschaffen und ihnen zugleich eine autarke, von den Fluktuationen des Welthandels befreite wirtschaftliche Existenz sichern, in gleichem Maße aber der Nation den Aufbau einer Gesellschaft ermöglichen, von der die gleichsam „ewige“ Überwindung aller vermeintlichen und tatsächlichen Übel erhofft werden durfte, die Industrialisierung und Urbanisierung mit sich gebracht hatten - eine "Erlösung“ von Stadt und Großindustrie, wie Goebbels 1925 in sein Tagebuch schrieb ${ }^{38}$. Daß Eroberungskrieg und Gesellschaftsaufbau die Bekämpfung und endlich das Ausscheiden aller fremdrassigen und feindlichen Elemente in Volk und Staat notwendig machten, verstand sich für diese biologistischen Nationalisten von selbst, und so banden die deutschen Rechtsextremisten ihren nationalistischen Imperialismus unauflöslich an einen bösartigen rassistischen Antisemitismus, dem sie mit geradezu religiöser Inbrunst anhingen. Daß freilich Vorbereitung und Führung eines Eroberungskriegs zunächst einmal die energische Fortsetzung von Industrialisierung und Modernisierung erfordern mußten, gehört zu jenen bizarren Widersprüchen, unter denen radikale Ideologien und Ideologen so oft zu leiden haben.

Die Möglichkeit westlicher Intervention hat die nach rechts drängende Grundtendenz der deutschen Nation lange Jahre ernstlich behindert und den Termin des rechtsradikalen Generalangriffs auf den liberaldemokratischen Parlamentarismus und auf die Sozialisten verschoben. Dies staute allerdings die Energien des Rechtsextremismus, den schon die Frustration durch die Niederlage von 1918 gereizt und gesteigert hatte. Als seit 1930 die außenpolitische Sicherheit Deutschlands zunahm und sich gleichzeitig die wirtschaftliche Situation - in der großen Krise der Weltwirtschaft - rapide verschlechterte, brach die nationalsozialistische Bewegung mit elementarer Naturgewalt los, und nachdem die NSDAP Anfang 1933 mit Hilfe konservativer Gruppen an die Regierung gekommen war, vermochte sie die Linke mühelos zu überrennen. Auch im nationalsozialistischen Deutschland koexistierten dann unter dem diktatorisch herrschenden Führer der NS-Bewegung die alten Herrschaftsgruppen in Wirtschaft, Armee und Verwaltung - dazu die Kirchen - mit einem neuen NS-Machtapparat in einem unsicheren und beiderseits von feindseligem Mißtrauen gekennzeichneten Bündnis. Da aber der deutsche Rechtsextremismus auf solch

38 Tagebücher von Joseph Goebbels, Bd. 1, S. 97. 
breiter Basis stand und so große politische Kraft besaß, konnte er seine konservativen Partner, die ihm für die Eroberung der Macht und für die erste Phase der Machtbefestigung unentbehrlich waren, im Lauf weniger Jahre erst zurückdrängen und dann völlig entmachten. Die Tendenzen der NSDAP und der Wille ihres Führers Adolf Hitler haben daher die Innenund namentlich die Außenpolitik Deutschlands in einem Maße bestimmt, wie es in Italien den Faschisten und Mussolini versagt blieb.

Auch in den südeuropäischen Ländern westlich Italiens, in Osteuropa und auf dem Balkan hat sich der liberaldemokratische Parlamentarismus entweder gar nicht oder - wie schon vor dem Krieg - nur in pervertierter Form halten können. Indes ist in diesen noch weitgehend agrarischen Ländern die gesellschaftliche Basis faschistischer oder verwandter Bewegungen sehr schmal und deren politische Bedeutung entsprechend gering gewesen. Die alten Führungsschichten - Großgrundbesitzer, bürgerliche Oligarchen, Klerus - waren, meist unter monarchischer Spitze, häufig stark genug, mit den ihnen zu Gebote stehenden Machtmitteln, vor allem mit der Armee, die Ablösung des auch für sie doch zunehmend gefährlichen Parlamentarismus durch ein autoritäres System zu erreichen. Wenn sie doch mit einer kräftigeren faschistischen Bewegung (Spanien: Falange; Rumänien: Eiserne Front) oder mit faschistischen Politikern (Griechenland: General Metaxas) zu rechnen und sich deren Hilfe zu bedienen hatten, waren sie die überlegenen Partner, die ihre Faschisten in dienendem Stande zu halten und nach dem innenpolitischen Sieg in Königsdiktaturen wie in Griechenland oder in quasi-monarchische Militärdiktaturen wie in Spanien und Ungarn $\mathrm{zu}$ integrieren wußten.

Ob ein Land zu den Siegern oder den Verlierern des Weltkriegs gehörte, ob es neutral geblieben war, spielte dabei kaum eine Rolle. Im Juni 1923 hob in Bulgarien ein Offiziersputsch die autoritäre Regierung Zankoff in den Sattel. Im September 1923 folgte in Spanien der Militärputsch, der die Diktatur des Generals Primo de Rivera begründete; nach etlichen - auch liberalen - Zwischenspielen setzten sich dann von 1936 bis 1939 in einem furchtbaren Bürgerkrieg und mit der Hilfe der deutschen Nationalsozialisten wie der italienischen Faschisten die alten Gewalten endgültig durch und unterwarfen das Land - samt der faschistischen Falange - der Diktatur des Generals Franco. In der Türkei festigte sich 1923 das diktatorische Regiment Kemal Paschas. In Albanien errichtete Achmed Zogu im Januar 1925 eine Präsidialdiktatur. In Polen brachte im Mai 1926 ein Militärputsch Marschall Pilsudski an die Macht, und zur gleichen Zeit putschte in Portugal General Gomes da Costa, dessen Regime nach seiner Ersetzung durch General Carmona in die Diktatur Salazars überging (Juli 1932). Litauen wurde im Dezember 1926 Diktatur und im Dezember 1932 autoritärer Einparteienstaat. Jugoslawien verwandelte sich im Januar 1929 durch einen Staatsstreich Alexanders in eine Königsdiktatur, welchem Beispiel Rumänien 1938 folgte, nachdem König Carol schon seit Februar 1930 autori- 
tär regiert hatte. In Österreich riß im März 1933 Dollfuß die Macht an sich, und dem Land wurde eine stark klerikal eingefärbte Spielart des Faschismus oktroyiert. Im März bzw. Mai 1934 kamen auch Estland und Lettland an die Reihe, und im August 1936 fielen die liberalen und demokratischen Ansätze in Griechenland dem Staatsstreich des Generals Metaxas zum Opfer. Lediglich in der Tschechoslowakei blieb das liberaldemokratische System stabil: Obwohl das Land mit der Problematik starker ethnischer Minderheiten belastet war, von denen sich die deutsche und die slowakische zunehmend in einem faschistischen Sinne radikalisierten, wurde die nach westeuropäischem Muster liberale und demokratische tschechische Gesellschaft erst dann in andere Bahnen gedrängt, als ihr der nationalsozialistische Imperialismus Deutschlands die staatliche Selbständigkeit nahm.

Fast überall haben die totalitären oder autoritären Rechtsdiktaturen auch positive Effekte gebracht. Durch Förderung der Industrialisierung, durch sozialpolitische Maßnahmen und durch den Aufbau neuer Machtapparate, die der alten Sozial- und Machtstruktur notwendigerweise feindlich begegneten und zu überfälligen Abbrucharbeiten bereit und fähig waren, sind vor allem das nationalsozialistische Regime in Deutschland und das faschistische System in Italien ungewollt in die Rolle von Entwicklungsdiktaturen geraten ${ }^{39}$. Selbst die angestrebte und weitgehend realisierte Militarisierung der Nation hatte positive Seiten, indem sie eine rationalere Organisation und eine höhere Mobilität der Gesellschaft erzwang, die sich günstig bemerkbar machen konnten - freilich erst später, nach dem Sturz der Diktatoren. Auf politischem Felde überwogen aber die restaurativen und bremsenden Elemente, und daß die bürgerlichen Ansprüche auf politische Gleichberechtigung zum imperialistischen Nationalismus verfälscht wurden, steigerte die außenpolitische Aggressivität der Staaten, in denen die liberale Demokratie zusammenbrach, zu solcher Schärfe, daß sich die außenpolitischen Spannungen in Europa unmöglich lösen konnten, vielmehr ein zweiter großer innereuropäischer Krieg immer drohender am Horizont erschien. Gewiß waren die meisten Länder Mittel-, Süd- und Osteuropas für eine abenteuerliche und kriegerische Außenpolitik zu schwach. Der mobilisierte Nationalismus entlud sich fast überall jahrelang nur in innerstaatlicher Aggressivität, den die politischen Gegner und die ethnischen Minderheiten zu spüren bekamen. Aber zu den Staaten, in denen der nationalistische Imperialismus triumphierte, gehörte mit Italien auch eine europäische Großmacht, und als mit Deutschland die potentiell stärkste Macht des Kontinent einen ähnlichen Weg ging, zeichnete sich die Wiederholung von 1914 - bei etwas veränderter Konstellation - bereits ab.

Zu allem Überfluß hat sich dann seit 1929/30 die zuvor immer noch in gewissen Grenzen gebliebene Dauerkrise der europäischen Wirtschaft in

39 Vgl. D. Schoenbaum, Die braune Revolution. Eine Sozialgeschichte des Dritten Reiches, Köln 1968. 
rasendem Tempo verschärft ${ }^{40}$. Aus der Schrumpfung und aus den Störungen des überseeischen wie des binneneuropäischen Marktes hatte sich eine Überproduktion ergeben, auf die alle europäischen Industrien mit einer erst allmählichen und endlich drastischen Einschränkung der Investitionen reagierten. Die Summierung solcher Reaktionen, so begründet jeder einzelne Entschluß im Rahmen der damaligen wirtschaftlichen Vorstellungen und im Rahmen des damaligen Wirtschaftssystems sein mochte, löste die letzten Bremsen des abwärts rollenden Gefährts: weitere Arbeitslose, weiterer Schwund der industriellen Nachfrage und Produktion, wiederum Arbeitslose und Rückgang der privaten Kaufkraft, abermals Reduzierung der Investitionen...! Die staatlichen und die kommunalen Haushalte sahen sich gezwungen, dem von der Schrumpfung des Sozialprodukts bescherten Steuerausfall Rechnung zu tragen, wenn sie nicht eine als Rückfall in inflationistische Praktiken verdächtigte Politik der Kredit- und Geldschöpfung verfolgen wollten. So ging überall auch die staatliche und kommunale Investitionstätigkeit - ein wichtiger Wirtschaftsfaktor - scharf zurück, die Ausgaben für soziale und sonstige Zwecke wurden gekürzt, die Gehälter und Löhne der Beamten, Angestellten und Arbeiter im öffentlichen Dienst gesenkt. Die Regierungen gaben mithin dem abwärts rollenden Gefährt noch einen kräftigen Stoß. In einigen Ländern, z.B. in Schweden, begannen die Kabinette schließlich die Unsinnigkeit einer staatlichen Finanz- und Wirtschaftspolitik einzusehen, die der Wirtschaft fortwährend lähmendes Gift injizierte, und nahmen mit Erfolg Ankurbelungsprojekte in Angriff. In den meisten Ländern versagten aber die volkswirtschaftlichen Kenntnisse und Fähigkeiten für eine erstaunlich lange Zeit. Da gleichzeitig, im Herbst 1929, die Hochkonjunktur in den Vereinigten Staaten zusammenbrach und von einer tiefen Depression gefolgt wurde, verbanden sich die beiden anfänglich voneinander unabhängigen Krisen und entwickelten sich - von der Verschmelzung erneut verschärft - zu einer alle bisherigen Erfahrungen sprengenden Katastrophe der Weltwirtschaft.

In dieser Situation fühlten sich die Regierungen sämtlicher Staaten zu der unvernünftigen - wenn auch verständlichen - und nur auf die eigene Rettung bedachten Rücksichtslosigkeit getrieben, wie sie bei einer von $\mathrm{Pa}$ nik ergriffenen Menschenmenge auftritt. In den Jahren 1927 und 1928 waren durchaus hoffnungsvolle Versuche unternommen worden, den internationalen Handel endlich von den Fesseln zu befreien, die ihn seit dem Kriege behinderten. Allein 1927 hatten unter den Auspizien des Völkerbunds vier große Expertentreffen stattgefunden, die sich mit derartigen Fragen beschäftigten. Die erste Weltwirtschaftskonferenz, im Mai 1927 in Genf eröffnet, war zu dem Schluß gekommen, daß die wirtschaftliche Erholung vornehmlich an der von den meisten Staaten noch immer getriebenen

40 H. James, The German Slump, Oxford 1986; Die Staats- und Wirtschaftskrise des Deutschen Reiches 1929/33, hrsg. v. W. Conze u. H. Raupach, Stuttgart 1967. 
Zollpolitik scheitere, und ein im Oktober 1927 einberufener Kongreß hatte eine Konvention ausgearbeitet, die einen umfassenden Plan zum Abbau der überall existierenden Beschränkungen von Import und Export anbot; bis Juli 1928 war die Konvention von fast dreißig Staaten unterzeichnet, freilich erst von siebzehn ratifiziert worden. Die große Krise hat alle diese Ansātze wieder zerstört. Den Anfang machten die Vereinigten Staaten. Zwischen Frühjahr und Juni 1930 schleuste Präsident Herbert C. Hoover die Hawley-Smoot-Bill durch den Kongreß, ein Gesetz, das die ohnehin schon hohen amerikanischen Zölle noch höher schraubte und die europäischen Handelspartner der USA hart traf. Nicht weniger als 1028 amerikanische Wirtschaftler - meist Wirtschaftswissenschaftler - appellierten gemeinsam an den Präsidenten, das Gesetz durch sein Veto zu blockieren, weil es den Trend zu vernünftigen Zöllen beenden, die Partner zu Gegenmaßnahmen provozieren und alles in allem die Krise verschlimmern werde. Präsident Hoover setzte sich, unter dem Druck kurzsichtiger einheimischer Interessen stehend, über die Proteste hinweg, und die Prophezeiungen der Wirtschaftsexperten erfüllten sich Punkt für Punkt. Das Beispiel, das die Vereinigten Staaten gegeben hatten, ließ den Genfer Liberalisierungsprojekten in der Tat keine Chance mehr. Der allgemeinen Flucht in den wirtschaftlichen Isolationismus, die nun einsetzte, fiel die Import-Export-Konvention ebenso zum Opfer wie ein von der britischen Regierung vorgeschlagener Waffenstillstand im Zollkrieg. Im März 1930 endete die Konferenz, die eine auf Grund der britischen Vorschläge entworfene Vereinbarung billigen sollte, mit einem völligen Mißerfolg, und die meisten Kabinette zogen jetzt um ihre Länder stattliche Zollmauern oder trafen, wie die deutsche Regierung, andere Maßnahmen, die den Import radikal reduzierten. Die simple Wahrheit, daß Handel auf Tausch beruht und daher eine generelle Drosselung der Importe eine generelle Drosselung der Exporte erzwingt, ist während der ausgebrochenen Panik gerade in den Ländern mißachtet worden, deren Wirtschaft in gleichem Maße von der Ausfuhr wie vom inneren Markt abhing. Schließlich schloß sich sogar Großbritannien, trotz langer freihändlerischer Tradition, der protektionistischen Bewegung an. Die Beschlüsse der Konferenz von Ottawa (Juli/August 1932 schufen ein handelspolitisches Präferenzsystem, das die angelsächsische Staatengemeinschaft - im Dezember hatte das Statut von Westminster die Eigenständigkeit der Dominions verankert und den Übergang vom Empire zum nur noch von der Krone zusammengehaltenen Commonwealth besiegelt - in einen geschlossenen Wirtschaftsraum verwandelte, der sich ebenfalls gegen auswärtige Konkurrenz abzusperren suchte.

Der Abfall in ökonomischen Nationalismus, der die Schrumpfung des Welthandels erheblich beschleunigt und die große Krise selbst wesentlich verschärft und verlängert hat, hätte allein schon genügt, auch die politischen Beziehungen zwischen den Staaten zu verschlechtern und die Arbeit des ohnehin gehandikapten Völkerbunds noch mehr zu erschweren. Wich- 
tiger war aber, daß Faschisten, Nationalsozialisten und alle verwandten rechtsextremistischen Geister - die ja seit langem ihren Drang zu aggressiver Außenpolitik gerne mit den Parolen eines zwischenstaatlichen Klassenkampfes begründeten und sich als „Habenichtse“ gerierten, die gegen glückliche Besitzende anzugehen hätten - die große Krise als schlagenden Beweis für die Richtigkeit eines auf die Schaffung riesiger und autarker Wirtschaftsräume zielenden Imperialismus empfanden und argumentativ nutzen konnten, daß außerdem sie selbst und auch simple Revisionisten im allgemeinen wirtschaftlichen Niedergang eine Chance sahen, die Liquidierung des von der Pariser Friedenskonferenz gezimmerten europäischen Systems ernsthaft in Angriff zu nehmen. Mussolini gab derartigen Neigungen charakteristischen Ausdruck, als er in einer großen Rede, die er am 25. Oktober 1931 in Neapel hielt, ein umfassendes Programm jener Liquidierung präsentierte, in dem neben der Streichung der Reparationen und sonstiger Kriegsschulden auch die Herstellung der militärischen Gleichheit - also das Gegenteil von Abrüstung - und die Bereinigung territorialer Fragen gefordert wurden ${ }^{41}$. Noch konnte Mussolini, der Führer einer Großmacht zweiten Ranges, lediglich Fanfarenstöße abgeben, die Europa zwar erschreckten, jedoch keine unmittelbare Aktion Italiens ankündigten. Indes begannen zur Zeit der neapolitanischen Rede zwei Voraussetzungen, die der Duce zu seiner Handlungsfähigkeit brauchte, im Wirbel der großen Krise bereits Wirklichkeit zu werden: der Ausbruch der zweiten und stärkeren europäischen Großmacht mit imperialistischer Tendenz, des Deutschen Reiches, aus dem Versailler System und ein fast schon totaler ideeller und politischer Bedeutungsverlust des Völkerbunds.

Seit März 1930 amtierte in Deutschland das Kabinett Brüning, und den Zentrumsmann Brüning hinderte sein westfälischer Katholizismus nicht daran, ein überzeugter Anhänger des preußisch-deutschen Obrigkeitsstaates, ein kritikloser Bewunderer der preußischen Militärtradition und ein glühender Nationalist zu sein. Auch er gehörte zu jenen Politikern, die in der wirtschaftlichen Katastrophe große Chancen für eine verfassungs- und gesellschaftspolitische Restauration und große Möglichkeiten für eine revisionistische Außenpolitik erkannten ${ }^{42}$. Gewiß ist er schon von seinem finanz- und wirtschaftspolitischen Konzept, das auf die Krise mit einer Politik der Deflation und der Restriktion antwortete, auf parlamentsfeindliche Wege geführt worden: Der Haushalt sollte ausgeglichen und die Währung stabil gehalten werden, was bei sinkenden Steuereinnahmen eine laufende Kürzung der staatlichen Ausgaben erforderte; der Import sollte gedrosselt, der Export jedoch durch Verbilligung gefördert werden, was beides, da man den Außenkurs der Mark nicht antasten wollte, nur zu erreichen war, wenn die Löhne und Gehälter bei steigenden Verbrauchssteuern stagnierten oder

41 Graml, Europa, S. 240.

42 H. Graml, Präsidialsystem und Außenpolitik, in: VfZ 21 (1973), S. 134-154. 
sogar gedrückt wurden, andererseits die Unternehmen von großen sozialen und steuerlichen Belastungen verschont blieben. Außerdem verbarg sich hinter der Sparpolitik noch der von schwerindustriellen und großagrarischen Interessenten durchgesetzte - als erholungsvorbereitend freilich weithin und auch von Brüning selbst für volkswirtschaftlich vernünftig angesehene - Entschluß, die Lasten der Depression nicht den Großproduzenten, sondern den Arbeitnehmern und den Arbeitslosen aufzubürden, dazu dem Klein- und Mittelbürgertum mit einem in der Deflation ständig an Wert verlierenden Haus- und Grundbesitz.

Eine solche Politik, die ausschließlich den Wünschen einer Minderheit gehorchte, konnte keine parlamentarische Mehrheit finden, und Brüning, der ihre Durchführung übernommen hatte, mußte sich alsbald auf die verfassungsrechtliche und persönliche Autorität des - 1925 gewählten - stockkonservativen Reichspräsidenten Paul v. Hindenburg, eben jenes Hindenburg, der im Kriege als Feldmarschall mit Ludendorff Chef der dritten OHL gewesen war, und auf die faktische Macht der Reichswehr - dank dem Versailler Vertrag eine Berufsarmee - stützen. Jedoch hat er diese Politik von Anfang an ganz bewußt auch als taktisches Mittel verstanden, mit dem er die Zurückstutzung des Reichstags auf den wilhelminischen Status und am Ende noch die Wiederherstellung der Monarchie zu erzwingen hoffte. Daneben war er entschlossen, die Lage zumindest zur Schaffung entscheidender Voraussetzungen für die Rückgewinnung der außenpolitischen Bewegungsfreiheit des Reiches auszunützen, d.h. zur Liquidierung der Reparationen und zur Erlangung der militärischen Gleichberechtigung Deutschlands. Da er zur Abschüttelung der Reparationen äußerste finanziell-wirtschaftliche Not als Argument benötigte, da er für sonstige revisionspolitische Schritte und für seine innenpolitischen Vorhaben die Existenz einer starken nationalistischen Bewegung als sehr hilfreich ansah, hat Brüning die Ausbreitung der Krise und den Aufstieg der Nationalsozialisten nicht nur hingenommen, sondern beides gefördert. Im Grunde verstand er seine eigene Amtszeit lediglich als Vorbereitungs- und Übergangsphase. Nach ihm sollte, als Produkt und Erbe seiner Politik, ein mit monarchischer Spitze versehenes Bündnis zwischen Konservativen und Nationalsozialisten Deutschland regieren und das Reich über eine erfolgreiche territoriale Revisionspolitik zur Weltmacht zurückführen. Allerdings hat Brüning, selbst kein Nationalsozialist, sondern konservativer Nationalist, wohl nicht daran gezweifelt, daß die preußisch-deutschen Konservativen stark genug seien, in jenem Bündnis stets die dominierende Rolle zu spielen und Hitler mit seinen Nationalsozialisten auf die Funktion von Lieferanten nationaler Energie zu beschränken.

Die selbstgesetzte Aufgabe als Schrittmacher hat Brüning auf innenpolitischem Felde nur zum Teil lösen können. Wohl ist in seiner Amtszeit, in der er mit dem Notverordnungsartikel 48 der Weimarer Verfassung regierte, der Reichstag in der Tat an den Rand der politischen Entschei- 
dungsebene gedrängt worden, nicht ohne Schuld der liberalen und sozialdemokratischen Kräfte, die den Verfall der Parlamentsmacht passiv hinnahmen und denen Brüning mit Appellen an ihre nationale Pflicht sogar immer wieder die erklärte Tolerierung seiner Politik abhandeln konnte. Der Restauration der Monarchie kam der Kanzler aber nicht einen Schritt näher. Erfolgreicher operierte er in der Außenpolitik. Indem er Deutschland bis hart vor den totalen finanziellen und wirtschaftlichen Kollaps steuerte, indem er den pragmatischen Rationalismus - und die Interessen Großbritanniens geschickt benützte und indem er schließlich gemeinsam mit England auch noch die Vereinigten Staaten auf seine Linie zog, gelang ihm eine Isolierung Frankreichs, die am Ende tatsächlich die Erledigung der Reparationsfrage möglich machte. Nachdem Deutschland vom Ende des Krieges bis zum Sommer 1931, als ein vom amerikanischen Präsidenten Hoover verkündetes Moratorium alle mit dem Krieg zusammenhängenden Zahlungen bereits für ein Jahr unterbrach, in bar und in Form von Sachlieferungen rund 23 Milliarden Mark Reparationen (etwa 20 Prozent der alliierten Forderungen) gezahlt hatte, setzte die Konferenz von Lausanne (16. Juni bis 9. Juli 1932) ihr „Finis“ unter das Reparationskapitel. Deutschland wurde $z$ war das Versprechen abgerungen, eine letzte Zahlung von 3 Milliarden Mark zu leisten, doch ist dieses Versprechen, das von keiner Seite ernsthaft gemeint war, nie mehr erfüllt worden: die Reparationsansprüche waren tatsāchlich tot. Gleichzeitig ist auch das Problem der amerikanischen Kriegskredite begraben worden, und zwar ganz simpel dadurch, daß die europäischen Schuldner die Zahlungen einstellten; allein Finnland kam seinen amerikanischen Verpflichtungen weiterhin nach. Brüning selbst war kurz vor Beginn der Lausanner Konferenz von Hindenburg abgehalftert worden. Aber der reparationspolitische Erfolg kam durchaus noch auf sein Konto. Sein Nachfolger Franz v. Papen, ein noch weiter rechts stehender Politiker, der ein halbes Jahr später zu einer der Schlüsselfiguren des Bündnisses zwischen Konservativen und Nationalsozialisten werden sollte, das Hitler die Eroberung des Staates ermöglichte, brauchte in Lausanne nur die Früchte der Vorarbeit Brünings einzusammeln ${ }^{43}$.

In ähnlicher Weise war es Brüning zuzuschreiben, daß Deutschland die zweite einschneidende Fessel seiner politischen Bewegungsfreiheit ebenfalls abstreifen und damit Frankreich den zweiten großen Gewinn des Krieges aus den Händen winden konnte. Am 11. Dezember 1932 mußte die französische Regierung mit ihrer Unterschrift eine Formel akzeptieren, die eine grundsätzliche Anerkennung der militärischen Gleichberechtigung Deutschlands aussprach und damit der deutschen Wiederaufrüstung ein entscheidendes Hindernis aus dem Weg räumte. Auch dies beruhte auf der diplomatischen Vorbereitung durch Brüning, der Deutschland wiederum die britische und die amerikanische Unterstützung zu sichern gewußt hatte.

43 Graml, Europa, S. 251 ff. 
In welchem Sinne konservativ-nationale Gruppen die zurückgewonnene Bewegungsfreiheit zunächst zu nutzen gedachten, hatte Brüning noch selbst deutlich gemacht. Während seiner Amtszeit sind in den Reden rechtsstehender deutscher Politiker - nicht zuletzt in den Reden von Kabinettsmitgliedern - die antipolnischen Töne immer schriller geworden, und in den europäischen Hauptstädten registrierten Politiker, Diplomaten und Soldaten sorgfältig, daß Deutschland zwar seine sozialen Ausgaben laufend kürzte, aber genügend Geld für den Bau von Panzerkreuzern fand, die damals allein dann einen militärischen Sinn hatten, wenn sie in der Ostsee unmittelbar gegen Polen wirken oder durch eine Absperrung der Ostsee französische Hilfe für Polen verhindern sollten. In südöstliche Richtung wies dagegen der im Frühjahr 1931 eingeleitete und bis zum Herbst von Frankreich wieder erstickte Versuch der Regierung Brüning, mit einer österreichisch-deutschen Zollunion den ersten Schritt zum politischen Anschluß Österreichs zu tun 44 .

Die sofortige Wirkung der revisionspolitischen Aktivität Brünings, der erfolgreichen wie der erfolglosen, bestand darin, daß in Frankreich der Gedanke an eine Fortsetzung der von Briand und Stresemann eingeleiteten deutsch-französischen Verständigung aufgegeben wurde. Vielmehr führte die Vergeblichkeit des französischen Widerstands sowohl gegen die Liquidierung der Reparationen wie gegen die allmähliche Wiederherstellung der militärischen Gleichberechtigung Deutschlands zu einem neuen und überaus heftigen Ausbruch des alten Sicherheitsfiebers. Wie man es in Paris sah, schafften sich die Deutschen zunächst in ihrem Budget Platz für Rüstungsausgaben, um dann, nach der internationalen Legalisierung ihrer militärischen Gleichberechtigung, tatsächlich für ein „polnisches Sadowa“ aufzurüsten. Die nicht zu übersehende nationalistische Radikalisierung in Deutschland lieferte der französischen Besorgnis von Tag zu Tag mehr Nahrung. Als Stresemanns großer Partner Briand am 7. März 1932 starb, hatten die deutsch-französischen Beziehungen abermals einen Tiefpunkt erreicht.

Die praktische Konsequenz, die in Frankreich aus der deutschen Entwicklung gezogen wurde, traf aber nicht etwa Deutschland, sondern vor allem den Völkerbund. Ausgerechnet zu einem Zeitpunkt, da man in Genf wieder Abrüstungspläne ernsthaft verfolgte, kamen die französischen Politiker zu dem Schluß, daß sie sich dieser wichtigen Aufgabe des Völkerbunds jetzt erst recht versagen müßten. Selbst ein grundsätzlicher Anhänger einer allgemeinen Abrüstung wie Edouard Herriot sagte: „Ich habe keine Illusionen. Ich bin überzeugt, daß Deutschland wieder aufrüsten will ... Morgen wird es eine Politik territorialer Forderungen treiben, mit einem gewaltigen Mittel der Einschüchterung: seiner Armee... Die instinktive Reaktion darauf ist die Feststellung, daß wir nicht einen Mann, nicht eine Ka-

44 Krüger, Außenpolitik von Weimar, S. $523 \mathrm{ff}$ 
none abschaffen werden." 45 So beschloß die Pariser Kammer im Juni 1931 den Bau von Kriegsschiffen, mit denen die deutschen Panzerkreuzer übertroffen werden sollten, und das wiederum ließ anfangs aussichtsreiche Verhandlungen scheitern, die zwischen Paris und Rom über eine Begrenzung der Flotten Frankreichs und Italiens angeknüpft worden waren. Ebenfalls im Juni 1931, als Termin und Ort einer vom Völkerbund einberufenen Abrüstungskonferenz bereits feststanden, übermittelte die französische Regierung dem Genfer Sekretariat eine Note, in der sie unmißverständlich erklärte, daß Frankreich nicht abrüsten werde, wenn es keine neuen Sicherheitsgarantien erhalte. Konnte von Frankreich keine Modifizierung dieses Standpunkts erreicht werden, so war, da die Forderung nach zusätzlichen Sicherheitsgarantien als irreal gelten mußte, die Abrüstungskonferenz von Anfang an zum Scheitern verurteilt und damit die deutsche Aufrüstung unvermeidlich. In Paris glaubte sich die Regierung zu ihrer Obstruktionspolitik jedoch um so mehr genötigt, als gerade die Krise um das Projekt der österreichisch-deutschen Zollunion gelehrt hatte, daß sich Frankreich bei der Abwehr territorialer Forderungen Deutschlands nicht auf die europäische Solidarität - und das war schließlich die entscheidende Voraussetzung erfolgreicher Abwehr - verlassen konnte. Zwar hatte Frankreich bei seinen Manövern gegen den Unionsplan die Hilfe Großbritanniens und Italiens gefunden; daß Deutschland die außenpolitische Isolierung riskierte, wenn sein Revisionismus Grenzen in Frage stellte, war durchaus deutlich geworden. Doch hatten die französischen Politiker sehr wohl bemerkt, daß sich die britische Regierung nur für die bequemere Lösung entschieden hatte, nämlich für die Unterstützung der im Augenblick noch stärkeren Macht, daß aber London die Sache selbst, den Anschluß Österreichs an Deutschland, mit beunruhigender Gelassenheit aufgenommen hatte. Würde England, wenn ein aufgerüstetes Deutschland solche Coups wagte, womöglich die dann bequemere Lösung wählen? Selbst Italien, das - obschon ansonsten revisionistisch - an der Erhaltung der österreichischen Unabhängigkeit unmittelbar interessiert war, hatte gezögert und sich der Front gegen die Zollunion erst angeschlossen, nachdem klargeworden war, daß sich Deutschland gegen Frankreich noch nicht durchzusetzen vermochte. Wie würde sich Mussolini verhalten, wenn er mit der Opferung Österreichs die Rückendeckung eines militärisch schlagkräftig gewordenen Deutschland für eigene Abenteuer erkaufen konnte? Und aus Prag wie aus Belgrad waren nicht die Beistandsversprechen von Verbündeten zu hören gewesen, sondern die Hilferufe abhängiger Klienten. Nie zuvor hatte man in Paris, trotz der Deutschland schließlich doch zugefügten Demütigung, so stark empfunden, wie brüchig im Grunde das System war, mit dem Frankreich seine Sicherheit garantieren wollte. Unter solchen Umständen kam die Abrüstungskonferenz, die am 2. Februar 1932 in Genf eröffnet wurde, in der

45 Graml, Europa, S. 263. 
Tat keinen Schritt weiter. Bald bot sie das gewohnt deprimierende Schauspiel fruchtloser Debatten über Sicherheitsgarantien und technische Details einzelner Abrüstungspläne. Im Sommer 1932 fühlte sich Deutschland bereits stark und sicher genug, mit dem Boykott der Konferenz zu drohen, sofern nicht die militärische Gleichberechtigung des Reiches endlich anerkannt werde. Ohne Deutschland wäre die Fortsetzung der Konferenz vollends sinnlos geworden, und so rangen jetzt die Vereinigten Staaten und Großbritannien den Franzosen in langwierigen Verhandlungen die am 11. Dezember geleistete Unterschrift unter jene schon erwähnte Formel ab, die das deutsche Verlangen, wenn auch noch in verklausulierter Form, erfüllte. Die Haltung Frankreichs in der eigentlichen Abrüstungsfrage versteifte sich nun allerdings erst recht. Wenn aber Frankreich seine Waffen behielt, obwohl andererseits Deutschland die militärische Diskriminierung durch den Versailler Vertrag abwarf, war der erste und im Grunde wichtigste Schritt zur deutschen Aufrüstung bereits getan, während gleichzeitig Prestige und politische Bedeutung des Völkerbunds schweren Schaden erlitten. Am 14. Dezember 1932 vertagte sich die bis dahin ergebnislose Abrüstungskonferenz auf den 31. Januar 1933, ohne daß sich für die Wiederaufnahme der Arbeit eine Überwindung der Stagnation abgezeichnet hătte ${ }^{46}$. Inzwischen hatte freilich die Idee der kollektiven Sicherheit, ohne deren Verwirklichung an größere Fortschritte der Abrüstung gar nicht gedacht werden durfte, ebenfalls einen harten, ja fast schon tödlichen Schlag erhalten. Zwar fiel der Schlag nicht in Europa selbst, doch machte er sich in Europa und für den weitgehend europäisch bestimmten Völkerbund deshalb nicht weniger rasch und nachhaltig bemerkbar; mit und nach der industriellen und kommerziellen war auch die politische Zentralität Europas zu Ende gegangen. Ausgerechnet zu Beginn der Abrüstungskonferenz, am 2. Februar 1932, hatte die Eröffnungssitzung um eine Stunde verschoben werden müssen, weil der Völkerbund noch die letzten Meldungen aus Schanghai erörterte, das die Japaner wenige Tage zuvor unter Einsatz aller modernen Waffen angegriffen hatten. Die Attacke war Teil einer größeren Operation gegen China, die schon in der Nacht vom 18. zum 19. September 1931 begonnen hatte, als japanische Truppen, die - auf Grund eines Vertrags mit China - zum Schutze der südmandschurischen Eisenbahn in der zu China gehörenden Mandschurei stationiert waren, Mukden, Antung und etliche andere Städte besetzten, nachdem die Bahnlinie von einer Explosion leicht beschädigt worden war, die mit Sicherheit das japanische Militär selbst inszeniert hatte. Im Laufe der folgenden Tage und Wochen okkupierten die japanischen Truppen fast die ganze Mandschurei, von nördlichen Gebieten abgesehen, wo russischer Einfluß dominierte, und rasch wurde klar, daß es

46 S. Nadolny, Abrüstungsdiplomatie 1932/33. Deutschland auf der Genfer Konferenz im Übergang von Weimar zu Hitler, München 1978; E. Bennett, German rearmament and the West, 1932-1933, Princeton 1979. 
ihnen mitnichten um den Schutz der Bahnlinie ging, sondern um die Annexion der Mandschurei oder doch um die Eingliederung des Landes in den japanischen Machtbereich ${ }^{47}$. Der japanische Imperialismus hatte die Rücksicht auf den pazifischen und fernöstlichen Status quo, der von Großbritannien und den Vereinigten Staaten 1922 erzwungen worden war, als sie auf der Konferenz von Washington eine maritime Abrüstung und Rüstungsbegrenzung der Seemächte durchgesetzt hatten, stets nur höchst widerwillig geübt. Namentlich die radikalste imperialistische Gruppe, das nationalistische Offizierkorps der Armee, das im gesellschaftlichen und politischen Gefüge Japans die Rolle einer faschistisch disponierten Schicht und fast schon einer faschistischen Partei spielte, drängte wie bereits früher darauf, daß Nippon seiner vermeintlichen Bestimmung folgen und alle seine wirtschaftlichen und gesellschaftspolitischen Probleme durch den Aufbau eines - zugleich die außenpolitische Machtlust befriedigenden - großostasiatischen Imperiums lösen müsse. Zum ersten wichtigen Objekt dieses Traums wurde die Mandschurei. Seit das exportabhängige Japan unter der Weltwirtschaftskrise litt, waren die Pressionen der Militärs, die vorsichtigeren Politikern ihres Landes die Richtigkeit einer imperialistischen Politik auch mit einer in der neueren Geschichte beispiellosen Kette von Attentaten beizubringen suchten, naturgemäß noch stärker geworden, und schließlich hatte eine Bande von Offizieren die Flucht nach vorn gewählt, zumal sie die Beute in Gefahr glaubte: Seit einiger Zeit bemühte sich die chinesische Regierung, ihre zuvor gelockerte Autorität in der Mandschurei zu restaurieren, und sie konnte solche Anstrengungen auf einen allmählich breiter fließenden Strom von Einwanderern aus dem eigentlichen China stützen. Ob die Regierung in Tokio über den mandschurischen Coup der Armee vorher informiert war, ist unklar. Jedenfalls entschloß sich das Kabinett zu sofortiger Billigung. Anfang 1932 wurden außerdem die chinesischen Verwaltungsbeamten in der Mandschurei aus ihren Ämtern entfernt und durch Kollaborateure ersetzt, die unter straffer japanischer Kontrolle arbeiteten. Am 18. Februar 1932 trafen sich die neuen Provinzgouverneure in Mukden und erklärten auf japanisches Geheiß die Trennung der Mandschurei von China. Am 1. März präsentierte Tokio der Welt die „souveräne" Republik Mandschukuo und ließ die Geburt des Marionettenstaates sogar beim Generalsekretariat des Völkerbunds anzeigen.

Mit seinem Angriff auf China - der übrigens in Japan tatsächlich wie ein großzügiges Arbeitsbeschaffungsprogramm wirkte und dem Land die ärgsten Nöte der internationalen Depression fernhielt - hatte die japanische Regierung aber gleich drei freiwillig geschlossene und freiwillig feierlich beschworene Verträge gebrochen: die Satzung des Völkerbunds, den Briand-Kellog-Pakt und das Neunmächteabkommen vom 6. Februar 1922 zur

47 J. Fox, Germany and the Far Eastern Crisis 1931-1938, Oxford 1982; G. Ratenhof, Das Deutsche Reich und die internationale Krise um die Mandschurei 1931-1933, Frankfurt-Bern 1984 
Sicherung des Status quo im Pazifik und in Fernost. Kein Zweifel: die kollektive Sicherheit, wie sie im Völkerbund institutionalisiert worden war, hatte jetzt ihre Feuerprobe zu bestehen. Aber die Genfer Maschinerie kam nur quälend langsam in Gang. Erst sieben Wochen nach Beginn der japanischen Aggression, am 24. Oktober 1931, raffte sich der Völkerbund zu einem Appell an Tokio auf, die japanischen Truppen zurückzuziehen und dann in direkte Verhandlungen mit China einzutreten. Sonst geschah zunächst nichts. Schließlich wurde am 10. Dezember eine Untersuchungskommission gebildet, die freilich bis zum 3. Februar 1932 wartete, ehe sie, geleitet von Lord Lytton, die Reise in die Mandschurei antrat, und zwar auf der langsamsten Route, die es gab, nämlich über Amerika und Japan. Im April 1932 traf sie ein - aber nicht mehr in der Mandschurei, sondern in der Republik Mandschukuo.

Die schwächliche Reaktion des Völkerbunds hatte ihre Ursache in der Passivität aller Großmächte. Zwar ist die Handlungsweise Japans von fast sämtlichen Regierungen verurteilt worden, und in fast sämtlichen Ländern forderte die offentliche Meinung energische Maßnahmen gegen Tokio. Aber nirgends waren die Kabinette und die Völker bereit, aus ihrer Entrüstung Konsequenzen zu ziehen, die das Risiko eines ernsthaften Konflikts eingeschlossen hätten. Nicht einmal die Vereinigten Staaten, die in der Mandschurei Interessen hatten, zudem das Prinzip der offenen Tür für ganz China bedroht sahen und zu der Zeit in Henry L. Stimson einen Außenminister besaßen, der zu den überzeugten Anhängern der kollektiven Sicherheit gehörte, vermochten zu einer harten Politik zu finden oder mitzureißen. Noch wurde die anti-japanische Stimmung durch die unerschütterte Abneigung gegen ferne und nicht als unbedingt notwendig empfundene Engagements paralysiert, das Verhältnis zum Völkerbund war nach wie vor mit den Parolen des innenpolitischen Streits von 1919/20 belastet, die Beziehungen zu den europäischen Staaten litten unter dem gerade wieder akut gewordenen Schuldenproblem, und den Tatendrang des Außenministers bremste Herbert Hoover, ein in außenpolitischen Dingen vorsichtiger und konfliktscheuer Präsident. So konnte Stimson die USA wohl näher an den Völkerbund heranführen, als man das kurz zuvor noch für möglich gehalten hätte. Doch mußte sich der Minister hüten, einen Kurs zu steuern, der Washington, allein oder zusammen mit Genf, in eine Aktion gegen Tokio gezogen hätte. Aus der engen Begrenzung seiner Handlungsfreiheit entwickelte Stimson jene Doktrin, die seither gerne benutzt wird, wenn einerseits die Ablehnung eines Zustands, andererseits aber der mangelnde Wille oder die mangelnde Fähigkeit zur Änderung umschrieben werden soll: die Doktrin der Nichtanerkennung ${ }^{48}$.

48 S. F. Bemis, A Diplomatic History of the United States, New Haven 1965; E. E. Morison, Turmoil and Tradition. A Study of the Life and Times of Henry L. Stimson, Boston 1960 . 
Auf diese Plattform begab sich dann auch der Völkerbund. Am 11. März 1932 verabschiedete die Vollversammlung des Bundes eine Resolution, die Stimsons Formel in Formulierungen Stimsons enthielt, und am 24. Februar 1933 nahm die Vollversammlung eine Entschließung an, die auf dem Bericht der Lytton-Kommission basierte, nämlich auf einer vernichtenden Kritik an der japanischen Politik und auf der Feststellung, daß die Regierung der Republik Mandschukuo ein Werkzeug Tokios und volksfremd sei. Wirtschaftliche oder gar militärische Sanktionen, wie sie die Satzung des Völkerbunds in Anbetracht der Sachlage und angesichts der hochmütigen japanischen Ablehnung aller Vermittlungsversuche vorschrieb, blieben jedoch aus. Japan hatte im Grunde während des ganzen Konflikts lediglich gegen rhetorische Kraftakte zu fechten. Als die japanische Regierung schon die bloße rhetorische Anprangerung ihrer Sünden unerträglich fand und auf die Resulution vom 24. Februar 1933 mit dem Austritt aus dem Völkerbund replizierte (27. März 1933), brauchte Tokio selbst bei diesem Schritt keine konkreten Nachteile zu befürchten. Üble Folgen ergaben sich aus der Affäre allein für den Völkerbund. Vom Verlust an Prestige und politischem Gewicht durch die Behandlung des Vorfalls abgesehen, stand nun neben den USA und der Sowjetunion eine dritte Großmacht außerhalb des Bunds. Hatte sich die kollektive Sicherheit in einen Schemen verwandelt, der noch oft beschworen wurde, aber kaum noch wahrgenommen werden konnte, so der Völkerbund aus einer institutionalisierten Hoffnung in eine hoffnungslose Institution.

\section{Hitlers Machtübernahme und Deutschlands Wendung gegen den Status quo}

Die Ablösung der Nachkriegsordnung durch eine neue internationale Anarchie war also bereits in vollem Gange, als die konservativ-nationalsozialistische Allianz in Deutschland am 30. Januar 1933 Adolf Hitler in den Sattel hob, den Führer der deutschen Nationalsozialisten. Mithin wäre die Zukunft - in Europa selbst wie in Übersee - auch ohne die Berliner Ereignisse spannungsreich und vielleicht gelegentlich kriegerisch geworden. Trotzdem hat Hitlers Machtübernahme eine tiefe Veränderung der Lage bedeutet. Mit ihr wurde ein abermaliger allgemeiner europäischer Krieg, der bislang nur - ähnlich der Situation in der Zeit vor 1914 - eine stets drohende Eventualität gewesen war, unausweichlich. Einerseits stand Hitler unter dem Druck einer Bewegung, die auf Grund ihrer gesellschaftspolitischen Vorstellungen und ihres Wesens auf ein totalitäres Herrschaftssystem und auf eine expansionistische Außenpolitik des zu errichtenden Sy- 
stems drängte ${ }^{49}$. Winston Churchill hat vor wie nach der nationalsozialistischen Machtergreifung stets die Ansicht verfochten, daß die NS-Bewegung kraft ihrer Natur und kraft der inneren Konstitution ihrer Angehörigen Gewalt anwenden werde, falls sie sich des Deutschen Reiches bemächtigen könne; nach den Eindrücken einer Reise durch Deutschland sprach er am 23. November 1932 im Unterhaus von den jungen Deutschen, die er in den NS-Uniformen durch die Städte des Reiches habe marschieren sehen, „mit dem Licht der Sehnsucht in ihren Augen, für ihr Vaterland zu leiden" 50 . Auf der anderen Seite war Hitler selbst die reinste Personifizierung der nationalsozialistischen "Weltanschauung“, der überzeugteste Prophet der von dieser Anschauung diktierten innen- und außenpolitischen Zielsetzung und auf dem Marsch zu den Zielen der ruheloseste und konsequenteste Antreiber der NS-Bewegung, weder durch Rationalität beeinträchtigt noch von moralischen Skrupeln oder der Scheu vor Risiken behindert. Da er ferner, nachdem er in den zwanziger Jahren mit „Mein Kampf“ die Bibel der Nationalsozialisten geschrieben hatte, zum autoritativen Theoretiker des Nationalsozialismus aufstieg, da er sich seiner Bewegung überdies als ihr weitaus wirkungsvollster, ja in bestimmter Hinsicht genialer Massenapostel unentbehrlich machte und da er sich schließlich in den innerparteilichen Flügelkämpfen als der machthungrigste, rücksichtsloseste und taktisch geschickteste Fechter erwies, erreichte er in der NS-Bewegung, die ja kraft ihrer Existenz- und Entfaltungsgesetze ohnehin nach einem diktatorischen „Führer" verlangte, eine wahrhaft herrscherliche Stellung, die es ihm erlaubte und die ihn dazu zwang, auf dem Weg zu den Endzielen der Bewegung über alle Fragen der Strategie und Taktik souverän und allein zu entscheiden ${ }^{51}$. Reichskanzler geworden, gelang es ihm, je mehr er seine deutschnationalen Partner entmachtete, die für seine Bewegung und ihn selbst gültigen Ziele und Gesetze auf die deutsche Nation und das Deutsche Reich zu übertragen, vor allem anderen das Gesetz, das sein Verhältnis zu seiner Bewegung prägte: aus dem Schöpfer und diktatorischen Führer der NSDAP wurde nun der Schöpfer und diktatorische Führer eines totalitären Herrschaftssystems in Deutschland. Grundsätzlich konnte es im Dritten Reich keinen innenpolitischen Akt und keine außenpolitische Aktion mehr ohne seine Billigung und Zustimmung geben, bedurften - aus welcher Monokratie in einem hochentwickelten und komplizierten Industriestaat mit den vielfältigsten internationalen Kontakten und Interessen not-

49 H. Graml, Wer bestimmte die Außenpolitik des Dritten Reiches, in: Demokratie und Diktatur. Geist und Gestalt politischer Herrschaft in Deutschland und Europa. Festschrift für Karl Dietrich Bracher, hrsg. v. M. Funke/H.-A. Jacobsen/H.-H. Knüller/ H.-P. Schwarz, Düsseldorf 1987, S. 223-236.

50 Gilbert, Churchill, V, S. 451.

51 W. Horn, Führerideologie und Parteiorganisation in der NSDAP 1919-1933, Düsseldorf 1972; A. Tyrell, Führer befiehl ... Selbstzeugnisse aus der "Kampfzeit“ der NSDAP, Düsseldorf 1969; D. Orlow, The history of the Nazi party 1919-1933, Pittsburgh 1969. 
wendigerweise die Polykratie genannten chaotischen Verhältnisse des nationalsozialistischen Deutschland entstanden - alle wichtigeren innen- und außenpolitischen Handlungen seiner Entscheidung. Faktisch traf der „Führer und Reichskanzler" aber in der Tat, und zwar wiederum souverän und allein, jede Entscheidung, die für das innere System richtungweisenden Charakter, erst recht jede Entscheidung, die für den außenpolitischen Kurs bestimmenden Charakter hatte ${ }^{52}$. Die Vorstellungswelt und die Ziele, das Verhalten und die Entschlüsse, ja selbst das Temperament und die Stimmungen dieses einen Mannes waren so plötzlich zu Faktoren geworden, die für die Geschicke Europas und der ganzen Welt ausschlaggebende Bedeutung besaßen.

Als einziger unter allen Akteuren auf der damaligen politischen Bühne Europas war Hitler sowohl überzeugter wie konsequenter Sozialdarwinist ${ }^{53}$. Sein Wesen und sein Instinkt zwangen ihn zu einer „Weltanschauung“, in der Politik schlechthin und namentlich Außenpolitik als unerbittlicher „Kampf ums Dasein“ erschienen, und in diesem Kampf sei, so sagte er, der "Sieg des Stärkeren“ ein Naturgesetz, das man nicht anerkennen oder verwerfen könne, gegen das lediglich Gehorsam oder Sünde möglich sei - wer dagegen sündige und schwach werde, gehe eben unter, und das sei gut. Daher begriff er den Krieg keineswegs als eine Erscheinung im Völkerleben, die zwar grundsätzlich zu vermeiden sei, der aber eben gelegentlich nicht ausgewichen werden könne, erst recht nicht im Sinne der Völkerbundsprinzipien als Polizeiaktion gegen Friedensstörer, sondern als eine durchaus normale Form zwischenstaatlicher Beziehungen und als ein durchaus notwendiges Mittel zur inneren Kräftigung wie zur äußeren Machterweiterung einer Nation. Der wahre Staatsmann, so lehrte er, müsse und werde deshalb Kriege immer wieder selbst herbeiführen. Aus seinen Schriften und aus seinen Äußerungen in kleinem Kreise ergibt sich unwiderleglich, daß er mithin allein in den Kategorien einer sichtbar von der Armee getragenen und schließlich von der Armee durchgesetzten aggressiven Außenpolitik zu denken vermochte, daß ihm der Frieden ein unbehaglicher $\mathrm{Zu}$ stand war, den er sobald wie möglich mit Krieg vertauschen wollte. Es ist von ihm kein Wort - Propagandareden ausgenommen - und keine Handlung überliefert, die seinen nach dem Beginn des Zweiten Weltkriegs gefallenen Ausspruch einschränken könnten, der Wille zum Schlagen sei immer in ihm gewesen. Eine begleitende Rolle spielte auch, daß Hitler - wie so viele Nationalsozialisten, Faschisten oder sonstigen Rechtsextremisten - in einem höchst fatalen Sinne von "geschichtlichem Denken" besessen war. Er wollte - wie sie - die Teilhabe und Teilnahme an „historischen“ Ereignissen und Missionen, er trachtete selbst mit brennendem Ehrgeiz danach,

52 Graml, Wer bestimmte die Außenpolitik des Dritten Reiches.

53 Vgl. J. C. Fest, Hitler. Eine Biographie, Frankfurt-Berlin-Wien 1973; A. Bullock, Hitler. Eine Studie über Tyrannei, Düsseldorf 1977. 
„in die Geschichte einzugehen“, und als „historisch“ erschienen ihm allein die großen kriegerischen Zusammenstöße der Nationen, zur „historischen“ Figur wurde man in seinen Augen allein durch den auf Schlachtfeldern erworbenen Ruhm. Seine Verehrung Friedrichs des Großen galt ja nicht dem alten König, der sein Land mit Pflichtbewußtsein und Fleiß als strenger Hausvater regierte, sondern dem Friedrich von Roßbach, Leuthen und Zorndorf, und wenn er sich Bismarck zum Vorbild nahm, so nicht den deutschen Kanzler, der in den siebziger und achtziger Jahren das dem jungen Deutschen Reich gegebene hegemoniale Potential behutsam im Dienste des europäischen Friedens einsetzte, sondern dem preußischen Machtpolitiker und Eroberer, der mit drei Feldzügen ein Reich geschaffen hatte. Hitler gehört in der Tat zu jenen Gestalten in der Geschichte, die es, unabhängig von Zielen und Programmen, zum Kriege drängt.

Innenpolitik im normalen Sinne des Begriffs, als Konflikt und Ausgleich der Anschauungs- und Interessengegensätze in einem politischen Gemeinwesen, gar als ständiges Bemühen um die Verwirklichung von politischer Demokratie und sozialer Gerechtigkeit, hat für Hitler nicht existiert. In seinen Augen war Innenpolitik nichts anderes als die Mobilisierung der Bevölkerung und die Präparierung des Staates für den Krieg. Hitler hat 1933/34 im Namen einer nationalsozialistischen Revolution die politische Freiheit in Deutschland beseitigt und die "Gleichschaltung" von Gesellschaft und Wirtschaft - d.h. ihre Unterwerfung unter seinen Willen - eingeleitet. Wie immer die unbeabsichtigten oder auch die von einzelnen nationalsozialistischen Funktionären beabsichtigten Resultate dieses Prozesses, der sich bis in den Krieg hineinziehen sollte, auch ausgesehen haben mögen - Hitler selbst ging es nicht um Revolution oder Reform, er faßte die Liquidierung der politischen Freiheit stets nur als Voraussetzung und den Prozeß der Gleichschaltung stets nur als Vollzug einer psychologischen, industriellen und militärischen Mobilmachung auf 54 .

Nie ließ er sich, anders als etwa Stalin, wissentlich auf Experimente ein, die zwar nach den Vorstellungen seiner Partei „linientreu“ sein mochten, aber eine zeitweilige Schwächung der militärischen oder wirtschaftlichen Kraft Deutschlands verursacht hätten. So hat er die alten Eliten in Heer und Verwaltung geschont, die Stellung der Unternehmer im Betrieb noch gestärkt und ihr Gewinnstreben begünstigt, hingegen den revolutionären Geist seiner Saal- und Straßenschlachtarmee, der SA, getötet, indem er am 30. Juni 1934 alle unruhigen SA-Führer einfach erschießen ließ. Allerdings scheute er - wie er ebenfalls bereits am 30. Juni 1934 bewies - keineswegs davor zurück, auch gegen die traditionellen deutschen Führungsschichten

54 K. D. Bracher / W. Sauer / G. Schulz, Die nationalsozialistische Machtergreifung. Studien zur Errichtung des totalitären Herrschaftssystems in Deutschland 1933/34, Köln $1960 ;$ K. D. Bracher, Die deutsche Diktatur. Entstehung, Struktur, Folgen des Nationalsozialismus, Köln 1969; M. Broszat, Der Staat Hitlers. Grundlegung und Entwicklung seiner inneren Verfassung, München 1969. 
mit Mordkommandos und noch bedenkenloser mit rüdester Personalpolitik oder kalkuliert nivellierenden Eingriffen zu operieren, wenn er dort Widerstände gegen seine Absichten spürte. Daß er, um stärker als seine Gegner zu sein, bei der Vorbereitung seiner Eroberungszüge die Industrialisierung und damit die Modernisierung Deutschlands wie der deutschen Gesellschaft vorerst energisch, ja rücksichtslos weitertreiben mußte, obwohl doch die NS-Bewegung und er selbst Politik zur Verwirklichung eines rückwärts gewandten feudalistisch-agrarischen Gesellschaftsbilds machen wollten, hat ihm - erleichtert durch seine naive Freude an den Produkten moderner Technik wie dem Auto - mit dem Blick auf seine Kriege erst recht kein Kopfzerbrechen bereitet; der Aufbau einer „gesunden“ Gesellschaft hatte eben, abgesehen von der jetzt schon einzuleitenden Ausscheidung aller Schädlinge - in erster Linie der Juden - aus dem Volkskörper, verschoben zu werden, bis die Deutschen nach siegreichen Kriegen die Rolle der Herrenschicht eines Imperiums übernehmen konnten. Andererseits hat er z.B. wirtschaftspolitische Maßnahmen, die, wie sein inflationistisches System der Rüstungsfinanzierung, nach einiger Zeit mit Sicherheit üble Folgen erwarten ließen, unbedenklich getroffen, wenn sie zunächst einmal Energien freisetzten. Da er annahm, seine Kriege relativ bald führen zu dürfen, glaubte er sich berechtigt, Deutschlands Kraft gleichsam mit schädlichen Drogen aufzuputschen. Es kennzeichnet sein Denken, daß sich in seiner Denkschrift zu einem Vierjahrsplan für die deutsche Wirtschaft, die im August 1936 entstand, kaum ein Wort über die normalen Ziele normaler Wirtschaftspolitik findet; vielmehr faßte er seine wirtschaftspolitische Zielsetzung in dem lapidaren Satz zusammen: „Die deutsche Armee muß in vier Jahren einsatzfähig sein; die deutsche Wirtschaft muß in vier Jahren kriegsfähig sein."

Indes band Hitler seinen Drang und seinen Willen zum Krieg - diese allen Spielarten des Rechtsextremismus eigene und im tiefsten Grunde tatsächlich zielunabhängige Kampfmoral, die auch Mussolini in seinen Schriften als die Essenz politischen Handelns beschrieb - an ein klares und von ihm durchaus ernst gemeintes Programm. Verhieß Mussolini dem faschistischen Italien das meditterane Imperium, so wollte Hitler dem nationalsozialistischen Deutschland ebenfalls ein lohnendes Ziel weisen. In den ersten Jahren seiner politischen Karriere war sein Horizont - wie der eines jeden politisch interessierten Deutschen - noch von Versailles beherrscht, und so hatte in seiner außenpolitischen Vorstellungswelt anfänglich Frankreich, als wichtigster Feind Deutschlands, die Hauptrolle gespielt. Schon vor dem mißglückten Novemberputsch des Jahres 1923 und dann endgültig in der unfreiwilligen Muße, zu der ihn nach dem Putsch die Landsberger Festungshaft verurteilte und die er zur Niederschrift seines programmatischen Buches „Mein Kampf“ benützte, setzte er aber den Deutschen und sich selbst eine Aufgabe, die, wie er glaubte, dem großen und harten, dem kalten und klaren Denken eines wahren Herrenvolkes und eines wahren 
Staatsmannes allein würdig sei: den Aufstieg Deutschlands zu einer Weltmacht, die ihre Kraft und ihren Rang mit der Beherrschung zunächst ganz Osteuropas fundieren und legitimieren müsse. Da er die Notwendigkeit imperialer Politik auch mit dem Argument begründete, die deutsche $\mathrm{Na}$ tion finde wirtschaftliche Sicherheit nur in einem autarken Wirtschaftsraum und wirtschaftliche Autarkie sei eben nur in einem gewaltigen Imperium $z u$ verwirklichen, läßt sich sagen, daß seine Wendung zum Imperialismus eines wirtschaftlichen Motivs nicht entbehrte, und dieses Motiv hat im Wirbelsturm der Weltwirtschaftskrise zweifellos noch an Bedeutung gewonnen. Drei andere Aspekte der Herrschaft über ein Imperium lagen Hitler jedoch stets mehr am Herzen: Erstens schien ihm einzig und allein ein Imperium Möglichkeiten für jene biologische Expansion des deutschen Volkskörpers zu liefern, die er als das alternativlose Heilmittel gegen die stete Schrumpfung der Nation und ihr endliches Absterben ansah; zweitens konnte einzig und allein ein Imperium den Deutschen jene Existenz als „Herrenvolk“ erlauben, die sie, wie er meinte, zur Rettung vor unerträglichen sozialen Spannungen und Bürgerkrieg, vor biologischer Entartung und moralischer Versumpfung in einem von Industrien und Riesenstädten überwucherten Deutschland brauchten; drittens verschaffte einzig und allein ein Imperium dem Deutschen Reich jene Erweiterung seines Raums und jenen Zuwachs an Kraft und Macht, die Hitler in der modernen Welt für unverzichtbare Voraussetzungen erfolgreicher Kriegführung gegen andere Groß- und Weltmächte hielt ${ }^{55}$.

Die deutsche Kriegszieldikussion des Weltkrieges hat ihn dabei ebenso beeinflußt wie dann die Bekanntschaft mit ähnlichen - und auch aus ähnlichem Gesellschaftsbild abgeleiteten - Eroberungsplänen, die vor ihm bereits deutschböhmische und deutschmährische Nationalsozialisten geschmiedet hatten, so Rudolf Jung in seinem 1919 erstmals erschienenen Buch „Der nationale Sozialismus“. Seit 1923 vertrat Hitler jedenfalls beharrlich die Maxime, Deutschland müsse sich „Lebensraum“ im Osten erkämpfen, und zwar „auf Kosten Rußlands“. Mit ihm war also im Januar 1933 ein Vertreter jenes Flügels der deutschen Restaurationsbewegung Reichskanzler geworden, der sich keineswegs mit einer Korrektur der negativen Kriegsergebnisse begnügen, sondern abermals nach den Gewinnen greifen wollte, die sich im Frühjahr 1918 abgezeichnet hatten. Die Heere eines nationalsozialistischen Deutschland sollten die gleichen Wege ziehen, auf denen 1917 und 1918 die Soldaten Ludendorffs nach Osten marschiert und geritten waren: durch die baltischen Länder, durch die Ukraine, bis zum Kaukasus. In diesen Feldzügen suchte Hitler sein Vorbild, und als politischen Anhalts- und Ausgangspunkt nahm er, ganz im Sinne Oswald Spenglers, das Friedensdiktat von Brest - Litowsk. Hitler war, in der zeitge-

55 E. Jäckel, Hitlers Weltanschauung, Stuttgart 1981; ders., Hitlers Herrschaft. Vollzug einer Weltanschauung, Stuttgart 1986; N. Rich, Hitler's War Aims. Ideology, the Nazi State and the Course of Expansion, New York 1973. 
mäßen Gestalt des rechtsradikalen Massenführers, zu einem guten Teil nichts anderes als ein Epigone der Alldeutschen und Ludendorffs. "Lebensraum im Osten" stellte freilich nur den Kern des Hitlerschen Programms dar. So stand für ihn, obwohl er schon aus bestimmten taktischen Gründen nicht an den baldigen Erwerb überseeischer Kolonien dachte, stets fest, daß Deutschland, nachdem es wieder mächtig geworden war und auf dem europäischen Kontinent ein Imperium begründet hatte, erneut in Afrika und Asien nach Kolonien greifen müsse, und zwar nicht unter Bescheidung auf den ehemaligen Besitz des wilhelminischen Reiches ${ }^{56}$. Auch schaute Hitler in Europa nie ausschließlich nach Osten. Zunächst einmal machte er sich von den antifranzösischen Emotionen, die sich an der Niederlage von 1918 und an der französischen Deutschlandpolitik in den ersten Nachkriegsjahren entzündet hatten, doch nicht völlig frei. Noch am 4. August 1929, auf dem Nürnberger Parteitag, rief Hitler einer Abordnung der pfälzischen SA, die auf Befehl der französischen Besatzungsmacht keine Braunhemden tragen durfte und daher in weißen Hemden auftrat, zu: „Es kommt einmal die Zeit, da ziehen wir den Franzosen die Röcke aus!"57 Im übrigen mußte immer die Eventualitāt im Auge behalten werden, daß die Westmächte der deutschen Ostexpansion in den Weg traten und dann noch vor Beginn der eigentlichen Lebensraum-Politik militärisch auszuschalten waren.

Doch über Emotionen und mögliche situationsbedingte Züge hinaus mischten sich in Hitlers imperiale Pläne die Effekte seines rassistischen und abermals die Konsequenzen eines fatalen „geschichtlichen“ Denkens. Der Führer der NSDAP und all die anderen Ideologen der NS-Bewegung hatten ja ihren rabiaten Nationalismus mit einem Rassismus verbunden, für den die deutsche Nation lediglich den politisch stärksten Teil der höchstrangigen Menschenrasse darstellte, nämlich der „arischen“ Rasse, die auch als "germanische“ oder „nordische“ Rasse definiert wurde; dabei galten ihnen die Deutschen keineswegs als die reinsten Exemplare der germanischen Rasse, vielmehr waren die rassisch reinsten Germanen, wie es der Begriff "nordisch“ bereits ausdrückte, in Nordeuropa zu finden. Wenn Hitler am 9. April 1940, als deutsche Truppen gerade in Dänemark und Norwegen einfielen, erklärte, „die beiden Länder geben wir nie mehr heraus“, wenn er einen Tag später triumphierend konstatierte: „Am Ende des 70er Krieges stand das Deutsche, am Ende dieses Krieges wird das Germanische Reich stehen!" 58 so äußerte er mitnichten neue Ideen, die ihm nur auf Grund der plötzlich entstandenen militärischen Situation eingefallen waren. Den Traum, von der Machtbasis Deutschland aus ein Skandinavien einschließendes germanisches Imperium zu errichten, hatten Hitler und seine Gefolgsleute immer getrāumt, und schon während der dreißiger Jahre

$56 \mathrm{~K}$. Hildebrand, Vom Reich zum Weltreich. Hitler, NSDAP und koloniale Frage 1919-1945, München 1969.

57 Tagebücher von Joseph Goebbels, Bd. 1, S. 405

58 Tagebücher von Joseph Goebbels, Bd. 4, S. 105. 
verwandelte sich der Traum zu fester Absicht. Heinrich Himmler, Chef der gesamten deutschen Polizei und als Reichsführer SS Leiter der ideologischen und politischen Kerntruppe des Regimes, kündigte den SS-Gruppenführern am 8. November 1938 in nächtlicher Rede an, daß der „Führer“ in absehbarer Zukunft „das großgermanische Reich“ schaffen werde, „das größte Reich, das von dieser Menschheit errichtet wurde und das die Erde je gesehen hat" 59 .

Hitlers Blick schweifte aber wieder und wieder auch nach Nordwesten, Westen und Süden. Am 3. November 1939, nach dem Feldzug in Polen und vor dem großen Angriff auf Westeuropa, brütete der „Führer“ über Plänen zur Aufteilung Frankreichs und faßte dabei den Entschluß, die Bewohner Südtirols, das er dem Bündnis mit dem faschistischen Italien geopfert hatte, nach Burgund zu verpflanzen ${ }^{60}$. Am 24. Oktober 1939 hatte er vor den Reichs- und Gauleitern eine lange Rede gehalten, in der er die Annexion Hollands, Belgiens und der Schweiz - nach dem Sieg im Westen und nach der Niederwerfung Rußlands - als festes Ziel seiner Politik nannte61. Am 23. November 1939 sagte er zu Walther v. Brauchitsch, dem Oberbefehlshaber des Heeres, daß er nach der Niederlage Frankreichs die Grenze des Deutschen Reiches von 1540 durchsetzen werde62. Anfang Februar 1940 schwärmte er vor Goebbels: „Das alte heilige Reich war die größte staatliche Schöpfung der nachrömischen Zeit. Seinen imperialen Charakter hatte es vom römischen Imperium übernommen, wir werden sie (sic) von ihm übernehmen. Aufgrund unserer Organisation und Auslese muß uns dabei einmal automatisch die Weltherrschaft zufallen."63 Und bei all solchen Äußerungen handelte es sich wiederum nicht um Eingebungen des Augenblicks, geweckt von dem erreichten und weiter erwarteten $\mathrm{Zu}$ wachs an militärischer Kraft und politischer Macht. Längst zuvor hatte Hitler die handliche Formel gefunden, in der sich die Ansprüche auf Holland, Belgien, Luxemburg, große Teile Frankreichs, die Schweiz - und übrigens auch nicht geringe italienische Territorien - summieren ließen, die Formel von der „Liquidierung des Westfälischen Friedens“. Bereits 1937 ist ihm diese Formel und die darin ausgedrückte Absicht zur Restauration des „Heiligen Römischen Reiches Deutscher Nation“ zur fixen Idee geworden, die gleichberechtigt neben der Lebensraum-Utopie steht ${ }^{64}$. In den ersten Monaten des Jahres 1940 hat dann Goebbels bereits die Inszenierung eines großen Spektakels vorbereitet, auf dem, nach einem siegreichen Westfeld-

59 H. Booms, Der Ursprung des 2. Weltkrieges - Revision oder Expansion? in: Geschichte in Wissenschaft und Unterricht, 1965, Heft 6, S. 353.

60 Tagebücher von Joseph Goebbels, Bd. 3, S. 630.

61 H. Groscurth, Tagebücher eines Abwehroffiziers 1938-1940, hrsg. v. H. Krausnick u. H. C. Deutsch, Stuttgart 1970, S. 385

62 Generaloberst Halder, Kriegstagebuch, Bd. I, bearb. v. H.-A. Jacobsen, Stuttgart 1962, S. 132.

63 Tagebücher von Joseph Goebbels, Bd. 4, S. 34.

64 Tagebücher von Joseph Goebbels, Bd. 3, S. 55, 132. 
zug, der Westfälische Frieden öffentlich und zeremoniell „ausradiert“ werden sollte. Am 1. März 1940 kam Goebbels zum Lokaltermin nach Münster, wo 1648 der Westfälische Frieden unterzeichnet worden war und wo nun, so Hitler am 2. März vor den Reichs- und Gauleitern, „der neue Frieden diktiert werden wird" 65 .

Indes war nicht nur Hitlers Zielsetzung - er selbst und viele seiner Gefolgsleute rechneten schon in den zwanziger Jahren damit, daß nach der Realisierung ihrer imperialen Träume der Endkampf um die „Weltvorherrschaft" oder die "Weltherrschaft" gegen die USA kommen werde - frei von allen Hemmungen, sondern auch, in Anbetracht eines solch uferlosen Expansionismus notwendigerweise, seine außenpolitische Methodik. Im übrigen ist sein biologisiertes und militarisiertes Denken nie vom Lichte europäischer Religiosität oder Philosophie erhellt worden, wenn er es auch liebte, die „Vorsehung“ zu beschwören und den Verehrer Nietzsches zu spielen. So waren ihm ethische Prinzipien fremd, und moralische Bindungen kannte er nicht. Schon als Parteiführer hatte er gezeigt, daß sich Vertragstreue mit seinem Charakter und mit seinem darwinistischen Credo nicht vertrug, und nachdem er Reichskanzler geworden war, glaubte er in der Außenpolitik ebenfalls zur Praktizierung seiner grundsätzlichen und ihm wesensgemäßen Infamie berechtigt zu sein; kurz vor dem Angriff auf Frankreich sagte er zu Goebbels: „Wir haben viele Verträge gebrochen; aber mußten wir das nicht, um endlich einmal Ordnung zu schaffen. Dazu gehörte nicht nur Kraft, sondern auch List. Das war immer so.“66 Daß nichts jemals seine Überzeugung erschütterte, in den zwischenstaatlichen Beziehungen seien die Verhandlungsmethoden amerikanischer Prohibitionsgangster angebracht und sogar üblich, lag allerdings auch daran, daß ihm die historische Herkunft und die existierende Verfassung der gesellschaftlichen und politischen Verhältnisse außerhalb Deutschlands gänzlich unbekannt waren. Seine Kenntnis nichtdeutscher Länder beschränkte sich auf die Kenntnis flandrischer Schützengräben, die er sich als Soldat im Weltkrieg erworben hatte, und die Lücken hat er, obschon er sich im Laufe der Jahre eine Fülle technischen und militärischen Wissens aneignete, nicht durch Reisen oder das Studium informativer Bücher geschlossen, sondern einfach mit den Trugschlüssen besetzt, die sich aus seiner „Weltanschauung" ergaben, und mit einigen der Vorurteile über Frankreich und Großbritannien, Rußland und die Vereinigten Staaten, die im deutschen Bürgertum heimisch geworden waren. Hitlers Machtantritt verwandelte Deutschland also nicht allein in einen Staat, der unerträgliche Expansionsund ebenso unerträgliche wie absurde Herrschaftsansprüche stellte, sondern zugleich in einem Staat, der die Großmächten oft eigentümliche Rücksichtslosigkeit zur prinzipiellen Brutalitāt steigerte und diese Brutali-

65 Tagebücher von Joseph Goebbels, Bd. 4, S. 57

66 Tagebücher von Joseph Goebbels, Bd. 4, S. 146. 
tät zu allem Überfluß auch noch mit der Unzuverlässigkeit und Unberechenbarkeit verband, wie sie unter bestimmten Umständen bei einem schwachen Land verständlich und verzeihlich sind. Wenn aber der stärkste Staat des Kontinents ein derartiges Verhalten an den Tag legte, durfte zum wenigsten die totale Balkanisierung der europäischen Politik erwartet werden. Anfang September 1936 besuchte David Lloyd George, der in der zweiten Hälfte des Weltkriegs britischer Premier gewesen war, Hitler auf dessen „Berghof“, und während der alt gewordene walisische Löwe, den der "Führer" mit geradezu devotem Respekt und mit voll entfaltetem österreichischen Charme behandelte, von Hitler positiv beeindruckt war, fand sich Tom Jones, enger Mitarbeiter Lloyd Georges und zeitweilig stellvertretender Sekretär des britischen Kabinetts, „paralysiert vor Entsetzen“, als er damals, zur Begleitung des „Elder Statesman“ aus London gehörend, in längeren Gesprächen einige Blicke in die „Weltanschauung“ des Gastgebers tun konnte ${ }^{67}$.

Der „Führer und Reichskanzler“ war mithin - auch unabhängig davon, daß er und die NS-Bewegung kraft ihres blinden und unstillbaren Aggressionsdrangs ohnehin unweigerlich auf ihren Untergang zusteuerten - schon deshalb von Anfang an zum Scheitern verurteilt, weil ihn sein barbarischabstruses Weltbild, sein ununterdrückbarer Hang zu schuftigen Methoden und ein ganz ungewöhnlicher Mangel an Kenntnissen über die Völker und Staaten der Erde zur Leitung der außenpolitischen Geschäfte eines Landes völlig untauglich machten. Andererseits gaben ihm die Mißachtung aller Spielregeln und die Lust zum Krieg Mittel zur Einschüchterung und zur Erpressung in die Hand, die ihm eine temporäre Überlegenheit verschaffen mußten. Sein stärkster Trumpf dabei war nicht etwa eine angeborene oder erworbene und sonstige Schwächen vielleicht für eine Weile ausgleichende Beherrschung der richtigen Taktik wenigstens bei Erpressungsmanövern, sondern das einfache Faktum, daß er, mit diktatorischer Macht ausgerüstet, an der Spitze des stärksten europäischen Staates stand, mit dem, nach der Erholung von der außenpolitischen Misere eines Jahrzehnts im Zeichen von Versailles, niemand gerne anbinden wollte. Immerhin hat Hitler, der ja siegreiche Kriege zu führen und Deutschland daher keineswegs in einen Konflikt mit einer überlegenen Mächtekombination zu verwickeln gedachte, wie ihn sich die kaiserlichen Politiker 1914 auf den Hals gezogen hatten, auch intensiv darüber nachgesonnen, wie die Risiken seiner Pläne zu verringern seien. Im Gegensatz zu vielen anderen deutschen Politikern und Publizisten, die Weltmachtträumen nachhingen, bemühte er sich ernsthaft um realistische taktische Konzepte. Die alldeutschen Forderungen der Vorkriegszeit und erst recht der Kriegsjahre kritisierte er denn auch herb als eine Wucherung der Ziele, die töricht gewesen sei, weil sie,

67 J. Colville, The Fringes of Power. 10 Downing Street Diaries 1939-1955, New YorkLondon 1985, S. 70. 
zu viele anzuvisierende Objekte gleichzeitig nennend, zwangsläufig den Zusammenschluß übermächtiger Koalitionen gegen Deutschland erzwungen habe.

Er predigte hingegen, jedenfalls für die Anfangsphase der neuen imperialen Politik des Reiches, die Konzentration auf die östliche Expansion. Darin sah er auch das richtige taktische Rezept, das die Gefahren einer Eroberungspolitik wenigstens auf ein kalkulierbares Maß reduziere. Wenn Deutschland, so schrieb er, die Herausforderung Großbritanniens, die sich das Kaiserreich geleistet habe, vermeide, vorerst auf Kolonien und stärkere Seestreitkräfte verzichte, sei es durchaus möglich, von England freie Hand in Osteuropa zu erhalten. Werde aber die britische Tolerierung erreicht, so sei auch die Passivität Frankreichs so gut wie sicher, das ja ohne britischen Beistand militärisch nicht handlungsfähig sei. Nach seiner Überzeugung war ferner die Bundesgenossenschaft des faschistischen Italien zu haben, wenn Berlin die italienischen Ambitionen im Mittelmeer und in Afrika unterstützte und öffentlich die deutschen Ansprüche auf Südtirol begrub. Sein Grundgedanke lief also darauf hinaus, die östlichen Ziele vom übrigen Europa zu isolieren. Sollte es die Isolierung der baltischen und russischen Beute erleichtern und beschleunigen, wenn Deutschland bei manchen ostund südosteuropäischen Staaten zunächst einmal Frankreich als Schutzmacht, namentlich gegen die UdSSR, ablöste, so war er dazu durchaus bereit. Lebte im übrigen in einem Manne wie Marschall Pilsudski nicht der Traum von einem großpolnischen Reich? Konnte daher ein Staat wie Polen nicht zur politischen Abschirmung und militärischen Unterstützung einer russischen Kampagne gewonnen werden? Sollten aber die Westmächte nicht bereit sein, Deutschland freie Hand im Osten zu geben, sollte deshalb die militärische Erledigung Westeuropas noch vor dem Ausgreifen nach Osten notwendig werden, waren die Allianz mit Italien und die Anbindung Polens womöglich noch wichtiger, erstere zur Fesselung britischer und französischer Streitkräfte, letztere zur Sicherung der Rückenfreiheit Deutschlands.

Das von imperialer Baulust bestimmte und an machtpolitischen oder strategischen Gesichtspunkten orientierte Denken Hitlers ist also von den normalen Emotionen des deutschen Nationalismus und des deutschen Revisionismus, die antifranzösisch, antibritisch, mit dem Blick auf Österreich und Südtirol anti-italienisch und mit dem Blick auf Danzig, Pommerellen und Oberschlesien erst recht antipolnisch waren, kaum mehr beeinflußt gewesen. Empörung über eine tatsächliche oder vermeintliche Diskrimierung deutscher Minderheiten konnte er, wie er mit seiner Haltung in der Südtirolfrage und dann auch mit seiner Polenpolitik bewies, nach den Geboten der Strategie oder auch nur nach den taktischen Erfordernissen des jeweiligen Augenblicks ein- oder ausschalten. In den zwanziger Jahren hatte er mit dieser Kälte gegenüber "nationalen“ Positionen in den Reihen der NSBewegung noch erhebliche Schwierigkeiten; immer wieder mußte er sich 
gehörig anstrengen, um in der Wolle gefärbte Nationalisten wie etwa Goebbels zur gleichen Kälte und zur gleichen Überordnung der imperialistischen Baupläne zu erziehen ${ }^{68}$. Ihm selbst war jedenfalls die völkische Ideologie in erster Linie Treibsatz seiner Raumpolitik, und von den Zielen des deutschen Revisionismus machte er sich zunächst nur diejenigen zu eigen, die am Wege nach Osten lagen und ohnehin vor dem Beginn der eigentlichen Raumpolitik erreicht werden mußten: Mit großdeutschen Parolen, die sich zudem auf das nationale Selbstbestimmungsrecht stützen ließen, konnte die Einbeziehung Österreichs und - über die Sudetendeutschen der Tschechoslowakei in den deutschen Machtbereich durchgesetzt werden, womit die Ausgangsstellung für den Stoß nach Osten bezogen war, und mit der taktisch richtigen Handhabung der deutschen Ansprüche an Warschau gedachte er Polen ins deutsche Lager zu holen.

Über den Zeitpunkt und die Reihenfolge solcher Eröffnungszüge hat er sich anfänglich allerdings ebensowenig geäußert wie über Termin und Umstände des Griffs nach den baltischen und russischen Territorien. Hitler wußte gut genug, daß ein Politiker zwar Ziele haben, aber zu diesen Zielen nicht nach einem festen Fahrplan gelangen kann, und an den Realitäten sind denn auch schon die von Hitler skizzierten taktischen Konzepte freilich ohne daß sich dadurch die Grundtendenzen seines Imperialismus verändert hätten - meist zuschanden geworden. Im übrigen war sich gerade Hitler, der ja außenpolitische Aktionsfähigkeit mit der Kraft und der Bereitschaft zu militärischen Schlägen identifizierte, sehr wohl bewußt, daß er eben einen militärisch noch schwachen Staat erobert hatte. So stand es für ihn fest, daß es in einer ersten und zeitlich sehr schwer abzuschätzenden Phase seiner Herrschaft allein darauf ankam, die für jede künftige Aktivität essentielle Aufrüstung Deutschlands einzuleiten und sie während jener unvermeidlichen Periode außenpolitisch abzuschirmen, in der das Reich noch verwundbar war, den Nachbarn jedoch bereits deutlich die künftige Herausforderung und Bedrohung signalisierte. Er hielt diese Aufgabe für überaus schwierig. Gewiß ist er in einem Augenblick an die Macht gekommen, der für ihn außerordentlich günstig war, und er hat die von seinen Vorgängern erreichte Besserung der Lage Deutschlands - durch die Abschüttelung der Reparationen und die Anerkennung der militärischen Gleichberechtigung des Reiches - ebenso registriert wie die von der großen Wirtschaftskrise bewirkte Anarchisierung der Staatengesellschaft und den von Japan verursachten Verfall der kollektiven Sicherheit. Gleichwohl fürchtete er Konsequenzen der Nachbarn, falls sie seine Absichten durchschauten. Bei seinem wölfischen Verständnis von Außenpolitik glaubte er sogar mit einer militärischen Intervention der Westmächte rechnen zu müssen. So sagte er wenige Tage nach der Machtübernahme, jetzt werde sich zeigen, ob Frank- 
reich noch Staatsmänner habe; wenn ja, werde es noch im Anfangsstadium der deutschen Aufrüstung über ihn und Deutschland herfallen 69 .

Daher gab er sich in den ersten Monaten nach dem 30. Januar 1933 größte Mühe, in Reden und Interviews als vernünftiger und friedfertiger Politiker zu erscheinen, der gar nicht daran denke, eine „Politik der Grenzkorrekturen auf Kosten fremder Völker" zu verfolgen ${ }^{70}$. Mit seinem Machtantritt schwor also Deutschland offenbar sogar den territorialen Revisionsansprüchen ab, von imperialistischen Plänen ganz zu schweigen, und auf ein Westeuropa, das aus Ruhebedürfnis glaubensbereit war, machte er mit seinen Versicherungen tiefen Eindruck. Auch präsentierte er das nationalsozialistische Deutschland, das ja gerade die linken politischen Kräfte brutal unterdrückte und ihre Führer in Konzentrationslager sperrte oder zur Emigration zwang, mit Eifer als den Schutzwall Europas gegen Bolschewismus und Sowjetrußland. Den Zweck solcher Tarnung hatte er bereits 1928 mit dem Satz umschrieben, nationalsozialistische Außenpolitik werde zunächst für Verhältnisse sorgen, „die die Wiedererstehung eines deutschen Heeres ermöglichen. Denn erst dann werden die Lebensnotwendigkeiten unseres Volkes ihre praktische Vertretung finden können."71

Freilich vermochte ein Mann wie Hitler nicht gänzlich passiv zu bleiben. Da er außerdem die „Wiedererstehung eines deutschen Heeres“ als ein Vorhaben ansah, das sofort in Angriff zu nehmen sei, Deutschland aber formal noch die Hände durch die militärischen Bestimmungen des Versailler Vertrags gebunden waren und es zudem gerade an einer internationalen Abrüstungskonferenz teilnahm, sah er sich in dieser Frage sogar rasch zur konsequenten und riskanten Fortsetzung der Revisionspolitik seiner Vorgänger genötigt. Allerdings hat ihm Frankreich diese Schritte wesentlich erleichtert, weil die französische Regierung nach wie vor versuchte, sowohl eine deutsche Aufrüstung wie eine französische Abrüstung zu vermeiden, und damit die seit Ende Januar 1933 erneut tagende Abrüstungskonferenz immer tiefer in eine Sackgasse manövrierte. Schon am 14. Oktober 1933 konnte Hitler es sich leisten, Deutschlands endgültigen Rückzug von der Konferenz und gleichzeitig auch noch den Austritt aus dem Völkerbund zu erklären. Mit einem einzigen Schnitt hatte er sich von jenen beiden Fäden befreit, die das nationalsozialistische Deutschland noch mit der Welt der kollektiven Sicherheit verknüpft gehabt hatten, ohne daß man ihm, angesichts der französischen Intransigenz, ernstlich einen Strick daraus hätte drehen können. Zwar ist die deutsche Aktion scharf und hart kritisiert worden. Daß der Völkerbund ein halbes Jahr nach dem Ausscheiden Japans ein weiteres Mitglied verlor, und $z$ war die Zentralmacht des europäischen Kontinents, ließ die Zukunft der Genfer Institution in noch düstererem

69 Th. Vogelsang, Neue Dokumente zur Geschichte der Reichswehr 1930-1933, in: VfZ 2 (1954), S. 435.

70 M. Göhring, Alles oder Nichts, Bd. I, S. 185.

71 Hitlers Zweites Buch. Ein Dokument aus dem Jahre 1928, Stuttgart 1961, S. 112 
Lichte erscheinen, und daß sich Deutschland nicht mehr an der Abrüstungskonferenz beteiligte, verwandelte die zunächst noch fortgesetzten Debatten in reine Spiegelfechterei. Ein normaler Vertreter normaler deutscher Interessen hätte sich mit der Vereitelung der französischen Machenschaften und mit einem zweifellos erfolgreichen Kampf um Deutschland genehmere Resultate der Konferenz begnügen können. Hitlers Handlungsweise war im Hinblick auf vorzeigbare deutsche Ziele überflüssig, in Wirklichkeit keineswegs mit der französischen Haltung zu rechtfertigen und von übler Vorbedeutung für den Frieden in Europa. Wenngleich aber Anlaß und Reaktion in keinem vernünftigen Verhältnis standen, hatte Frankreich dem „Führer“ doch jenes Quentchen Recht zugespielt, das Deutschland vor härteren Reaktionen der europäischen Staaten, namentlich Großbritanniens, schützte.

Angesichts der Passivität, mit der Europa den deutschen Akt hinnahm, hat Hitler nicht gezögert, gleich einen Schritt weiter zu gehen und nach der Abrüstungskonferenz auch noch dem Abrüstungsgedanken den Todesstoß zu versetzen. Ungeniert machte er sich nun an ein Aufrüstungsprogramm großen Stils, das die militärischen Paragraphen des Versailler Vertrags endgültig in den Papierkorb fegte. Dem Anfang 1934 veröffentlichten Reichshaushalt konnte jedermann entnehmen, daß die militärischen Ausgaben des Reiches um 90 Prozent steigen und jetzt auch Ausgaben für eine an sich noch immer strikt verbotene Luftrüstung einschließen sollten. Das hatte sofortige Folgen. Auf der einen Seite setzten zwischen den europäischen Kabinetten ungewöhnlich lebhafte und ungewöhnlich sinnlose Verhandlungen ein, die von der Vorstellung beherrscht waren, daß nach dem Begräbnis der Abrüstungskonferenz - die im Mai 1934 den im Herbst 1933 erhaltenen Wunden tatsächlich erlegen war - wenigstens eine partielle Rüstungsbeschränkung, etwa ein Luftpakt, erreicht werden müsse. Auf der anderen Seite zwang die Entwicklung in Deutschland, das offensichtlich zur Aufstellung und Ausrüstung einer hochmodernen Angriffsarmee überging, auch die übrigen Staaten nach langen Jahren der Stagnation zur Erhöhung ihrer Rüstungsbudgets. Binnen kurzem war die Idee der Abrüstung in Wahrheit von der Realität eines neuen Wettrüstens verdrängt. Die französische Regierung teilte dem britischen Kabinett bereits am 17. April 1934 mit, daß die angelaufene deutsche Aufrüstung Frankreich zu Gegenmaßnahmen nötige, und am 4. März 1935 publizierte die britische Regierung ein Weißbuch, in dem sie ankündigte, daß auch Großbritannien die Mängel seiner Rüstung beseitigen werde, weil das deutsche Vorgehen andere Alternativen abgeschnitten habe; sie wies ferner ausdrücklich darauf hin, daß „auch der Geist, in dem das deutsche Volk organisiert wird, zu dem allgemeinen Gefühl der Unsicherheit" beitrage. Duff Cooper, in den dreißiger Jahren erst Kriegs- und dann Marineminister, schrieb einmal in einem Privatbrief an Churchill: „Die Deutschen bereiten den Krieg mit mehr allgemeinem Enthusiasmus vor, als je zuvor eine ganze Nation in 
eine solche Vorbereitung gesteckt hat." "72 Wohl war Duff Cooper einer optischen Täuschung erlegen, als er in Deutschland einen „allgemeinen Enthusiasmus" für den Krieg zu beobachten glaubte, doch machte die generelle Uniformierung und Militarisierung der deutschen Nation, die im Frühjahr 1933 mit großer Energie eingeleitet worden war, derartige Urteile unvermeidlich.

Freilich ergab sich bald ein schreiendes Mißverhältnis zwischen den westlichen Proklamationen, man müsse, wolle, werde die deutsche Aufrüstung entsprechend beantworten, und den tatsächlich getroffenen Maßnahmen. Die westeuropäischen Länder sahen sich durch wirtschaftliche Schwierigkeiten und finanzpolitische Bedenken wie auch durch stärkste Widerstände einer schon auf den Gedanken an einen erneuten Krieg allergisch reagierenden Bevölkerung zu einem zögernden Beginn und zu einem recht gemächlichen Tempo gezwungen; gelegentlich wurden sie auch durch ein schwerfälliges militärisches Establishment, das überdies aus den Erfahrungen des Weltkriegs oft ganz irrige Schlüsse zog, zur Wahl falscher Wege verführt. Zwischen 1933 und 1938 gab jedenfalls Deutschland mehr Geld für militärische Zwecke aus als Großbritannien, Frankreich und die Vereinigten Staaten zusammen. Das britische Weißbuch aber nahm Hitler zum Anlaß, um die bereits im Papierkorb liegenden Fetzen des Versailler Vertrags herauszuholen und gleichsam mit dramatischer Geste auf den $\mathrm{Ab}$ fallhaufen der Geschichte zu schleudern: Unter Hinweis auf die freche britische Provokation befahl er am 16. März 1935 die Wiedereinführung der allgemeinen Wehrpflicht und die beschleunigte Aufstellung einer Armee, die binnen kurzem 36 Divisionen zählen sollte. Und am 2. Mai 1935 teilte er Sir John Simon, dem damaligen britischen Außenminister, in einem Gespräch triumphierend mit, die deutsche Luftwaffe sei schon jetzt stärker als die britische.

Die deutsche Rüstungs- und Militarisierungspolitik hätte den Argwohn der Nachbarn Deutschlands und aller Verteidiger des Status quo auch dann geweckt, wenn in Berlin noch Konservative oder Deutschnationale regiert hätten. In den europäischen Hauptstädten waren sich jedoch die meisten Politiker durchaus bewußt, daß die nationalsozialistische Bewegung und ihr Führer zusätzliche und besondere Bedrohungen darstellten. Allein schon die Innenpolitik des neuen Regimes erregte ebenso viel Entsetzen und Verachtung wie Furcht. Ausgerechnet zu einem Zeitpunkt, da die antideutsche Stimmung der Kriegsjahre abgeklungen war und den Deutschen ihr Platz unter den kulturell wie politisch tonangebenden Nationen nicht mehr bestritten wurde, warf die Hälfte der deutschen Bevölkerung die politische Freiheit einfach weg, um dann beifällig oder gleichgültig zuzusehen, wie die jetzt herrschende Minderheit auch noch jede Rechtssicherheit zerstörte, einen terroristischen Polizeistaat errichtete, einem als Theorie ebenso lä-

72 Gilbert, Churchill, V, S. 489. 
cherlichen wie in der praktischen Anwendung schrecklichen Antisemitismus huldigte und das kulturelle Leben Deutschlands energisch von den Einflüssen der bedeutenderen geistigen wie künstlerischen Strömungen der europäischen Gegenwart zu „säubern“ begann. Angesichts der geradezu entgegengesetzten Entwicklung in Nord- und Westeuropa und auch angesichts der deutlich geringeren Radikalität anderer europäischer Diktaturen geriet Deutschland alsbald in moralische, geistige und kulturelle Isolierung. Das nationalsozialistische Deutschland zog sogar - entsprechend der Totalität seiner Abwendung von den europäischen Traditionen - bereits in den dreißiger Jahren eine tiefere Abneigung auf sich und fand weniger Verständnis als das kaiserliche Deutschland selbst während des Krieges. So schrieb Winston Churchill im Sommer und Herbst 1935 einen Aufsatz, der, im Novemberheft des Magazins „Strand“ veröffentlicht, die Entfremdung zwischen dem europäischen Westen und dem neuen Deutschland sehr deutlich machte. Darin hieß es:

"Die Juden, die am Ende des Großen Krieges, durch ihren illoyalen und pazifistischen Einfluß, zum Zusammenbruch Deutschlands beigetragen haben sollen, wurden auch für die Hauptstütze des Kommunismus und für die Urheber defaitistischer Lehren in jeder Form gehalten. Daher mußten die Juden Deutschlands, eine Gemeinde, die nach Hunderttausenden zählt, aller Macht beraubt, aus jeder Stellung im öffentlichen und gesellschaftlichen Leben verjagt, aus den freien Berufen ausgeschlossen, in der Presse stumm gemacht und zu einer verdorbenen und widerwärtigen Rasse erklärt werden. Das 20. Jahrhundert ist mit Verblüffung Zeuge geworden, wie diese grausamen Doktrinen nicht nur verbreitet, sondern von Regierung und Bevölkerung mit brutalem Eifer angewandt wurden. Keine vergangenen Verdienste, kein erwiesener Patriotismus, nicht einmal im Krieg empfangene Wunden, konnten Menschen Immunität geben, deren einziges Verbrechen darin bestand, daß ihre Eltern sie in die Welt gesetzt hatten. Jede Art von Verfolgung, ob schwer oder kleinlich, ob gegen Wissenschaftler, Schriftsteller und Komponisten von Weltruf oder gegen die armseligen kleinen jüdischen Kinder in den staatlichen Schulen, wurde praktiziert, wurde glorifiziert und wird noch immer praktiziert und glorifiziert. Eine ähnliche Ächtung traf Sozialisten und Kommunisten jeder Färbung. Die Gewerkschafter und die liberale Intelligentsia sind gleichermaßen geschlagen. Die leiseste Kritik ist ein Vergehen gegen den Staat. Die Gerichtshöfe haben, wenn sie auch in gewöhnlichen Fällen tätig sein dürfen, bei allen Formen politischer Vergehen sogenannten Volksgerichtshöfen Platz zu machen, die aus eifrigen Nazis zusammengesetzt sind. Neben den Übungsplätzen der neuen Armeen und den großen Flughäfen verunstalten die Konzentrationslager den deutschen Boden. In diesen werden tausende von Deutschen durch Zwang und Einschüchterung zur Unterwerfung unter die unwiderstehliche Macht des Totalitären Staates gebracht." $Z$ war wäre diese Isolierung allein noch kein außenpolitischer Faktor gewesen. Daß sich die 
Deutschen plötzlich zu einem Dasein als Sklaven und Barbaren entschlossen oder sich mit einem solchen Dasein immerhin abzufinden schienen, mochte ja noch als innerdeutsche Angelegenheit gelten. Jedoch ist außerhalb des Reiches nicht unbemerkt geblieben, daß die erschreckenden Vorgänge in Deutschland nicht etwa, wie ähnliche Gewaltsamkeiten während der Französischen oder der Russischen Revolution, mit einer temporären Konzentration auf die Beseitigung unerträglich gewordener innerer $\mathrm{Zu}$ stände und mit dem wilden Elan beim vermeintlichen Durchbruch zur Verwirklichung einer großen humanen Utopie erklärt werden konnten. Sie geschahen vielmehr im Zeichen einer "nationalen Erhebung“, die sich offensichtlich fürs erste in der mentalen Militarisierung und der organisatorischen Mobilmachung der deutschen Nation erschöpfte. Mithin deutete alles auf eine Entladung nach außen.

Trotzdem hätte Hitler eine Intervention nicht zu fürchten brauchen. Von der Schwindsucht der internationalen Solidarität und der kollektiven Sicherheit abgesehen, fehlte in Frankreich, der an sich zur alleinigen oder zur Leitung einer kollektiven Intervention prädestinierten Macht, jede Bereitschaft zu interventionistischen Abenteuern. Schon im Frühjahr 1933 hatten die Pariser Politiker auf einen polnischen Vorschlag, der Herrschaft Hitlers durch einen Präventivkrieg den Garaus zu machen, mit kühler Ablehnung reagiert ${ }^{73}$. Zwar hat damals in Frankreich noch niemand an der eigenen militärischen Überlegenheit und Aktionsfähigkeit gezweifelt. Doch machte sich in Paris die Erinnerung an den Einfall ins Ruhrgebiet bemerkbar. 1923 war keines der französischen Ziele erreicht worden, vielmehr hatte das Vorgehen Frankreichs bis zum ebenso unvermeidlichen wie unrühmlichen Abbruch des Unternehmens den deutschen Nationalismus gekräftigt, ein wirtschaftliches und politisches Chaos in Europa angerichtet und Paris in ernste Zerwürfnisse selbst mit den Verbündeten verwickelt. Welche Wirkung mußte erst eine Politik der periodischen Okkupationen haben! Alle französischen Politiker waren mittlerweile zu der Einsicht gekommen, daß die zentrale und stärkste europäische Großmacht nicht mit den Rezepten Poincarés behandelt werden durfte und daß Europa eine solchermaßen ausgeübte Hegemonie Frankreichs auch nicht hinnehmen konnte.

So hat die französische Regierung lediglich bündnispolitische Anstrengungen unternommen, um ein aufgerüstetes und angesichts der nationalsozialistischen Herrschaft doppelt bedrohliches Deutschland mit einer derart starken Koalition zu konfrontieren, daß Hitler am Ende auf den Gebrauch des fertigen Instruments verzichten mußte. Seit Ende 1933 und besonders seit Anfang 1934, nachdem am 9. Februar der energische Louis Barthou im Kabinett Doumergue das Außenministerium übernommen hatte, arbeitete

73 H. Roos, Die „Präventivkriegsplāne“ Pilsudskis von 1933, in: VfZ 3 (1955), S. 344-363. Dazu aber M. Wojciechowski, Die polnisch-deutschen Beziehungen 1933-1938, Leiden 1971. 
die französische Diplomatie intensiv daran, zunächst einmal die inzwischen gelockerten Fäden des französischen Allianzsystems wieder fester zu knüpfen. In der Tat ist es Barthou gelungen, Frankreichs Verhältnis zur Kleinen Entente zu beleben und dem im Februar 1934 abgeschlossenen Balkanpakt, dem Griechenland, die Türkei und mit Rumänien und Jugoslawien auch zwei Mitglieder der Kleinen Entente angehörten, eine gewisse politische Bedeutung zu verleihen. Jedoch gab sich Barthou keiner Täuschung hin: Derartige Regionalpakte mochten gut genug sein, den Status quo gegen den regionalen Revisionismus potentieller Bundesgenossen Deutschlands, nämlich Ungarns und Bulgariens, zu sichern; eine Front zur Abschreckung Deutschlands bedurfte der Ergänzung durch stärkere Partner. Daher hat das französische Außenministerium sowohl unter Barthou wie anfänglich unter seinem Nachfolger Pierre Laval - Barthou fiel am 8. Oktober 1934 in Marseille dem Attentat auf König Alexander von Jugoslawien zum Opfer - zielbewußt die Erneuerung der kompletten Kriegskoalition gegen Deutschland angestrebt, d.h. die Gewinnung Rußlands und Italiens. Hitler hat das französische Werben in Moskau und Rom unfreiwillig begünstigt, als er sich, bei aller anfänglichen Vorsicht, noch während der ersten Aufrüstungsphase zu einer antirussischen Politik gezwungen sah und sich außerdem zur Verstimmung Italiens verleiten ließ. Das Ende der langjährigen Freundschaft zwischen Bolschewiki und deutschnationalen Revisionisten hing einmal mit der innenpolitischen Rolle Hitlers zusammen. Er hatte die Macht nicht zuletzt als Retter der deutschen Gesellschaft vor dem Kommunismus beansprucht und erhalten. Namentlich die in der Partei und in der SA dominierende klein- und mittelbürgerliche Anhängerschaft hätte es - und das gilt auch für die Landwirte - nicht verstanden, wenn der „Führer" gleich nach der Machtübernahme und ohne erkennbare Not die ideologische und die in tausend Saal- und Straßenschlachten brutal ausgefochtene politische Feindschaft ignoriert und eine außenpolitische Verständigung mit der kommunistischen Vormacht gesucht hätte. In dieser Anfangsperiode seiner Herrschaft mußte Hitler auf solche Stimmungen noch Rücksicht nehmen. Dazu paßte eine Abkühlung der Beziehungen zu dem künftigen Angriffsobjekt auch in seine außenpolitische Taktik. Je überzeugender er den Part des Antikommunisten und des europäischen Markgrafen gegen die Sowjetunion spielte, um so leichter mußte nach seiner Meinung die gewünschte Annäherung an das ebenfalls sowjetfeindliche Großbritannien fallen. So zeigte er Moskau in außenpolitischen Fragen eine kühle Schulter, der Handel mit der Sowjetunion ging zurück, und im Laufe des Jahres 1933 schlief auch die militärische Zusammenarbeit zwischen Reichswehr und Roter Armee ein 74 . In Moskau wiederum waren die ruß-

${ }^{74}$ F. A. Krummacher / H. Lange, Krieg und Frieden. Geschichte der deutsch-sowjetischen Beziehungen. Von Brest-Litowsk zum Unternehmen Barbarossa, München 1970; E. H. Carr, Berlin-Moskau. Deutschland und Rußland zwischen den beiden Weltkriegen, Stuttgart 1954. 
landfeindlichen und antibolschewistischen Schriften und Reden der nationalsozialistischen Führer aufmerksam studiert worden. Offenbar regierten in Berlin jetzt Männer, die nicht mehr, wie die Politiker der Weimarer Republik, auf Polen starrten, sondern ihre Blicke auf sowjetisches Territorium richteten. So glaubte auch Stalin, der rote Diktator im Kreml, freundschaftliche Kooperation mit wachsamer Zurückhaltung vertauschen zu müssen. Hitlers ostentative Feindseligkeit, begleitet von rüdester und giftigster antisowjetischer Propaganda, konnte das Mißtrauen Stalins nur verstärken. Nach kurzer Zeit durfte der deutsch-sowjetische Gegensatz als eine feste Größe der europäischen Politik betrachtet werden.

Gleichzeitig gab Hitler der Versuchung nach, in Österreich aktiv zu werden, wo eine relativ starke NSDAP existierte, die organisatorisch mit der reichsdeutschen Partei verbunden war und Hitler unterstand. Zwar scheint Hitler damals noch nicht an eine staatsrechtliche Vereinigung Österreichs mit Deutschland gedacht zu haben ${ }^{75}$. Aber der Gedanke, die vom deutschen Reichskanzler dirigierte österreichische Oppositionspartei in Wien in den Sattel zu setzen und auf diese Weise Österreich ohne Beseitigung der Grenzen gleichzuschalten, lag doch sehr nahe. Einige Zeit scheinen sowohl Hitler wie die Führer der österreichischen NSDAP den Sturz des Wiener Dollfuß-Regimes für ein fast ebenso unproblematisches Unternehmen gehalten zu haben wie das im Frühjahr 1933 inszenierte Verjagen der Regierungen in den nichtpreußischen Ländern Deutschlands, und Hitler hat anscheinend wirklich geglaubt, mit einer solchen Gleichschaltung internationale Widerstände gegen eine reichsdeutsche Beherrschung Österreichs unterlaufen zu können. An der energischen Abwehr des Wiener Kabinetts, das die NSDAP am 19. Juni 1933 verbot, zersplitterte allerdings der Akt der Machtergreifung in einzelne terroristische Aktionen, und die österreichische NSDAP sah sich nun in ein zähes Ringen verstrickt, das vorerst keine Aussicht auf Erfolg hatte und das überdies den an der österreichischen Unabhängigkeit interessierten Staaten Zeit zum Eingreifen bot. Der Versuch, einen verschleierten Anschluß zu erreichen, rief vor allem Italien auf den Plan. Zwar hatte sich Mussolini schon mehrmals zum Anwalt des deutschen Anspruchs auf militärische Gleichberechtigung gemacht und immer häufiger die politische Zusammenarbeit mit Deutschland gesucht. Anfang Juni 1933 gab er Goebbels, der nach Rom gekommen war, als Richtschnur für die Außenpolitik des NS-Regimes die Parole: „Nur nie Ruhe!" und er fügte hinzu: „Sagen Sie Hitler, daß er sich auf mich verlassen kann. Ich gehe mit ihm durch dick und dünn."76 Aber noch hatte der "Duce“ Momente, in denen ihm der „Führer“ als „falscher Nachahmer“ und "gefährlicher Träumer" erschien, dem Realismus und Vorsicht fehlten.

75 D. Ross, Hitler und Dollfuß. Die deutsche Österreich-Politik 1933-1934, Hamburg 1966; J. Gehl, Austria, Germany and the Anschluß 1931-1938, London 1963.

76 Tagebücher von Joseph Goebbels, Bd. 2, S. 426. 
Die antisemitisch-rassistischen Marotten Hitlers und der übrigen Nazis, die da die naturgegebene Überlegenheit einer nordischen Rasse behaupteten, empfand der Italiener ohnehin als ebenso beleidigend wie grotesk und gefährlich. Vor allem hatte Mussolini jedoch keine Lust, Hitler mit der Gleichschaltung Österreichs einen billigen Triumph und konkreten Machtgewinn zu erlauben, solange Italien von Deutschland noch keine angemessene Gegenleistung brauchte und das Reich zu einer derartigen Leistung auch noch gar nicht in der Lage war, zumal Österreich - im Hinblick auf die Sicherung der Brennergrenze - anerkanntermaßen italienisches Interessengebiet darstellte und folglich ein deutscher Erfolg in Wien mit einer diplomatischen Niederlage Italiens gleichgesetzt werden mußte. Im übrigen wollte Mussolini der deutschen Aggressivität den Weg in den Donauraum und auf den Balkan wenigstens so lange wie möglich verlegen; der römische Imperialismus reklamierte dort ja für sich selbst Einflußzonen. So hat der Duce Ende Juli 1933 Hitler mit der Intervention Italiens - und der Westmächte - gedroht und danach das enge Einvernehmen zwischen Rom und Wien bei jeder Gelegenheit betont. Am 17. März 1934 unterzeichneten Mussolini, Dollfuß und der ungarische Ministerpräsident Julius Gömbös die „Römischen Protokolle“, in denen sich die drei Staaten zur politischen Konsultation und zur wirtschaftlichen Vorzugsbehandlung verpflichteten. Die politische Bedeutung der "Protokolle“ lag aber in erster Linie darin, daß sich Italien mit ihnen öffentlich als Schutzmacht Österreichs engagierte und damit Deutschland vor einer Fortsetzung des österreichischen Abenteuers ausdrücklich warnte 77 .

Am 14. und 15. Juni trafen die beiden Diktatoren in Venedig erstmals persönlich zusammen, aber die Begegnung hat weder Mussolinis Urteil über Hitler noch die italienische Österreichpolitik modifiziert. Hitler mußte sich in der österreichischen Frage auf eine gewisse Wartefrist einrichten und von der revolutionären Gleichschaltung auf eine mehr evolutionäre Politik umschalten. Da er jedoch aus innenpolitischen und innerparteilichen Gründen seine Schwäche nicht offen zugeben wollte - gerade entschied sich das Problem mit Ernst Röhm und der SA -, zeigte er seinen österreichischen Gefolgsleuten nun eine vieldeutig-passive Haltung, die nicht recht begriffen und von einigen Heißspornen sogar als Ermunterung zu einem Putschversuch mißverstanden wurde. Der Putsch scheiterte kläglich, führte aber am 25. Juli 1934 zur Ermordung von Bundeskanzler Dollfuß. Mussolini rechnete nach den Eindrücken, die er in Venedig gewonnen hatte, nicht mehr mit einer offenen deutschen Einmischung in Österreich, doch benutzte er die Gelegenheit trotzdem zu einer dramatischen Demonstration und beorderte etliche italienische Divisionen an Italiens Nord-

77 E. di Nolfo, Mussolini e la politica estera italiana 1919-1933, Padua 1960; J. Petersen, Hitler-Mussolini. Die Entstehung der Achse Berlin-Rom 1933-1936, Tübingen 1973. 
grenze. Die deutsch-italienischen Béziehungen hatten offenbar einen Tiefpunkt erreicht.

Unter diesen Umständen war es unvermeidlich, daß Rußland und Italien auf die französischen Avancen einzugehen und sich Frankreichs Versuchen zur „Einkreisung“ Deutschlands anzuschließen schienen. Die Sowjetunion setzte jetzt eine Politik fort, die, von der japanischen Aggression im Fernen Osten angestoßen, nach einer Entlastung der sowjetischen Westgrenzen strebte und bereits vor 1933 zur Normalisierung der Beziehungen zu den westlichen Nachbarn, Ende November 1932 auch zu einem Nichtangriffspakt mit Frankreich geführt hatte. Angesichts eines nationalsozialistischen Deutschland konnte die gewünschte Entlastung offenbar nur mehr mit einem verstärkten - diplomatischen - Engagement erreicht werden. In der zweiten Hälfte des Jahres 1933 schlug der sowjetische Außenminister Litwinow ein russisch-französisches Bündnis vor, und nachdem Barthou das französische Außenministerium übernommen hatte, wurden bald Fortschritte erzielt. Die anfänglichen Bemühungen Barthous und Litwinows, eine französisch-sowjetische Allianz mit regionalen Garantiepakten aller osteuropäischen Staaten und aller Mittelmeerländer zu koppeln oder in derartigen Pakten zu verstecken, blieben fruchtlos, und so kehrten beide zum Gedanken der offenen Allianz zurück. Am 18. September 1934 trat die Sowjetunion, um eine Bedingung zu erfüllen, die Frankreich auf Grund seiner sonstigen internationalen Verpflichtungen stellen mußte, sogar in den verachteten Völkerbund ein, und der Weg zum formellen Bündnis war frei. Gleichzeitig kam eine französisch-italienische Annäherung zustande. Anfang 1935 fuhr Barthous Nachfolger Laval nach Rom und vereinbarte ein koordiniertes militärisches Vorgehen, falls Deutschland die Unabhängigkeit Österreichs antasten oder eine Remilitarisierung des Rheinlands wagen sollte. Wenig später schien Frankreichs Einkreisungspolitik auf ihrem Höhepunkt angelangt. Nachdem Hitler im März 1935 die Wiedereinführung der allgemeinen Wehrpflicht verkündet und die Aufstellung einer starken Armee befohlen hatte, konterten Frankreich, Italien und Großbritannien mit einer am 14. April 1935 in Stresa formulierten „Entschließung“, in der sie ihre Entschlossenheit bekräftigten, die Unabhängigkeit Österreichs zu schützen und das Rheinland entmilitarisiert zu halten. Am 2. Mai 1935 folgte der Abschluß der französisch-sowjetischen Allianz, die dem Anschein nach Osteuropa mit der „Front von Stresa“ verknüpfte, zumal sich am 16. Mai die Unterzeichnung eines sowjetisch-tschechoslowakischen Beistandspakts anschloß, der allerdings an den französisch-tschechoslowakischen Bündnisfall gebunden wurde.

So hatte also Hitlers Außenpolitik, die den Revisionismus seiner Vorgänger mit der Ankündigung eines nationalsozialistischen Expansionismus mischte, das Deutsche Reich anscheinend in eine zumindest höchst unbequeme Isolierung gesteuert. Die tatsächliche Lage war für Berlin indes weniger düster. Schon die diversen Vertragssysteme, die im gemeinsamen Be- 
zugspunkt Paris scheinbar ein Zentrum und sogar eine Zentrale erhalten hatten, zeigten Schwächen, die sie selbst für einen defensiven Zweck - und sie waren defensiv gedacht - untauglich machten. Die französisch-sowjetische Allianz etwa war in Wirklichkeit eine leere Geste. Paris und Moskau waren ja nur dann zu politischer und militärischer Zusammenarbeit fähig, wenn Frankreichs ost- und südosteuropäische Bundesgenossen ebenfalls in ein Bündnisverhältnis zur Sowjetunion traten. Von der Tschechoslowakei abgesehen, die Deutschland mehr fürchtete als die Sowjetunion, ließen sich jedoch die französischen Klientelstaaten nicht zu einem solchen Schritt bewegen. Im Gegenteil! Der von Frankreich patronisierte Balkanpakt richtete sich nach den Intentionen seiner Mitglieder nicht zuletzt gegen die UdSSR, und Polen versagte sich jeder Abmachung, die für Warschau die Möglichkeit heraufbeschwor, eine als gefährlich empfundene russische Hilfe annehmen zu müssen. Die als Ergebnis des Krieges eingetretene Veränderung der politischen Geographie Europas erwies sich als unüberwindliches Hindernis einer einfachen Restaurierung der antideutschen Kriegskoalition. Die Arbeit der Pariser Friedenskonferenz und die Bolschewisierung Rußlands hatten, wie sich nun herausstellte, die äußere Sicherheit Deutschlands merklich erhöht. Laval nahm denn auch, anders als Barthou, das Bündnis mit Moskau, das er als Geste gegen Hitlers Rüstungspolitik selbst abgeschlossen hatte, nie ernst. In erster Linie benutzte er die Allianz als Instrument seiner Innenpolitik, nämlich zur Zähmung der moskaufreundlichen französischen Linken, während er ihren außenpolitischen Wert vornehmlich von ihrer Brauchbarkeit als Tauschobjekt erblickte: für Frankreichs Verzicht auf das Bündnis mochte Berlin zu einer Gegenleistung bereit sein. Laval machte kein Hehl daraus, daß er eine direkte Verständigung mit Deutschland anstrebte. Ein solches Ziel nötigte ihn zur Schonung der Gefühle Hitlers, und so hütete er sich geradezu davor, Frankreichs östlichen Bündnissen politische Effektivität zu geben. Statt in Warschau und Bukarest auf eine Annäherung an die Sowjetunion zu dringen, verbot er auch noch den Tschechoslowaken jede militärische Kooperation mit Rußland, die in Berlin Mißfallen erregt hätte. Während er offiziell an der traditionellen Pariser Bündnispolitik festhielt, schwenkte er unter der Oberfläche auf einen Kurs ein, der, wenn er nicht revidiert wurde, nur mit Frankreichs Rückzug aus Osteuropa enden konnte ${ }^{78}$.

Das französisch-italienische Verhältnis wiederum blieb stets durch die Tatsache belastet, daß Frankreich und Italien als die dominierenden Mächte zweier verfeindeter Staatengruppierungen auftraten. War Mussolinis Intensivierung der italienisch-österreichisch-ungarischen Zusammenarbeit einerseits gewiß als diplomatisches Manöver gegen Deutschland gemeint, so richtete sie sich faktisch doch zugleich gegen Jugoslawien und 
Rumänien, also gegen die von Frankreich dirigierte Kleine Entente. Selbst im Hinblick auf Deutschland und Österreich durfte die Interessengemeinschaft zwischen Rom und Paris nicht als sicherer Faktor betrachtet werden. Im Frühjahr 1933 hatte Mussolini einen Viermächtepakt zwischen Großbritannien, Frankreich, Italien und Deutschland vorgeschlagen, der Europa dem Diktat dieser vier Großmächte unterwerfen und zugleich die Tür zu einer großzügigen Revision des Status quo aufstoßen sollte. $Z$ war hatte die französische Regierung den Pakt durch eine geschickte Anpassung des Vertragstextes an die Satzung des Völkerbunds elegant entwertet, und Mussolini gab sich schließlich mit dieser französischen Fassung zufrieden, die am 15. Juli 1933 in Rom von den Vertretern der vier Staaten unterschrieben wurde; Hitler nahm den Viererpakt ohnehin lediglich als eine Geste, die, als erster internationaler Vertrag des nationalsozialistischen Deutschland, mithalf, dem NS-Regime in der gefährlichen Anfangsphase "Ruhe und Luft" zu verschaffen79. Aber wenn der Viermächtepakt auch keine praktische politische Bedeutung erlangte, so hatte die Episode doch gelehrt, daß Mussolini nach wie vor darauf brannte, im Interesse des faschistischen Imperialismus die Reste der kollektiven Sicherheit zu liquidieren, und daß er nach wie vor auf dem Sprung stand, seinen eigenen Imperialismus mit deutschem Expansionismus zu koordinieren, sofern sich die deutsche Aggressivität Ziele außerhalb der italienischen Interessenzonen wählte. Bald sollte sich außerdem herausstellen, daß gerade die demonstrative Protektion Österreichs mitnichten der Erhaltung des Status quo, sondern ganz im Gegenteil der Förderung des faschistischen Imperialismus galt. Vom japanischen Beispiel und vom offenkundigen Verfall der kollektiven Sicherheit ermuntert, begann nämlich Mussolini, wobei er ältere koloniale Ambitionen Italiens aufgriff, afrikanische Eroberungspläne zu schmieden, und er glaubte, durch seine Haltung in der österreichischen Frage könne er Frankreich und Großbritannien so sehr verpflichten, daß beide Mächte italienischen Aktionen in Afrika, d.h. gegen Äthiopien, nichts in den Weg legen würden. Sollte diese taktische Funktion seiner Österreichpolitik überflüssig werden, entweder durch die Erfüllung seiner Wünsche oder durch unerwartete Opposition der Westmächte, sollte er andererseits für neue Pläne oder gegen die Westmächte den Beistand Deutschlands brauchen, konnte es ihm durchaus einfallen, seinen Kurs radikal zu ändern und Österreich zu opfern.

Im übrigen schlugen in jenen frühen Stadien der Hitlerschen Außenpolitik ausgerechnet die bereits aufgedeckten spezifisch nationalsozialistischen Elemente eine erste Bresche in das französische Allianzsystem. Waren die Warschauer Politiker nach der französischen Ablehnung von Pilsudskis Präventivkriegsplänen recht enttäuscht und plötzlich von Zweifeln an der Bündnistreue Frankreichs befallen, so bemerkten sie andererseits

79 Tagebücher von Joseph Goebbels, Bd. 2, S. 430. 
bald, daß der nationalsozialistische Reichskanzler in Berlin von der Polenfeindschaft weitgehend unabhängig war, wie sie der preußisch bestimmte deutsche Nationalismus pflegte, daß er die preußische Vorliebe für eine stets antipolnische - Allianz mit Rußland nicht teilte, sondern von der Eroberung russischen Territoriums träumte. Sie wußten gut genug, daß die polnische Unabhängigkeit ebenfalls verlorengehen mußte, wenn Hitler sich tatsächlich russisches Territorium aneignete. Doch hielten die polnischen Politiker das nationalsozialistische Eroberungsprogramm eben nur für einen Traum, während sie die sofortige diplomatisch-politische Konsequenz des Traums, die Entfremdung zwischen Deutschland und Rußland, als eine für Polen sehr nützliche und unmittelbar auswertbare Realität registrierten. So setzte sich in Warschau allmählich die Auffassung durch, daß erstmals seit 1919 eine direkte deutsch-polnische Verständigung möglich sei und gesucht werden müsse ${ }^{80}$. Hitler kam Polen bereitwillig entgegen. Das brachte ihm zwar die verständnislose und herbe Kritik deutschnationaler und preußisch-konservativer Kreise ein, die sich, mit Recht von der Notwendigkeit eines Minimums an Geschäftsmoral in den zwischenstaatlichen Beziehungen überzeugt, die totale Skrupellosigkeit Hitlers im Umgang mit feierlich beschworenen internationalen Vereinbarungen noch nicht vorzustellen vermochten und daher die Annäherung an Polen ganz ernsthaft als Verzicht auf wichtigste Forderungen des deutschen Revisionismus verstanden. Aber Hitler ließ sich die Chance nicht entgehen, zur Abschirmung der Aufrüstung Deutschlands als friedfertiger Antirevisionist dazustehen und dabei zugleich die Verbindung zwischen Warschau und Paris anzusägen, vielleicht schon Polens Eingliederung in den deutschen Machtbereich anzubahnen.

Am 26. Januar 1934 wurde in Berlin ein deutsch-polnischer Nichtangriffsvertrag unterzeichnet, der den beiden Staaten die Verpflichtung auferlegte, sich mindestens zehn Jahre lang ,in den ihre gegenseitigen Beziehungen betreffenden Fragen, welcher Art sie auch sein mögen, unmittelbar zu verständigen“ und bei Streitfragen „unter keinen Umständen ... zur Anwendung von Gewalt zu schreiten". Etliche polnische Politiker glaubten tatsächlich, die deutsche Anerkennung des Status quo erhalten und Polens Westgrenze gesichert zu haben, doch blieb bei vielen Mißtrauen lebendig, und Pilsudski selbst sprach zweifelnd von „ungesunden Romanzen mit den Deutschen“, die wohl doch kein gutes Ende finden könnten ${ }^{81}$. In der Tat hatte die polnische Regierung lediglich das polnisch-französische Bündnis halb entwertet und die französisch-sowjetische Allianz, an der sie sich jetzt ebensowenig beteiligen durfte wie an anderen antideutschen Kombinationen, von Anfang an zur Ineffektivität verurteilt. Nebenbei hatten die Warschauer Politiker auch noch das Verhältnis zwischen Paris und Prag be-

${ }^{80} \mathrm{Vgl}$. Wojciechowski, Die polnisch-deutschen Beziehungen.

81 Jozef Beck an Boleslaw Wieniawa-Dlugoszewski, AAN Warschau, 24, R. 306-309. 
schädigt, da nun fraglich wurde, ob die Tschechoslowakei ein militärisches Vorgehen gegen Deutschland - etwa bei einer Remilitarisierung des Rheinlands oder bei einem Anschluß Österreichs - aktiv unterstützen konnte, wenn sie nicht im Norden durch die Mitwirkung Polens gedeckt war. Kein Wunder, daß Goebbels den polnischen Außenminister Oberst Jozef Beck als „klugen Kopf“ bezeichnete und die deutsch-polnische Verständigung als „einen ruhenden Pol in den fließenden Erscheinungen der Weltpolitik" 82 .

Vor allem aber hätte jede Mächtegruppierung, die dazu bestimmt war, Hitler in Schach zu halten, der führenden Teilnahme Großbritanniens bedurft, und in London war niemand zu einer solchen Teilnahme bereit. Naturgemäß begegneten Hitler und das nationalsozialistische Deutschland gerade auch in England stärkstem Mißtrauen und einer aus Widerwillen und Verachtung gemischten Abneigung. Mit Recht konstatierte Churchill am 23. Juli 1936, daß lediglich etliche Angehörige der „smart society“, ein paar reiche Finanziers und sonstige Elemente, die zur Niederhaltung der Arbeiterklasse mit der Idee eines starken Staates liebäugelten, Verständnis für das NS-System aufbrächten, während dieses System einem Labour-Mann als ebenso unerträglich erscheine wie „dem durchschnittlichen britischen

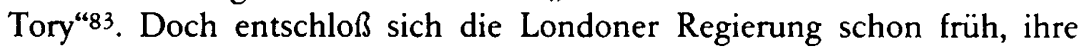
Deutschlandpolitik nicht auf ihr Mißtrauen zu gründen und das oft taktlose und arrogante Gehabe der neuen deutschen Machthaber zu ignorieren. Dem britischen Pragmatismus fiel es schwer, den Reichskanzler Hitler als den Verfasser der in "Mein Kamp“" zu Papier gebrachten - und von den britischen Politikern und Diplomaten sehr wohl aufmerksam studierten ausschweifenden Pläne zu behandeln. Auch scheute man in London die Konsequenz, die sich aufdrängte, wenn man Hitlers Buch als Leitfaden der Außenpolitik des nationalsozialistischen Deutschland verstand: den Präventivkrieg. Die öffentliche Meinung, die jede kriegerische Verwicklung noch kategorisch ablehnte, hätte einen Präventivkrieg gar nicht zugelassen; sie widersetzte sich ja sogar jener zusätzlichen Rüstungsanstrengung, wie sie die britische Regierung für notwendig hielt, wenn sich Großbritannien an einer Koalition beteiligen sollte, die einen Krieg mit Deutschland immerhin in den Bereich des Möglichen rückte. Ferner galten in London noch immer die Grundsätze Lloyd Georges und Sir Austen Chamberlains, nach denen eine britische Verpflichtung zugunsten ost- und südosteuropäischer Grenzen nicht von entsprechenden britischen Interessen gedeckt und daher unerwünscht sei. Solange im übrigen die deutsche Ostexpansion lediglich eine in ferner Zukunft liegende Eventualität zu sein schien, die außerdem vermutlich der Verwirklichung nie näher kommen konnte, dünkte es dem einen oder anderen britischen Politiker sogar eine nützliche Sache, wenn sich die in Deutschland offenbar vorhandene Aggressivität 82 Tagebücher von Joseph Goebbels, Bd. 2, S. 490.

83 Gilbert, Churchill, V, S. 768. 
nach Osten entlud und wenigstens Westeuropa verschonte. Am 29. Juli 1936 sagte Stanley Baldwin, ein Jahr zuvor Premierminister geworden, zu einer Abordnung konservativer Parlamentarier, die von der Regierung eine stärkere Beachtung der wachsenden deutschen Gefahr forderte, es werde ihm "nicht das Herz brechen“, wenn sich Hitler "nach Osten wenden“ sollte. Die erhabene Ignoranz, die so manchen britischen Politiker in nichtinsularen und außenpolitischen Angelegenheiten auszeichnete, ließ den Premier sogar hinzufügen, daß doch wohl niemand in der Abordnung meine, Großbritannien sei zur Unterstützung Frankreichs verpflichtet, sollten die Franzosen im Falle eines deutsch-russischen Kriegs auf der Seite Rußlands intervenieren, ,dank dieses schrecklichen Pakts, den sie abgeschlossen haben“! „Wenn in Europa schon gekämpft werden muß, dann möchte ich doch gerne, daß das Kämpfen von den Bolschis und Nazis besorgt wird." ${ }^{84}$

In solcher Lage blieb als einzige Alternative die Fortsetzung der traditionellen Appeasement-Politik. Konkret hieß das jetzt: daß sich London mit der deutschen Aufrüstung abfand, daß sich England von allen französischen Einkreisungsversuchen fernhielt, was mit lauten Bekenntnissen zur kollektiven Sicherheit wie mit den unverbindlichen Unterschriften unter Dreimächte-Deklarationen zur österreichischen Frage kaschiert werden sollte, und daß die britische Regierung jede Gelegenheit zu separaten Abmachungen mit Hitler wahrnahm, zu Abmachungen, die zwar Konzessionen kosten, den deutschen Diktator jedoch binden und domestizieren mochten. So hat das britische Kabinett, während die deutsche Aufrüstung bereits auf vollen Touren lief, mit Berlin hartnäckig über partielle Vereinbarungen, etwa einen Luftpakt, verhandelt und damit der bündnispolitischen Aktivität Frankreichs viel von ihrer Gefährlichkeit für Hitler genommen. Am 18. Juni 1935 kam dann der deutsch-britische Flottenvertrag zustande, der Deutschland eine Hochseeflotte zubilligte, die 35 Prozent der gesamten Commonwealth-Flotte erreichen durfte (bei U-Booten sogar 100 Prozent). Mit diesem Vertrag, der Hitler gar nichts kostete, weil er vorerst an ein gröBeres maritimes Rüstungsprogramm weder dachte noch denken konnte, hatte die britische Regierung nicht allein die vertragswidrige bisherige Aufrüstung Deutschlands - einschließlich der Einführung der allgemeinen Wehrpflicht - nachträglich gesegnet und ihrerseits den Versailler Vertrag gebrochen, sondern überdies die Beteiligung Englands an der kurz zuvor in Stresa formulierten Politik öffentlich desavouiert und der „Front von Stresa" damit die politische Seriosität weitgehend genommen. Hitler aber, dem im Januar 1935 gerade der Versailler Vertrag einen psychologisch wie politisch wertvollen Erfolg beschert hatte, als das Saarland nach der im Vertrag vorgesehenen Volksabstimmung wieder Reichsgebiet geworden war, Hitler durfte sich sagen, daß das Gespenst der Isolierung endgültig gebannt 
war, und er sagte sich ferner, daß er jene Verständigung mit Großbritannien, die ihm eines Tages freie Hand im Osten geben würde, nun eingeleitet habe.

\section{Die Formierung der expansionistischen Mächte}

Trotzdem herrschte in Berlin noch immer Unsicherheit. Ob sich der Völkerbund nicht doch zu wirksamer Aktivität aufraffte, wenn eine europäische Macht das Gleichgewicht in Eurpa gefährden sollte, ob die Pariser Bündnisse nicht doch funktionierten, wenn einer der Partner Frankreichs tatsächlich in Bedrängnis geraten oder gar die französische Sicherheit unmittelbar bedroht sein sollte, wußte niemand mit Bestimmtheit zu sagen; beide Fälle waren noch nicht getestet worden. Die Erinnerung an die militärische Leistung der Westmächte während des großen Krieges saß noch fest im Gedächtnis der deutschen Führer, ebenso die harte französische Nachkriegspolitik und die stets gegebene Funktionsfähigkeit der nach wie vor bestehenden britisch-französischen Entente. Daß Großbritannien und Frankreich größere Abenteuer des faschistischen Italien bislang unterbunden hatten, mahnte ebenfalls zur Vorsicht. Im Grunde war die konkrete außenpolitische Lage Deutschlands Mitte 1935 noch immer so beengt, daß ein Durchbruch zu expansionistischer Politik fast unmöglich schien. Zwar wuchs die militärische Stärke Deutschlands von Monat zu Monat, und eine auch an außenpolitischen Gesichtspunkten orientierte Handelspolitik sorgte dafür, daß der deutsche Einfluß auf dem Balkan ständig zunahm und dort - auch in den Staaten der Kleinen Entente - mit dem französischen Einfluß zu konkurrieren begann, zumal die französischen Versuche, das kommunistische Rußland wieder ins europäische Kräftespiel zu ziehen, bei der Kleinen Entente beunruhigend wirkten; in Ansätzen verrieten die autoritären Balkanregime außerdem das Bedürfnis, sich ideologisch und gesellschaftspolitisch an Deutschland anzulehnen. Aber noch war die Vereinbarung von Locarno in Kraft, die Berlin zur Entmilitarisierung des Rheinlands verpflichtete, und solange Deutschland im Rheinland weder Truppen stationieren noch Befestigungen bauen durfte, konnte Frankreich aggressive Aktionen des Deutschen Reiches sofort mit der Besetzung deutschen Territoriums und mit einem praktisch nicht zu bremsenden Feldzug beantworten. Wie dieser Zustand geändert werden sollte, war nicht recht zu sehen. Solange Italien mit Frankreich in der österreichischen Frage liiert war, mußte angenommen werden, daß es auch seine Rolle als Garantiemacht von Locarno ernst nahm, und im Mai 1935 hatte sich Hitler selbst, um die internationale Erregung über die Einführung der allgemeinen Wehrpflicht zu dämpfen, dazu hinreißen lassen, in öffentlicher Rede feierlich die Respektierung von Locarno zu versprechen. Im übrigen hatte er Großbritan- 
nien und Polen wohl von einem eindeutig antideutschen Kurs weggelockt, aber mitnichten für seine Politik gewonnen. Die britische Regierung gab durch nichts zu erkennen, daß sie bereit sei, im Sinne der Hitlerschen Konzeption als Spießgesellin deutscher Expansionspläne zu fungieren, und in Warschau waren Andeutungen, daß man gemeinsam gegen die Sowjetunion vorgehen könne, ohne Echo geblieben.

Erst zwei Ereignisse, zu denen es ganz ohne deutsches Zutun kam, brachten dann plötzlich alle dem nationalsozialistischen Deutschland günstigen Tendenzen voll zur Geltung und öffneten Hitler eine Gasse, die ihm doch den Ausbruch aus dem diplomatischen Stellungskrieg, in dem er feststeckte, erlaubte: der Angriff Mussolinis auf Abessinien und der Bürgerkrieg in Spanien.

Als sich im Laufe des Jahres 1935 immer klarer abzeichnete, daß Mussolini, von der Straflosigkeit des japanischen Angriffs auf China ermuntert und auf Grund der Funktion Italiens in der gegen Hitler gerichteten diplomatischen Front von der Passivität der Westmächte überzeugt, tatsächlich mit der Errichtung eines faschistischen Imperiums beginnen werde, und zwar durch die Annexion des afrikanischen Kaiserreichs Abessinien, breitete sich denn auch in Berlin alsbald Erleichterung und frohe Erwartung aus. Hitler rechnete, anders als Mussolini, durchaus mit einer harten Reaktion Frankreichs und namentlich Großbritanniens, und daß im Konflikt Italiens mit den Westmächten eine große Chance für seine Pläne lag, erkannte er sofort. Bereits im August 1935 notierte Goebbels in seinem Tagebuch: „Nun wird Krieg in Abessinien unvermeidlich sein. Der Führer ist glücklich." 85 Denn, so schrieb der Propagandaminister einige Wochen später: „Nur ordentlich streiten. Unterdeß streifen wir die Ketten ab." 86 In der Tat brachte der Duce, als er nach längerer politischer und militärischer Vorbereitung seine Armeen am 3. Oktober 1935 wirklich in Marsch setzte, die Dinge in Europa wieder in Bewegung, und zwar in eine Bewegung, die im Lauf weniger Monate die Kräfteverhältnisse völlig veränderte.

An sich bot Mussolinis Aktion die große Möglichkeit zu einer Renaissance der kollektiven Sicherheit und zu einem friedenssichernden Erfolg der Verteidiger des Status quo. Wenn Frankreich und England - Abessinien war ja Mitglied des Völkerbunds - sich auf die Genfer Prinzipien berufen und mit einer sowohl raschen wie energischen Intervention des Bunds unter ihrer Führung gedroht hätten, wie sie angesichts der zunächst eindeutig anti-italienischen Haltung fast aller europäischen Länder wohl zu erreichen gewesen wäre, dann wäre Mussolini wahrscheinlich rechtzeitig zurückgewichen, und hätte er sich halsstarrig gezeigt, wäre es kein Problem gewesen, ihn mit all den wirtschaftlichen und militärischen Mitteln, die das Genfer Verfahren vorsah, zum Rückzug zu zwingen. Solche Niederlagen

85 Tagebücher von Joseph Goebbels, Bd. 2, S. 504.

86 Ebenda, S. 510. 
des faschistischen Italien hätten ihren Eindruck auf Berlin bestimmt nicht verfehlt. Jedoch stellte sich heraus, daß Mussolinis Spekulation auf die Passivität der Westmächte nicht unbegründet war. Im Hinblick auf Hitler und das nationalsozialistische Deutschland rechnete die französische Regierung ihre Kooperation mit Italien inzwischen in der Tat zu den wichtigsten Elementen der Pariser Außenpolitik, und so beschloß sie, auch im abessinischen Konflikt alles zu vermeiden, „was die derzeitigen französisch-italienischen Beziehungen belasten oder trüben könnte ". ${ }^{87} \mathrm{Daß}$ man den europäischen Status quo und damit auch die europäische Stellung Frankreichs endgültig einem freien Spiel der Kräfte auslieferte, wenn man sich auf Grund einer bündnispolitischen Überlegung praktisch zum Komplicen eines europäischen Aggressors machte, blieb in Paris unberücksichtigt, obwohl die Unterstützung Italiens angesichts der seit langem notorischen Unzuverlässigkeit des Duce nicht das geringste über die künftige Bundesgenossenschaft Roms besagte. Wie so oft seit dem Weltkrieg ließ sich Frankreich von der Furcht vor Deutschland zu einer Politik verleiten, die sowohl der moralischen wie der taktischen Qualitäten ermangelte.

Die britische Regierung teilte die französische Auffassung, daß Italien nicht in die Arme Deutschlands getrieben werden dürfe, und ließ sich daher weitgehend auf die Pariser Linie ziehen. Andererseits dachten einflußreiche britische Politiker noch immer in den Kategorien der kollektiven Sicherheit, und auch die öffentliche Meinung forderte Maßnahmen gegen Mussolini. Daraus resultierte eine überaus seltsame Politik. Einerseits sollte der Duce mit drohenden Gesten von seinem Vorhaben abgebracht oder wenigstens zu einem Kompromiß genötigt werden, der London eine klare Option zwischen Rom und Genf ersparte. Auf der anderen Seite sollte jedoch jede Drohung von Beteuerungen der Freundschaft und von Bekundungen des Verständnisses für den italienischen Standpunkt begleitet werden. Ließ sich Mussolini dadurch aber nicht von seinem Ziel abdrängen, sollte die dann unvermeidliche Option für Genf in einer Form geschehen, die zwar der Völkerbundssatzung formal Genüge tat und die britische Öffentlichkeit zufriedenstellte, doch wiederum Mussolini keinen Anlaß zu einem Wechsel seiner politischen. Freundschaften gab. Schritte, die in die Nähe eines Krieges mit Italien führen mochten, schieden von vornherein aus ${ }^{88}$.

Auf Grund der französisch-britischen Haltung reagierte der Völkerbund auf den italienischen Angriff wohl mit Sanktionen, aber nur mit wirtschaftlichen Sanktionen relativ harmloser Art. Der Überfall auf ein Mitglied des Bundes wurde praktisch widerstandslos hingenommen, und Genf erlitt eine vernichtende Niederlage, die das Ende der politischen Funktion des Völ-

87 A. Eden, Earl of Avon, Angesichts der Diktatoren. Memoiren 1923-1938, Köln 1964, S. 279.

88 M. Funke, Sanktionen und Kanonen. Hitler, Mussolini und der internationale Abessinienkonflikt 1934/36, Düsseldorf 1970. 
kerbunds bedeutete. Als die Delegierten der Vollversammlung am 4. Juli 1936 die Einstellung der Sanktionen beschlossen, begruben sie auch den Gedanken der kollektiven Sicherheit: Europa trat unwiderruflich in eine neue Ära des internationalen Faustrechts ein. Einige Wochen vor dem Beginn des Feldzugs in Abessinien hatte Winston Churchill einer Bekannten, von der er auf einer privaten Gesellschaft gefragt worden war, warum ihn die - bereits klar erkennbaren - Pläne Mussolinis so besorgt stimmten, die Bedeutung des Vorgangs in wenigen Sätzen präzise erläutert:

"Wir haben uns bemüht, es den Nationen heutzutage, durch den Völkerbund und das ganze Geflecht des Völkerrechts, unmöglich zu machen, einander Unrecht zuzufügen. Indem er das Kaiserreich Äthiopien niederzuwerfen sucht, unternimmt Mussolini einen überaus gefährlichen und wahnwitzigen Angriff auf das ganze geschaffene Gebilde, und die Folgen eines solchen Angriffs sind noch gar nicht abzuschätzen. Wer vermag zu sagen, was daraus in einem Jahr, in zwei oder drei Jahren werden wird? Mit einem Deutschland, das in halsbrecherischem Tempo rüstet, mit einem England, das in einen pazifistischen Traum verloren ist, mit einem korrupten und im Innern zerrissenen Frankreich, mit einem distanzierten und indifferenten Amerika - Madame, meine Liebe, zittern Sie da nicht um Ihre Kinder?" 89

$\mathrm{Zu}$ allem Überfluß hatten sich die Westmächte mit der Opferung des Völkerbunds keineswegs die Freundschaft Italiens erkauft. Angesichts der wirtschaftlichen Schwächen Italiens und angesichts der militärischen Rückschläge, die das italienische Heer in der ersten Phase des Feldzugs hinnehmen mußte, hatten schon die harmlosen Sanktionen, die der Völkerbund tatsächlich verhängte, Mussolini in Schwierigkeiten gebracht. Er vergaß weder diese Schwierigkeiten noch die moralische Isolierung, in die er sich durch seine räuberische Politik selbst manövriert hatte, für die er aber die Opposition der Westmächte, so schwächlich und unernst sie gewesen war, verantwortlich machte. Als Paris, London und Genf endgültig vor Mussolini kapitulierten, da kapitulierten sie vor einem inzwischen gründlich verärgerten Duce. Außerdem war Mussolini nun überzeugt davon, daß jeder weitere Zug italienischer Eroberungspolitik auf die Gegnerschaft der Westmächte treffen werde, daß der Westen jedoch keinen stärkeren Widerstandswillen mehr besitze und zur Hinnahme neuer annexionistischer Aktionen gezwungen werden könne, sofern sich Italien mit einem starken Bundesgenossen liiere. Mussolini blickte also nun erst recht nach Deutschland, dem er schon während des abessinischen Abenteuers nähergerückt war.

Bereits im Januar 1936 unternahm er einen Schritt, der die außenpolitische Konstellation in Europa völlig veränderte. Er ließ die deutsche Regierung wissen, daß er seinen seit 1933 vertretenen Standpunkt in der österreichischen Frage revidiert habe: zwar sei er noch an der Erhaltung der for- 
mellen Selbständigkeit Österreichs interessiert, werde aber nichts dagegen einwenden, wenn Deutschland den Nachbarstaat in einen Satelliten verwandle. Am 11. Juli 1936 konnte Hitler mit der Wiener Regierung in der Tat ein Abkommen schließen, das die Konsequenz aus Mussolinis Schwenkung zog; Österreich mußte sich sowohl zu einer „deutschen“ Außenpolitik wie zur Beteiligung der österreichischen NSDAP an der Regierungsverantwortung verpflichten und war damit schon beinahe gleichgeschaltet. Zuvor hatte Mussolini praktisch bereits als Verbündeter Hitlers gehandelt, indem er dem deutschen Diktator bei der Liquidierung von Locarno und bei der Remilitarisierung des Rheinlands Flankenschutz gab ${ }^{90}$. Hitler hatte sich in den ersten Monaten des abessinischen Konflikts noch vorsichtig zurückgehalten. Die nationalsozialistischen Führer besaßen von den Motiven der französisch-britischen Italienpolitik nur eine verschwommene Vorstellung und glaubten daher zunächst - auch ihrer eigenen Denkungsart entsprechend - an eine von imperialen Interessen diktierte harte Reaktion vor allem Großbritanniens. So hat sich die Reichsregierung einem gegen Italien verhängten Waffenembargo sogleich angeschlossen und die deutschen Exporte nach Italien anfänglich gar nicht, später nicht wesentlich erhöht. Hitler hat in Genf sogar mitteilen lassen, daß sich Deutschland in diesem Sinne an der Sanktionspolitik des Völkerbunds beteilige. Jedoch begriff Hitler bald, daß Paris und London der italienischen Aktion nicht so energisch entgegentraten, wie er erwartet hatte. Als sich ihm dann auch noch Mussolini in der österreichischen Frage zu nähern begann, witterte er, daß sich im Schatten der abessinischen Krise plötzlich die langersehnte Chance zur Erledigung von Locarno und damit zum Ausbruch aus dem frustrierenden diplomatischen Stellungskrieg bot. So ging er jetzt auf die italienischen Avancen ein, und nach vorheriger Verständigung mit Mussolini erklärte er am 7. März 1936 den Vertrag von Locarno für erledigt und ließ rund 30 000 Mann in das bislang entmilitarisierte Rheinland einmarschieren - nicht ohne, aus Furcht vor einem westlichen Gegenschlag, seinen Vertragsbruch mit Versprechungen künftigen Wohlverhaltens und mit dem Hinweis auf die nun durchaus mögliche Rückkehr Deutschlands in den Völkerbund zu garnieren.

$\mathrm{Da}$ er - seiner oft langen strategischen und taktischen Argumentationstiraden ungeachtet - mehr instinktiv als kalkuliert handelte und sich von der jeweiligen Situation stets nur ein von seiner "Weltanschauung" und von seinem Charakter bestimmtes Zerrbild zu machen vermochte, hat Hitler den Einmarsch ins Rheinland damals wie später als sein riskantestes außenpolitisches Unternehmen angesehen. Ein Jahr später erzählte er beim Mittagessen im Kreise seiner Paladine, daß er die Rheinlandbesetzung beinahe

90 E. M. Robertson, Zur Wiederbesetzung des Rheinlandes 1936, in: VfZ 10 (1962), S. 178-205; ders., Hitler und die Sanktionen des Völkerbundes. Mussolini und die Besetzung des Rheinlands, in: VfZ 26 (1978), S. 237-264. 
noch im letzten Augenblick rückgängig gemacht hätte, als sich die Botschafter Frankreichs und Großbritanniens bei ihm anmeldeten; doch seien die Unterredungen mit André Francois-Poncet und Sir Eric Phipps dann ganz harmlos verlaufen ${ }^{91}$. In Wirklichkeit waren seine Besorgnisse völlig unbegründet. Die Westmächte hatten durch ihre eigene Italienpolitik in der abessinischen Krise und durch die neue Deutschlandpolitik des Duce sowohl die moralische wie die politische Basis verloren, die sie für ein Vorgehen gegen Deutschland gebraucht hätten. Sie mußten - wobei sich die verantwortlichen Politiker zusätzlich noch auf die in der Tat verbreitete Abneigung der öffentlichen Meinung gegen eine Intervention und erstmals auch auf noch keineswegs gegebene militärische Schwächen beriefen - Hitlers Vertragsbruch tatenlos hinnehmen, zumal die deutsche Sünde moralisch, rechtlich und namentlich in der Sache doch geringer wog als die so leicht bestrafte italienische Sünde; schließlich waren die deutschen Truppen nicht in ein anderes Land eingefallen, sondern lediglich, in einem immerhin verständlich erscheinenden Akt der Wiederherstellung von Souveränität, in deutsche Städte eingerückt.

Die Folgen der westlichen Passivität waren allerdings groß. Die französische Regierung hatte die Möglichkeit aus der Hand gegeben, bei östlichen Aggressionen Deutschlands rasch und relativ gefahrlos zu intervenieren. Sie hatte damit praktisch auch schon bekundet, daß Frankreich nicht länger, wie seit Kriegsende beansprucht und versprochen, als unerbittlicher Wächter des Status quo auftreten, vielmehr seine Interessen künftig enger definieren und nur noch bei einer unmittelbaren Bedrohung der französischen Sicherheit militärisch in Aktion treten werde. Die letzte Stütze der französischen Führungsposition war zerbrochen. In Warschau, Belgrad, Bukarest und selbst in Prag wurde logischerweise der Schluß gezogen, ein Arrangement mit Deutschland und folglich eine gewisse Anlehnung an Deutschland seien nun unvermeidlich geworden. Vom wachsenden wirtschaftlichen Einfluß unterstützt und angesichts der französischen Schwäche auch als Protektor gegen Sowjetrußland mißtrauisch willkommen geheißen, begann Deutschland zumindest auf dem Balkan Frankreich abzulösen. Im übrigen hatte auch Großbritannien eine Haltung an den Tag gelegt, die deutlich zu verstehen gab, daß London gegen den Aufstieg Deutschlands zur führenden Macht des Kontinents nichts unternehmen wolle, sofern Berlin die anderen Mächte nicht zur Abwehr einer Eroberungspolitik zwinge, die eben nicht den deutschen Einflußbereich, sondern das deutsche Herrschaftsgebiet erweitern werde.

Hitler hingegen fühlte sich endlich frei. Mit der Liquidierung von Locarno waren die Fesseln des letzten multilateralen internationalen Systems abgestreift, dem Deutschland noch angehört hatte. Nach der Remilitarisierung des Rheinlands konnte in absehbarer Zeit - durch die Stationierung

91 Tagebücher von Joseph Goebbels, Bd. 3, S. 72. 
stärkerer Kräfte und die Anlage moderner Befestigungen - eine militärische Rückendeckung gegen Frankreich geschaffen werden, und da es sich hierbei um eine handgreifliche Veränderung der Machtlage handelte, begriff Hitler auch, daß er der Trennung Osteuropas von den Westmächten in der Tat ein gutes Stück nähergekommen war. Aus der Londoner Passivität wiederum las er heraus, daß Großbritannien eine deutsche Ostexpansion vermutlich tatsächlich tolerieren werde, wobei ihm erste Zweifel kamen, ob das enge und „ewige Bündnis" mit London, das er bislang als notwendige Voraussetzung angesehen und von dem er noch im Vorjahr gesprochen hatte, wirklich erforderlich sei. Daß England, entgegen seinen Erwartungen, Mussolinis Annexion Abessiniens hinnahm, hatte ihm tiefen Eindruck gemacht, und so begann sich in ihm keimhaft die Vorstellung zu formen, daß er freie Hand im Osten auch schon dann bekommen könne, wenn er den Briten mit politischen Pressionen und militärischen Drohungen genügend einheize. „England ist schwach“, so hieß es nun in Berlin. „Keine Weltmacht mehr. Schlappe Führung. Man weiß also in Zukunft, was davon zu halten ist." 92 Mit Mussolini hingegen hatte er in einer Weise zusammengearbeitet, die er als Vorstufe zu einer festen Allianz verstand. Wenn Hitler vor seinem Coup den Druck auf Berlin und die westliche Interventionsbereitschaft überschätzt hatte, so verfiel er nun in eine noch weniger realistische Überschätzung des eigenen Handlungsspielraums und der westlichen Konzessionsbereitschaft. Da er den Coup sowohl gegen den Rat des Generalstabs wie gegen die Bedenken des Auswärtigen Amts riskiert hatte und sich folglich den Durchbruch des Dritten Reiches zu der nun gegebenen internationalen Stellung aufs eigene Konto schrieb, stieg überdies sein ohnehin abnorm entwickeltes Sendungs- und Selbstbewußtsein. Die Beherrschung der schon bisher sehr ausgeprägten Neigung, Wunschbilder und die eigene Intuition dem Votum der Experten vorzuziehen, wurde ihm vollends unmöglich. Seiner Ansicht nach kam es jetzt nur noch darauf an, militärisch stärker zu werden.

Zunächst blieb ihm das Glück freilich gewogen. Alle Tendenzen, die in der abessinischen Krise und in der Rheinland-Affäre hervorgetreten waren, der Rückzug des Westens in einen ratlosen Quietismus, die Aktivitätssteigerung der beiden expansionistischen Mächte und die Anziehungskraft, die Rom und Berlin aufeinander ausübten, wurden noch verstärkt, als im Juli 1936 ein von General Franco geführter Rechtsputsch gegen die legale Madrider Regierung einen offenen Bürgerkrieg in Spanien auslöste. Frankreich und Großbritannien konnten nicht intervenieren, da jede klare Parteinahme schwere innere Konflikte zwischen den eigenen linken und rechten Gruppen zur Folge gehabt hätte. Hingegen griffen Mussolini und Hitler sofort mit Material und Truppen zugunsten der Putschisten ein, allerdings ohne daß dabei die politische Verwandtschaft mit Franco und mit der

92 Tagebücher von Joseph Goebbels, Bd. 2, S. 601. 
auf Seiten der Generäle kämpfenden spanischen Faschisten eine größere Rolle gespielt hätte. Mussolini wollte sich die Gelegenheit nicht entgehen lassen, Spanien in eine gewisse Abhängigkeit von Italien zu bringen und dem faschistischen Imperialismus eine bessere strategische Position im westlichen Mittelmeer - durch Franco abgepreßte militärische Stützpunkte - zu verschaffen. So rückte auch Tunis in Reichweite, zumal italienische Stützpunkte in Spanien eine generelle Verschlechterung der strategischen Lage Frankreichs zu bedeuten schienen, weil sie die Chance eröffneten, im Kriegsfall Frankreich vom französischen Nordafrika abzuschneiden. An solchen Ambitionen zerbrach aber notwendigerweise auch noch der Rest der italienisch-französischen Freundschaft, die Pariser Politiker wie Laval so mühsam durch den abessinischen Konflikt zu retten gesucht hatten, und die Kampfansage an Frankreich manövrierte Mussolini außerdem in eine Situation, in der sich das Bündnis mit Berlin aus einer verlockenden und bislang erst zum Flirt gediehenen Möglichkeit in eine bare Notwendigkeit verwandelte, wenn die völlige Isolierung Italiens und ein schmachvoller Abbruch der Intervention verhindert werden sollte.

Eben deshalb war Hitler am italienischen Engagement in Spanien brennend interessiert ${ }^{93}$. Sein Hauptgrund für eine deutsche Intervention war gewiß die Überzeugung, daß ein Fehlschlag des rechten Aufstands den linken Kräften in ganz Europa - womöglich auch in Deutschland - enormen Auftrieb geben würde. Hitler rechnete sogar damit, daß den im Regierungslager stehenden spanischen Kommunisten bei einer Niederwerfung der Rebellion die Macht zufallen müsse und daß dann die kommunistische Welle sogleich über die Pyrenäen schlagen werde, Frankreich ebenfalls die Bolschewisierung bescherend; er glaubte tatsächlich, daß es sich bei dem französischen Sozialistenführer Leon Blum, damals in Frankreich Ministerpräsident einer Volksfrontregierung, um einen „bewußten Agenten der Sowjets“ handle, um einen „Zionisten und Weltzerstörer"94. Nun hatte der „Führer" gegen eine geschehene oder unmittelbar drohende Bolschewisierung Frankreichs grundsätzlich gar nichts einzuwenden; gerade Mitte der dreißiger Jahre erhoffte er sich ja von einer solchen Krise im westlichen Nachbarstaat den großen Anlaß für das umfassend „ordnungstiftende“ Eingreifen Deutschlands auf dem europäischen Kontinent. Doch erst in ein paar Jahren. Im Augenblick war das Reich dafür militärisch noch zu schwach, weshalb man, wie er am 2. Dezember 1936 in einer Kabinettssitzung sagte, nur wünschen könne, „daß Krise vertagt wird, bis wir fertig sind“. Derzeit komme es in erster Linie auf die Aufrüstung an, bei der Geld keine Rolle spielen dürfe: „Denn in der Krise entscheiden die Waffen,

93 W. Schieder / Ch. Dipper (Hrsg.), Der Spanische Bürgerkrieg in der internationalen Politik 1936-1939, München 1976; H.-H. Abendroth, Die deutsche Intervention im Spanischen Bürgerkrieg. Ein Diskussionsbeitrag, in: VfZ 30 (1982), S. 117-129.

94 Tagebücher von Joseph Goebbels, Bd. 2, S. 743. 
nicht gedeckte oder ungedeckte Wechsel."95 Daneben aber diente die deutsche Unterstützung Francos in Hitlers Augen nicht zuletzt dem Zweck, einen Krieg zu fördern, der ihm Italien in die Arme treiben mußte.

Bald durfte er auch den Gewinn seiner Spekulation einstreichen. Am 20. Oktober 1936 kam Graf Ciano, Schwiegersohn Mussolinis und italienischer Außenminister, nach Berlin, wo er mit Hitler, der jetzt auch die italienische Herrschaft in Abessinien offiziell anerkannte, eine enge politische Zusammenarbeit vereinbarte, die jeweiligen Expansionsräume - Mittelmeer und Osteuropa - absteckte und dem deutschen Diktator versicherte, Italien werde auch bei der Vorbereitung eines Krieges an seiner Seite stehen. Mussolini selbst verkündete am 1. November 1936 die Existenz einer „Achse“ Rom-Berlin. Diese neue Partnerschaft ist nicht als Bündnis alten Stils, sondern als Ausdruck ideologisch-politischer Solidarität präsentiert worden. Tatsächlich lief sie auf eine gemeinsame Kriegserklärung an den Status quo hinaus, die das gestiegene Selbstvertrauen von "Duce“ und „Führer" deutlich genug dokumentierte. Die Regierungen der Westmächte konnten aber nicht einmal gegen die italienisch-deutsche Intervention in Spanien etwas unternehmen, da auch dies eine Parteinahme im Bürgerkrieg bedeutet und daher in den westlichen Ländern innenpolitische Krisen heraufbeschworen hätte; auch wäre die Gefahr eines großen europäischen Konflikts größer geworden. Im übrigen schlug sich das stalinistische Rußland, das gerade in die Ära der jeder rationalen Erklärung spottenden „Säuberungen“ eintrat und dem europäischen Bürgertum wie auch einem erheblichen Teil der europäischen Arbeiterschaft mehr denn je als unheimliche Bedrohung erschien, auf die Seite der Madrider Regierung und sicherte damit auch in den westeuropäischen Ländern der italienisch-deutschen Hilfe für Franco eine gewisse und manchmal zum Wohlwollen gesteigerte Toleranz.

Die Wandlung der internationalen Lage ermunterte die nationalsozialistischen Führer Deutschlands alsbald auch zu einer ersten Übung in „Weltpolitik“, worunter sie aber, anders als der klassische und ordinäre Imperialismus deutschnationaler Gruppen, zunächst nicht den Versuch verstanden, mit dem Erwerb von Kolonien in Übersee Fuß zu fassen, sondern vorerst nur eine weltweite Bündnispolitik, die Deutschlands Stellung in Europa stärken und den Übergang zur Expansion auf dem europäischen Kontinent erleichtern sollte. So schlossen sie am 25. November 1936 einen Vertrag mit Japan, der in seinem veröffentlichten Teil Tokio und Berlin zur Bekämpfung der Komintern verpflichtete und deshalb Antikominternpakt getauft wurde, der jedoch in einem geheimen Zusatzprotokoll wohlwollende Neutralität vorschrieb, falls einer der Vertragspartner mit Rußland zusammenstoßen sollte, und den beiden Mächten freundschaftliche Vereinbarungen mit Moskau praktisch verbot. Das Abkommen war auf deutscher Seite fast ohne Mitwirkung des Auswärtigen Amts zustande gekommen und im we-

95 Ebenda. 
sentlichen - natürlich unter dem wachsamen Auge des „Führers“ - das Werk Joachim v. Ribbentrops, der seit 1932, als er sich der NSDAP angeschlossen und sich Hitler durch gesellschaftliche Beziehungen nützlich gemacht hatte, zum Spezialisten für spezifisch nationalsozialistische Außenpolitik aufgestiegen war; als Leiter der NSDAP-offiziellen „Dienststelle Ribbentrop" hatte er maßgeblichen Anteil am deutsch-britischen Flottenabkommen gehabt, und im Sommer 1936 war er zum Botschafter des Reiches in London ernannt worden, ohne jedoch auf die Leitung der „Dienststelle" und auf seine Sonderrolle als "nationalsozialistischer" Außenpolitiker in der Umgebung des „Führers“" zu verzichten ${ }^{96}$. Seine Partner auf japanischer Seite waren Repräsentanten jener quasi-faschistischen Heeresoffiziere, die seit Jahren einen großostasiatischen - keineswegs auf die Mandschurei beschränkten - Imperialismus Japans forderten. Der Pakt mit der nach „Italien und Deutschland dritten faschistischen Großmacht der Welt“, wie Karl Haushofer im „Völkischen Beobachter“ schrieb, hatte denn auch den Sinn, neben den Territorien am Mittelmeer und neben Osteuropa einen weiteren Großraum, eben Ostasien, für Expansion abzustecken und eine gewisse Koordination der japanischen Aggressivität mit den europäischen Imperialismen zu erreichen. Allerdings sollte es nie zu einer planmäßigen Zusammenarbeit kommen. Aber die Proklamierung der deutschjapanischen Solidarität machte doch auf die interkontinentale Wechselwirkung aufmerksam, die allein schon von der Existenz eines europäischen und eines asiatischen Zentrums expansionistischer Aktivität ausging. Der Pakt wirkte zudem als ausdrückliche Erklärung, daß Deutschaland und Japan diese Ergänzungsfunktion, die das gegnerische Lager zur Zersplitterung der Mittel und zu einer unentschlossen - nachgiebigen Politik verleiten mußte, künftig bewußt zu benutzen gedachten. Drückte Japan, durch die deutsche Rückendeckung ermutigt, noch stärker als bisher auf die asiatischen Interessen Rußlands und Großbritanniens, so mochte, wie Hitler hoffte, die Sowjetunion in Europa angreifbarer und England den deutschen Wünschen gefügiger werden ${ }^{97}$.

In der politischen Realität erhielt das Abkommen freilich einen ausgesprochen antibritischen Effekt. Die japanischen Imperialisten nahmen die Entlastung, die sie nach der nun anscheinend gegebenen Einschränkung der sowjetischen Handlungsfreiheit zu spüren meinten, zum Anlaß, Vorstöße in jene Richtung zu unternehmen, wo ihre eigentlichen Ziele lagen, China und praktisch ganz Südostasien, wo sie aber sogleich auf britische, holländische und amerikanische Interessen trafen, wo erst recht ihre weiteren Ambitionen als unerträgliche Herausforderung des Commonwealth

96 W. Michalka, Ribbentrop und die deutsche Weltpolitik 1933-1940. Außenpolitische Konzeptionen und Entscheidungsprozesse im Dritten Reich, München 1980.

97 L. Presseisen, Germany and Japan. A Study in Totalitarian Diplomacy 1933-1941, Den Haag 1958; Th. Sommer, Deutschland und Japan zwischen den Mächten 1935-1940, Tübingen 1962 . 
und der USA erschienen. Nachdem japanische Truppen am 7. Juli 1937 in China selbst eingefallen waren und sich bald in offensichtlich langwierige Kämpfe verstrickt hatten, stand fest, daß Japan einen Expansionskurs gewählt hatte, der geradewegs zum Zusammenstoß mit den großen Seemächten führen, dem japanisch-sowjetischen Gegensatz hingegen einen wesentlichen Teil seiner Schärfe nehmen mußte; seit der Bindung in China war die japanische Armee zu einem großen Konflikt mit einer anderen bedeutenden Landmacht ohnehin nicht mehr fähig. Daß der Antikominternpakt also in Wirklichkeit die außenpolitische Gesamtlage der Sowjetunion verbesserte und namentlich den Druck auf Großbritannien erhöhte, ist aber in Berlin gar nicht ungern gesehen worden. Hitler war der Meinung, daß man in London überseeischen Interessen größere Bedeutung beimesse als Vorgängen auf dem europäischen Kontinent, und so hielt er die Aufstachelung Japans für besonders geeignet, England anderweitig zu binden und der britischen Bereitschaft zur Tolerierung der deutschen Expansion nachzuhelfen. Der korrespondierende Bedeutungsverlust des japanisch-sowjetischen Gegensatzes ist ihm offenbar nie bewußt geworden, und daß eine Zusammenarbeit mit Japan neben der Feindschaft Englands die Mobilisierung der USA auch gegen Deutschland als Zukunftsmöglichkeit heraufbeschwor, hat er erst recht nicht erkannt. So ist es von der nationalsozialistischen Führung sogar als Erfolg gewertet worden, daß sich die antibritischen Aspekte der Verbindung mit Japan noch deutlicher abzeichneten, als am 6. November 1937 das „weltpolitische Dreieck“ Berlin-Rom-Tokio entstand und mit Italien dem Antikominternpakt ein Staat beitrat, den außer der ideologischen Differenz keine konkrete politische Streitfrage von der Sowjetunion trennte, den jedoch Mussolinis meditteraner Ehrgeiz auf antifranzösische und antibritische Wege gebracht hatte. „Theoretisch antikommunistisch, doch tatsächlich unmißverständlich antibritisch", charakterisierte Graf Ciano den Sinn des „Dreiecks“, und er hat auch festgehalten, daß der Antikominternpakt, wie schon die Achse Berlin-Rom, über engere diplomatische Zwecke hinaus vor allem eine grundsätzliche Kampfansage an den Status quo darstellte. „Die Nationen“, so notierte er zum italienischen Beitritt in seinem Tagebuch, ,betreten gemeinsam den Pfad, der sie vielleicht zum Kriege führt. $\mathrm{Zu}$ einem Kriege, der notwendig ist, um die Kruste zu durchbrechen, die die Energie und die Bestrebungen der jungen Nationen erstickt." 98 Am 11. Dezember 1937 verließ auch Italien den Völkerbund.

Mit alledem geriet Hitler rasch in eine Stimmung, die ihn Abkürzungswege zum Krieg suchen ließ. Bereits im November 1936 begann er davon zu träumen, daß die Aufrüstung, in die er „märchenhafte Summen“ hineinstecke, schneller die gewünschten Resultate zeitigen und ihn früher zum Handeln instand setzen werde als noch vor ein oder zwei Jahren erwartet: 
„1938 sind wir ganz fertig.“99 Im Lauf des Jahres 1937 sprach er immer häufiger davon, daß in absehbarer Zukunft eine große Auseinandersetzung - ein "Weltkampf“ - kommen werde, die ihm dann die Liquidierung des Westfälischen Friedens erlaube 100 . Zugleich beschwor er wieder des öfteren die deutsche „Raumnot“, die es zu beheben gelte, und zwar tat er das auch in aller Öffentlichkeit, so Anfang Oktober 1937 auf dem Bückeburger Bauerntag. „Die Bauern sind begeistert", kommentierte Goebbels ${ }^{101}$. Im Kreise seiner Vertrauten machte der „Führer“ in solchen Zusammenhängen kein Hehl mehr daraus, daß ihn nun die Frage bewege, ob die zur Realisierung seines Programms erforderliche Zwischenphase, in der Deutschlands Grenzen und Deutschlands politischer Einfluß unmittelbar an die baltische und russische Beute heranzuschieben waren, nicht schon demnächst eingeleitet werden dürfe: Die Gegensätze zwischen Italien und den Westmächten, die wachsende Abhängigkeit Italiens von Deutschland, Japans Konflikte mit der Sowjetunion und mit den Seemächten, die Koordinierung der beiden europäischen Imperialismen mit dem ostasiatischen Imperialismus, schließlich die inneren Krisen, unter denen Verteidiger des Status quo wie Frankreich litten - in einer politischen Landschaft, aus der die kollektive Sicherheit wieder eliminiert war und an deren Rand der Völkerbund nur noch ein Schattendasein fristete, mochten das Faktoren sein, die es Deutschland trotz einer gewiß immer noch mangelhaften Rüstung gestatteten, einige Rußland vorgelagerte Staaten bereits jetzt „so oder so fest in unsere Hand" zu nehmen, wie eine interne Interpretation besagte. Konkret bedeutete das: Hitler warf von Monat zu Monat begehrlichere Blicke auf die Tschechoslowakei und auf Österreich. „Beide müssen wir haben“, hieß es im März 1937102, und Goebbels notierte damals: „Diese Tschechen haben mit Recht eine Judenjungenangst." 103 Wenige Monate später prophezeite Hitler, daß er ,in Österreich ... tabula rasa machen“ werde, und zwar „mit Gewalt“, daß ferner „die Tschechei ... überrannt“" werden müsse. Mit höhnischer Befriedigung schrieb Goebbels in sein Tagebuch: „Arme Tschechei. Sie wird in näherer und weiterer Zukunft nichts zu lachen haben." 104 In einer Besprechung, die am 5. November 1937 in der Reichskanzlei stattfand, hat der „Führer" dann seinen engsten außenpolitischen und militärischen Gehilfen in aller Deutlichkeit gesagt, daß er als erste Objekte seiner „Raumpolitik“ die Tschechoslowakei und Österreich einzuverleiben gedenke - vielleicht bereits $1938^{105}$.

99 Tagebücher von Joseph Goebbels, Bd. 2, S. $726 \mathrm{f}$.

100 Tagebücher von Joseph Goebbels, Bd. 3, S. 45, 55.

101 Ebenda, S. 138, 288.

102 Ebenda, S. 79.

103 Ebenda, S. 65, 223, 266.

104 Ebenda, S. 307.

105 B.J. Wendt, Großdeutschland. Außenpolitik und Kriegsvorbereitung des Hitler-Regimes, München 1987, S. $11 \mathrm{ff}$. 
Daß Hitler ebenfalls ein Abessinien fordern werde und daß darunter mindestens die bekannten Ansprüche des deutschen Revisionismus zu verstehen seien, ist denn auch überall in Europa erwartet worden. Aber anders als 1914 wäre Europa diesmal tatsächlich bereit gewesen, die Realisierung begrenzter territorialer Wünsche Berlins und eine weitgehende Ausbreitung der wirtschaftlich-politischen Einflüsse Deutschlands auf dem Kontinent zu tolerieren. Entscheidend war dafür die Haltung Großbritanniens, das selbst angesichts steigender deutscher Forderungen darauf beharrte, eine Verständigung mit Hitler zu suchen. Allerdings besaß Großbritannien, wenn es nicht von der Macht der USA gestützt wurde, in der Tat nicht mehr die Kraft, sowohl Japan wie den aggressiven Staaten Europas entgegenzutreten, und in den USA dominierte noch immer die Abneigung gegen eine Verstrickung in ferne Händel. Kurz vor dem Höhepunkt der abessinischen Krise, am 31. August 1935, nahm der amerikanische Kongreß sogar eine Neutralitäts-Akte an, die es dem Präsidenten unmöglich machte, im Kriegsfall einen angegriffenen Staat wirtschaftlich und politisch zu bevorzugen oder den Angreifer zu benachteiligen. Nicht einmal der japanische Vormarsch in China rüttelte die öffentliche Meinung genügend auf. Der amerikanische Isolationismus lieferte mithin England einen gewichtigen Grund, in Europa mit Italien und Deutschland wenigstens einen Modus vivendi finden zu wollen.

Allerdings hatten die meisten Briten - auch die Politiker der Dominions - die amerikanische Selbstgenügsamkeit als Grund ihrer Neigung zum europäischen Appeasement gar nicht nötig und benutzten sie allenfalls als plausible Rechtfertigung der eigenen Haltung. Nach wie vor weigerte sich die überwältigende Mehrheit der britischen Bevölkerung, einen neuen Krieg ins Auge zu fassen und einer den Krieg immerhin nicht mehr ganz ausschließenden Politik zu folgen; anders als in Deutschland und Italien, wo beträchtliche Teile der Nationen, national bis nationalistisch empfindend, doch wesentlich kriegsbereiter waren als die entsprechenden französischen und britischen Schichten, wo weitere Gruppen sich von der Propaganda der Regime wenigstens betäuben ließen und oppositionelle Reste sich politisch völlig ausgeschaltet sahen, zog in England die Abneigung gegen den Krieg dem außenpolitischen Spielraum der Regierung in der Tat enge Grenzen. Überdies amtierte seit Mai 1937 ein Premierminister, der geradezu die Personifizierung des britischen Friedenswillens war. Neville Chamberlain, ein Stiefbruder Sir Austen Chamberlains, des Außenministers der Locarno-Periode, hatte weder für Diktaturen noch für Diktatoren etwas übrig ${ }^{106}$. Jedoch betrachtete er die Verhinderung eines abermaligen europäischen Krieges als eine Aufgabe, die allem anderen vorangehen müsse, im wahrsten Sinne des Wortes als eine Mission, und er betrachtete diese Aufgabe außerdem als eine von Gott ihm persönlich aufgetragene 
Mission, in deren Dienst er sein ganzes - zuletzt als erfolgreicher Schatzkanzler erworbenes - politisches Prestige ebenso stellte wie seine beträchtliche Energie und einen gegen $Z$ weifel oder kritische Argumente weitgehend immunen Starrsinn. Da er Sendungs- und Selbstbewußtsein mit einem starken Machtwillen verband und genau im Schnittpunkt der Wünsche einer klaren Majorität sowohl der Bevölkerung wie ihrer politischen Repräsentanten stand, gelang es ihm auch, während seiner missionarischen Aktivität die von ihm geführte Konservative Partei einer fast schon autokratischen Herrschaft zu unterwerfen und lange Zeit exakt auf der von ihm verfolgten Linie zu halten. Voraussetzungen des Chamberlainschen Appeasement waren die Überzeugung, daß im Grunde doch auch Hitler und Mussolini rationale Staatsmänner seien, die saturiert werden könnten, und die Entschlossenheit, bei der Saturierung der beiden Diktatoren auch schwerste Opfer zu bringen. Chamberlain ließ sich nicht einmal durch die Erkenntnis abschrecken, daß die passive Toleranz der britischen Regierung keinesfalls genügen werde, eine friedliche Erfüllung der deutschen und italienischen Ansprüche zu sichern. Vielmehr war klar, daß Frankreich zur gleichen Toleranz veranlaßt werden mußte und daß dies wiederum nur möglich war, wenn die diversen französischen Bündnisverpflichtungen nicht in Kraft zu treten brauchten, wenn mithin London und Paris die osteuropäischen Klientelstaaten Frankreichs, an die sich deutsche Forderungen richteten, zur Konzessionsbereitschaft zwangen.

Vier Faktoren erleichterten es Chamberlain, seiner unbezweifelbaren Friedensliebe nachzugeben. Er vermochte - in der Tradition Lloyd Georges und Austen Chamberlains stehend - kein besonderes britisches Interesse an Ost- und Südosteuropa zu erkennen. Ferner hinderte ihn eine tief eingewurzelte Abneigung gegen den Kommunismus wie gegen die Sowjetunion vorerst daran, ein Bündnis mit Moskau zu suchen, das den Ausfall der USA hätte ersetzen können; die Abneigung verführte ihn sogar zu der Erwartung, die Zusammenarbeit mit dem immerhin antikommunistischen Dritten Reich werde dazu beitragen, bolschewistischen Expansionsgelüsten einen Riegel vorzuschieben; als Resultat seiner Politik erhoffte er sich ohnehin ein Kollegium der europäischen Großmächte England, Italien, Frankreich und Deutschland, das nach dem Zerfall der kollektiven Sicherheit Europa führen, den Frieden garantieren und die Sowjetunion aussperren sollte. Drittens war er - wie ein beträchtlicher Teil der britischen Führungsschicht - von der Sorge beeinflußt, die Anstrengung eines neuen Krieges werde die britische Gesellschaft unweigerlich zu einer sozialistischen Umgestaltung führen. Schließlich kam ihm, wenn er Mussolini und Hitler als rationale Männer und bloße Revisionspolitiker einschätzte, wenn er dazu noch die Befriedigung der Revisionswünsche als für Großbritannien unbedenklich ansah, zugute, daß seine Kenntnis der kontinentaleuropäischen Verhältnisse bescheiden war und er sowohl von der Natur wie vor allem auch von den Folgen außenpolitischen Handelns und außenpoliti- 
scher Prozesse keine zulängliche Vorstellung besaß. Hingegen war Chamberlain frei von der Absicht, Deutschland gegen die Sowjetunion zu lenken oder Hitler wenigstens freie Hand im Osten zu geben. Er wollte dem nationalsozialistischen Deutschland die Revision der einen oder anderen territorialen Bestimmung des Versailler Vertrags zugestehen und verschaffen, nicht etwa eine uferlose Eroberungspolitik erlauben, bei der ja Großbritannien selbst die Abhängigkeit vom Dritten Reich drohen mußte.

Die Konzeption Chamberlains, der natürlich die militärische Schwäche Englands ebenfalls berücksichtigte und gegen seine zunächst wenig zahlreichen Kritiker gerne als Argument benützte, war gewiß von Anfang an zum Scheitern verurteilt, da Hitlers Kriegslust und Expansionsdrang eben nicht saturiert werden konnten, vielmehr durch jeden Erfolg und auch durch die permanente Aggressivität der NS-Bewegung ständig angeheizt wurden. Mehr noch: die Appeasement-Politik mußte Hitler eine Weile lang Gewinne bescheren, aus denen das Dritte Reich laufend Zunahmen seiner wirtschaftlichen, politischen und militärischen Kraft zog. Wer also der Meinung war, daß der Waffengang mit dem nationalsozialistischen Deutschland unvermeidlich sei, verfolgte naturgemäß mit wachsendem Horror eine Politik, die den künftigen Feind zunächst immer noch formidabler machte. Auf der anderen Seite ging die Appeasement-Politik von einer überzeugenden moralischen Motivation aus, anfänglich auch von einem immerhin vertretbaren politischen Kalkül. Auch vollbrachte die Chamberlainsche Politik eine wichtige - freilich gänzlich unbeabsichtigte - Leistung: sie entlarvte Hitler. Ohne eine Periode der Konzessionen wäre der Welt für den unausweichlichen Konflikt nie die Gewißheit gegeben worden, daß es Hitler eben nicht um Revision ging, sondern zumindest um die Verwirklichung des in "Mein Kampf" formulierten Programms und offenbar noch darüber hinaus um eine nicht mehr geographisch bestimmbare Machterweiterung. Jahre später, im August 1940, als Großbritannien dem in Frankreich siegreichen Hitler allein gegenüberstand, hat John Colville, Sekretär erst Chamberlains und dann Churchills, die Bemerkung eines Kollegen festgehalten, erst die Appeasement-Politik und ihr Scheitern hätten das Land gegen Hitler und das nationalsozialistische Deutschland geeint; ohne diese Voraussetzung wäre sicherlich eine starke Antikriegspartei entstanden ${ }^{107}$. In solcher Sicht konnte es in Kauf genommen werden, daß Chamberlain dem deutschen Diktator für den Versuch, Europa zu unterwerfen, zu einer günstigeren Ausgangsposition verhalf.

Zunächst fiel Hitler Österreich zu, allerdings auf eine Weise, die kaum Rückschlüsse auf seine wahren Ziele erlaubte und daher die AppeasementPolitik noch nicht ernstlich auf die Probe stellte ${ }^{108}$. Das autoritäre Regime Kurt v. Schuschniggs, der dem 1934 ermordeten Dollfuß gefolgt war, hatte,

107 Colville, The Fringes of Power, S. 232.

108 J. Gehl, Austria, Germany and the Anschluß. 
obschon strukturell zur Teilung der Macht unfähig, nach dem im Juli 1936 mit Hitler geschlossenen Abkommen den österreichischen Nationalsozialisten größeren Spielraum geben müssen, einer Bewegung also, die ihrer $\mathrm{Na}-$ tur nach ebenfalls die ganze Macht beanspruchte. Die Folge war ein permanenter Konflikt, der lediglich Waffenstillstände zuließ, die von beiden Seiten wenig respektiert wurden, und um die Jahreswende 1937/38 entwikkelte sich eine Situation, die der von 1933/34 glich. Hitler stand vor der Wahl, entweder zu intervenieren oder seine Anhänger ein zweites $\mathrm{Mal}$ im Stich zu lassen. Angesichts der völlig veränderten Gesamtlage kam für ihn ein neuerlicher Rückzug nicht mehr in Frage. Nach Verlautbarungen britischer Politiker durfte er außerdem auf die Inaktivität Englands rechnen, und Mussolini hatte, als er im September 1937 Deutschland besuchte, erklärt, daß er nun auch zur Billigung einer deutschen Intervention in Österreich bereit sei. Im übrigen war Hitler klar geworden, daß ein rascher Erfolg gegen die Tschechoslowakei - gegen das in seinen Augen strategisch wichtigere Ziel - durch die Verfügbarkeit Österreichs wesentlich erleichtert werden mußte, weil dies die Umgehung des tschechischen Befestigungsgürtels gestattete, der lediglich die Grenzen nach Deutschland deckte. Trotzdem hat sich Hitler anfänglich noch für ein paar Monate offenbar damit begnügen wollen, der österreichischen NSDAP mit massivem politisch-militärischen Druck - so am 12. Februar 1938 durch die brutale Einschüchterung Schuschniggs, als der österreichische Regierungschef mit dem „Führer“ auf dem Obersalzberg zusammentraf - zur Macht zu verhelfen und ihr die Gleichschaltung Österreichs zu ermöglichen. Als Schuschnigg während des erfolgreich eingeleiteten Gleichschaltungsprozesses doch wenigstens insofern Widerstand zu leisten suchte, als er eine Volksabstimmung ansetzte, die durch ein entsprechendes Bekenntnis einer Mehrheit der Österreicher immerhin die formale staatliche Selbständigkeit Österreichs sichern sollte, entschloß sich Hitler aber rasch zur militärischen Besetzung des Landes, die in der Nacht vom 11. zum 12. März 1938 begann und Österreich am 13. März in eine Provinz Deutschlands verwandelte. Von einem beträchtlichen Teil der österreichischen Bevölkerung, der einen lange gehegten Traum der deutschen Nationalbewegung erfüllt sah, jubelnd begrüßt, schafften die einrückenden Truppen freilich auch jenen Organen des NS-Staates freie Bahn, die sogleich, von den österreichischen Nationalsozialisten eifrig unterstützt, ein wahres Schreckensregiment gegen alle politisch Mißliebigen, von den Sozialisten bis zu den Katholiken, errichteten und eine beispiellos brutale Judenverfolgung inszenierten; Kurt v. Schuschnigg verschwand ebenfalls in den Haftanstalten des Regimes.

Wenn Hitler über Außenpolitik sprach, gebrauchte er bezeichnend häufig Wendungen aus dem Jargon des Glücksspiels. Anfang Februar 1934 hatte er in einer Rede vor den Spitzenfunktionären seiner Partei sogar verlangt, daß der ganzen deutschen Nation jene "Spielerleidenschaft" eingeimpft werden müsse, die er als notwendige Eigenschaft eines Außenpoliti- 
kers von Geblüt ansah ${ }^{109}$. Auch nach dem österreichischen Erfolg verhielt er sich wie ein Spieler, der den Einsatz und den gesamten Gewinn sogleich auf den nächsten Becherwurf setzt. Er dachte gar nicht daran, nun erst die österreichische Beute zu verdauen und das zwar nicht überraschte, aber indignierte und vor allem ängstlich gewordene - doch erwartungsgemäß völlig passiv bleibende - Europa wieder etwas zur Ruhe kommen zu lassen. Er wollte keinen Grund dafür erkennen, das zusammen mit Österreich längst ins Visier genommene zweite Opfer, die Tschechoslowakische Republik, noch eine Weile zu verschonen. Allerdings war die Zeit der fast blinden Wagnisse (Rheinlandbesetzung) und der fast zufälligen Triumphe (Österreich) vorbei. Deutschland nahm jetzt eine Stellung ein, die im Grunde bereits stärker war als 1914 die Position des Deutschen Reiches und der Donaumonarchie zusammen, da die Staaten Ost- und Südosteuropas nicht mehr, wie damals, die Freiheit hatten, durch gelegentliche Anlehnung an Rußland eine Schaukelpolitik zwischen der östlichen Großmacht und Mitteleuropa zu treiben; das bolschewisierte Rußland war doch ein viel gefährlicherer Freund als das zaristische. Die ost- und südosteuropäischen Politiker mußten, wie immer sie über Hitler und Deutschland denken mochten, ihren außenpolitischen Orientierungspunkt in Berlin suchen. Auch Ungarn, wo lange Zeit das Wort Mussolinis größtes Gewicht gehabt hatte, befand sich jetzt im deutschen Machtbereich und geriet - trotz des aus Stolz wie aus Vorsicht resultierenden Widerstrebens der Budapester Führer - zunehmend unter deutsche Vormundschaft; im übrigen wußten die ungarischen Politiker sehr genau, daß Hitler nun in einer Lage war, in der er, anders als bisher Mussolini, die Erfüllung der revisionistischen Ansprüche Ungarns tatsächlich verheißen konnte. Im vollen Bewußtsein dieser beinahe schon hegemonialen Stellung war Hitler nicht mehr geneigt, auf eine irgendwann einmal auftauchende günstige Gelegenheit zur Improvisierung seines nächsten Coups zu warten, vielmehr sollte dieser im Rahmen eines genau kalkulierten Zeitplans sorgfältig inszeniert werden ${ }^{110}$.

Drei „operative“ Grundgedanken für das Vorgehen gegen die Tschechoslowakei hatte sich Hitler noch vor der österreichischen Krise einfallen lassen und gleich auch die Verwirklichung in die Wege geleitet. Von Mussolini, der 1935 der Welt einzureden versucht hatte, daß in Abessinien finsterste Barbarei herrsche und Italien einfach gezwungen sei, dem Land die Zivilisation zu bringen, übernahm er die Technik, das Opfer in den Augen Europas zu diskreditieren. Bereits im Herbst 1937 erhielten Presse, Rundfunk und Diplomatie den Auftrag, die europäische Öffentlichkeit - und damit zugleich die Deutschen selbst - davon zu überzeugen, daß Prags bündnispolitische Verbindung mit Paris, mit Moskau und mit der Kleinen Entente eine dreiste, ja unerträgliche Bedrohung des Deutschen Reiches dar-

109 Akten des Hauptarchivs der NSDAP, Hoover Instituion, Reel 54, folder 1290.

110 T. Taylor, Munich, S. $377 \mathrm{ff}$. 
stelle, daß die CSR angesichts ihrer bunten Nationalitätenkarte ohnehin eine Fehlleistung der Pariser Friedensmacher gewesen sei und sich auf Grund der - unbestreitbaren - Versäumnisse ihrer Nationalitätenpolitik auch seither nicht die Berechtigung zur staatlichen Existenz erworben habe, daß insbesondere die Lage der deutschen Bürger dieses Landes an Knechtschaft grenze und häufig genug sogar durch brutale Verfolgung charakterisiert werde. Bereits im Oktober 1937 notierte Goebbels befriedigt: „Kampagne gegen Prag geht unentwegt weiter. Nun horchen London und Paris schon auf." ${ }^{111}$ Ferner glaubte Hitler, die Lokalisierung einer Aktion gegen die CSR nicht allein durch die moralisch-politische Isolierung Prags sichern zu müssen, sondern auch noch durch die Internationalisierung der kommenden Krise, d.h. durch das Anheuern von Komplicen. Noch im November und Dezember 1937 setzten Versuche ein, Polen gegen die CSR zu gewinnen, und im Januar 1938 warb Hitler selbst um Jugoslawien, also um ein Mitglied der „Kleinen Entente“; entsprechende Winke gingen erst recht an Ungarn. Zum Höhepunkt einer Tschechen-Krise schließlich, der dann den Anlaß zur deutschen und internationalen Intervention und Invasion zu liefern hatte, sollte die allmähliche Zuspitzung einer innenpolitischen Krise der Republik führen, und dafür gedachte Hitler die Sudetendeutschen in einer ähnlichen Rolle agieren zu lassen, wie sie in Österreich die dortige NSDAP gespielt hatte. Tatsächlich hatte sich von 1933 bis 1938 die Mehrheit der Sudetendeutschen in einer Partei organisiert, die zwar bei ihrer Gründung Sudetendeutsche Heimatfront getauft und 1935 in Sudetendeutsche Partei umbenannt - ursprünglich eine am Ziel der Autonomie orientierte nationale Sammlungsbewegung gewesen war, aber im Lauf weniger Jahre so viele faschistische und nationalsozialistische Elemente an sich gezogen und hervorgebracht hatte, daß sie nun durchaus zum Instrument für die Pläne Hitlers taugte; die Gründe lagen - von den Faktoren abgesehen, die in allen Gliedern der deutschen Nation zum Rechtsextremismus geführt hatten - im harten und seit 1918 von Prag oft kleinlich und rücksichtslos ausgefochtenen deutsch-tschechischen Nationalitätenkonflikt, in den Nöten der auf den Sudetengebieten besonders schwer lastenden Wirtschaftskrise, im Beispiel der reichsdeutschen Entwicklung und in zielbewußter reichsdeutscher Einwirkung auf die SdP. Konrad Henlein an der Spitze der SdP die in der Realităt auch mögliche hausbacken-biedere Spielart des faschistischen Massenführers - geriet jedenfalls seit 1935 mehr und mehr in ideologische, politische und finanzielle Abhängigkeit von Berlin, und im Dezember 1937 war die Gleichschaltung der SdP praktisch vollendet.

Kaum von den lärmenden Wiener Anschlußfeiern zurückgekehrt, machte sich dann Hitler - nun auch die Verbesserung der strategischen Lage vor Augen, die ihm die Annexion Österreichs gegenüber der CSR

111 Tagebücher von Joseph Goebbels, Bd. 3, S. 308. 
verschafft hatte - energisch daran, die internationale Spannung um Prag und den innenpolitischen Konflikt in der CSR zu forcieren und die Manipulation beider Krisen so zu kalkulieren, daß ihr Höhepunkt und der Termin des deutschen Angriffs schon für den Frühherbst 1938 vorgesehen werden konnten. Dem diente eine abermalige Intensivierung der antitschechischen Propaganda, dem diente die am 28. März 1938 Henlein erteilte Weisung Hitlers, von der Prager Regierung „immer so viel zu fordern, daß wir nicht zufrieden gestellt werden können"112, dem diente eine zunehmend deutlichere deutsche Sprache in Warschau wie in Budapest und dem diente zumal die jetzt ebenfalls konkretisierte militärische Planung. Seit dem 7. Dezember 1937 im Besitz eines militärpolitisch und operativ offensiven Aufmarschplans für den Krieg gegen die Tschechoslowakei ("Fall Grün"), nachdem das Reichskriegsministerium die bislang defensive Weisung an die Wehrmacht auf Grund der Hitlerschen Darlegungen vom 5. November entsprechend bearbeitet hatte, begann sich Hitler im Frühjahr 1938 intensiv mit den militärischen Details zu beschäftigen. Wohl sagte er kurz nach der Erledigung des österreichischen Problems, daß es ihm mit der Lösung der tschechoslowakischen Frage „nicht eilig“ sei113, doch war er ja ein Mann, bei dem „nicht eilig“ meist mit „erst in ein paar Monaten“ übersetzt werden mußte. Am 21. April konferierte er jedenfalls mit General Keitel, dem Chef des Oberkommandos der Wehrmacht (OKW) - so hieß das Kriegsministerium, seit Hitler am 4. Februar Minister Werner v. Blomberg verabschiedet und persönlich den Oberbefehl über die Wehrmacht übernommen hatte -, bereits über den Anlaß eines Angriffs, wobei er dem Militär auseinandersetzen zu müssen glaubte, daß ein „strategischer Überfall aus heiterem Himmel ohne ... Rechtfertigungsmöglichkeit“ nicht angängig sei; ein solches Vorgehen sei „nur zur Beseitigung des letzten Geg-

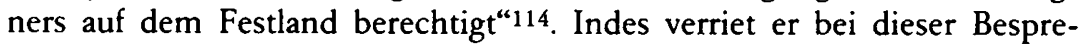
chung, daß er sich auch den Kopf darüber zerbrach, wie operiert werden könne, falls die $\mathrm{SdP}$ aus irgendeinem Grunde versagen sollte; als geeigneter Anlaß zu „blitzartigem Handeln“, so überlegte er, könne ja auch „die Ermordung des deutschen Gesandten“ dienen. Am 20. Mai legte das OKW eine neue Weisung für den „Fall Grün“ vor, in der Hitlers Intentionen in die wiederum für ihn sehr typische Formel gefaßt war, er habe nicht die Absicht, die Tschechoslowakei „schon in nächster Zeit durch eine militärische Aktion zu zerschlagen“, es sei denn, daß sich eine günstige Gelegenheit biete115. Wenige Tage danach befand er denn auch die vom Heer für September angesetzten Übungen ,im überraschenden Einnehmen von Befestigungen“ als „zu spät“, und zugleich befahl er eine Änderung des

112 ADAP, D, II, Nr. 167.

113 Booms, Der Ursprung des 2. Weltkriegs, S. $351 \mathrm{f}$.

114 Ebenda, S. 339.

115 Wendt, Großdeutschland, S. 145. 
OKW-Entwurfs, dessen neue Fassung, am 30. Mai präsentiert, mit den Worten begann: „Es ist mein unabänderlicher Entschluß, die Tschechoslowakei in absehbarer Zeit durch eine militärische Aktion zu zerschlagen." „Spätestens ab 1.10.38“, so hieß es weiter, müsse der militärische Angriff möglich sein ${ }^{116}$. Ferner ließ er - seit Juni - entlang der deutsch-französischen Grenze in einem höllischen Tempo Befestigungswerke anlegen, die, unter der recht hochtrabenden Bezeichnung „Westwall“, Frankreich beeindrucken und von einer militärischen Intervention zugunsten der CSR abschrecken sollten.

Hitlers Plan hat weder eine friedliche Beilegung der inszenierten Krise noch eine Abtretung der sudetendeutschen Gebiete je in Betracht gezogen. Seine Taktik bezweckte die Isolierung der CSR für einen kurzen und lokalisierten Krieg, denn nur ein solcher Krieg erlaubte die sofortige Unterwerfung der ganzen Tschechoslowakei, die er für die Fortsetzung der Ostexpansion brauchte; auch wollte er, wie er zu Konrad Henlein sagte, der ,jungen Wehrmacht“ Gelegenheit zu einer „Bewährungsprobe“ geben ${ }^{117}$. Indes hielt er die Eroberung der CSR nicht allein aus strategischen, machtpolitischen und auch - angesichts der Rohstoffe des Landes und seiner agrarischen wie industriellen Leistungsfähigkeit - wirtschaftlichen Gründen für unverzichtbar. Nie verlor Hitler den „volkspolitischen“ Gesichtspunkt der biologischen Expansion der deutschen Nation aus den Augen, und unter solchem Gesichtspunkt waren Böhmen und Mähren auch als Germanisierungsobjekte wichtig. Kurz vor dem Höhepunkt der Sudetenkrise sagte er intern: „Wir dürfen diese Völker, vor allem die Tschechen und ähnliches Gelichter nicht hochpäppeln, wir werden sie vielmehr einmal herausdrücken. Wir wollen nicht diese Völker, wir wollen ihr Land."118

Chamberlain hat dem „Führer" dieses Konzept freilich vorerst verdorben. Im Bunde mit der französischen Regierung, der inzwischen die Appeasement-Politik ebenfalls als der zunächst einzig gangbare Weg erschien und die sich daher trotz der Pariser Allianz mit Prag von Chamberlain gerne auf die britische Linie ziehen ließ, setzte der Premier die tschechoslowakische Regierung unter massivsten Druck. Anfang September erzwang er von Prag die Annahme aller halbwegs vertretbaren sudetendeutschen Forderungen, also jener Forderungen, die noch auf eine Autonomie für die Sudetendeutschen und nicht schon auf die Auflösung des Staates hinausliefen. Als Hitler nun seine Ansprüche höher schraubte und die Abtretung der Sudetengebiete verlangte, nahmen London und Paris das tschechoslowakische Kabinett derart in die Zange, daß es schließlich am 21. September auch in die Abtretung einwilligte. Fast hătte die Appeasement-Politik schon in diesem Stadium die Wirkung gehabt, Hitlers Kriegs- und Erobe-

116 Ebenda, S. 146.

117 Mitteilung F. Bürger (Vertreter Henleins in Berlin) an den Verf., 24.9.1956.

118 Tagebücher von Joseph Goebbels, Bd. 3, S. 515. 
rungswillen vor aller Welt zu demaskieren. Über die tschechischen Konzessionen böse enttäuscht, stellte nämlich der „Führer" jetzt, um irgendeinen Kriegsgrund zu behalten, ultimativ Forderungen zum Termin der Besetzung des Abtretungsgebiets und zu den Formen der Annexion, die so unsinnig rigoros waren, daß man an ihrem provokatorischen $Z$ weck nicht mehr zweifeln konnte. Beinahe wäre so in den letzten Septembertagen doch noch ein Krieg ausgebrochen, an dem sich die Westmächte beteiligt hätten; am 26. September machte die britische Flotte mobil. Unter dem Eindruck der plötzlich drohenden westlichen Haltung und unter dem Eindruck einer Erklärung Mussolinis, Italien sei nicht kriegsbereit, wich Hitler noch einmal zurück und fand sich bereit, am 29. September in München ein drittes Mal mit Chamberlain, der bereits am 15. September in Berchtesgaden und am 22. September in Bad Godesberg mit ihm persönlich verhandelt hatte, und mit den Regierungschefs Frankreichs und Italiens zusammenzutreffen. In München aber wanden die westlichen Politiker Hitler auch noch den letzten und mehr als fadenscheinigen Kriegsgrund aus der Hand, indem sie nun selbst die deutschen Terminwünsche nahezu vollständig akzeptierten. Da Chamberlain außerdem mit seinen drei Deutschlandreisen und mit seinem Verhalten auf der Münchner Konferenz den Friedenswillen der Westmächte bis zur Demütigung deutlich und nicht zuletzt auch für die deutsche Bevölkerung erkennbar gemacht hatte, mußte Hitler endgültig nachgeben und sich damit begnügen, daß das noch am 29. September unterzeichnete Münchner Abkommen lediglich die Sudetengebiete einbrachte.

Um Krieg und die totale Eroberung der CSR betrogen, unterschrieb Hitler außerdem ein weiteres Dokument, das ihm Chamberlain am Ende der Konferenz vorlegte und das britisch-deutsche Konsultationen vorsah, falls künftig wieder Fragen auftauchen sollten, die beide Länder berührten. Chamberlain verließ sich nicht zuletzt auf Hitlers Namenszug unter dieser Konsultationsvereinbarung, als er, nach London zurückgekehrt, am Abend des 30. September sagte: "Ich glaube, das ist der Frieden für unsere Zeit.“ Der britische Premier glaubte tatsächlich, Hitler nun abgefangen zu haben, der während der Krise mehrmals in aller Öffentlichkeit die Sudetengebiete als seine „letzte territoriale Forderung in Europa“ bezeichnet, eine deutsche Herrschaft über Tschechen indigniert als nationalsozialistischem Empfinden völlig fremd abgelehnt und dann in München die Verpflichtung übernommen hatte, die neuen Grenzen der verstümmelten CSR zusammen mit den drei anderen Mächten von München zu garantieren. Mit der Münchner Konferenz sei mithin, so meinte Chamberlain, endlich jenes Kollegium der vier europäischen Großmächte - unter Ausschluß der Sowjetunion - begründet, das an die Stelle des zusammengebrochenen Genfer Systems der kollektiven Sicherheit treten müsse. 